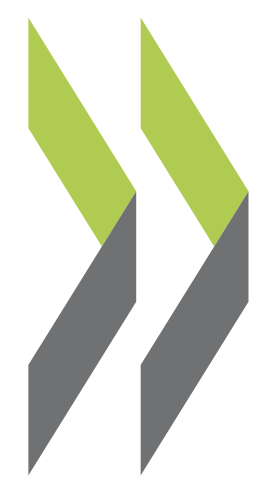

OECD Local Economic and Employment Development (LEED) Papers 2013/14

\section{The Local Dimension of SME} and Entrepreneurship Issues and Policies in Mexico

\section{Jonathan Potter,}

Marco Marchese,

Maryann Feldman,

Tom Kemeny,

Helen Lawton-Smith,

Andy Pike 


\title{
THE LOCAL DIMENSION OF SME AND ENTREPRENEURSHIP ISSUES AND POLICIES IN MEXICO
}

\author{
By \\ Marco Marchese, Jonathan Potter, Andy Pike, Tom Kemeny, \\ Maryann Feldman and Helen Lawton-Smith ${ }^{1}$
}

Background Paper of the "Local Dimension to SME and Entrepreneurship Policy in Mexico" Chapter 5 of the publication:

\section{OECD Studies on SMEs and Entrepreneurship Mexico: Key Issues and Policies}

1. The report has been prepared by Marco Marchese, economist at the OECD LEED Programme, under the supervision of Jonathan Potter, senior economist at the OECD LEED Programme. Individual contributions to the report are as follow: Marco Marchese (chapter 1, chapter 5; chapter 6; Conclusions); Andy Pike, University of Newcastle (chapter 2); Helen Lawton-Smith, Birkbeck College (chapter 3); Tom Kemeny and Maryann Feldman, University of North Carolina at Chapel Hill (chapter 4). 


\section{Table of contents}

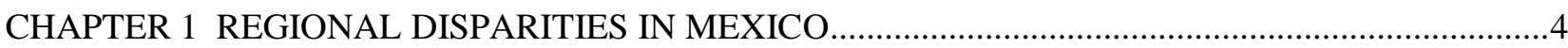

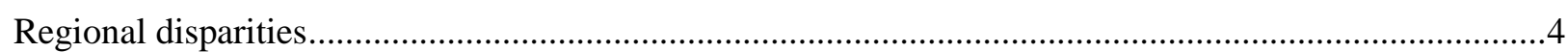

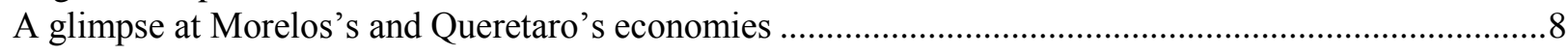

CHAPTER 2 POLICY COORDINATION AND POLICY TAILORING .................................................10

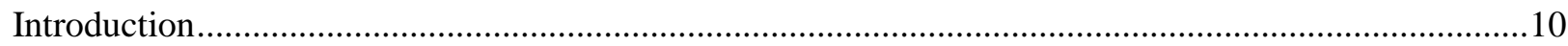

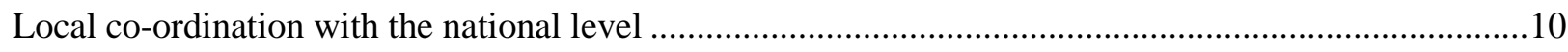

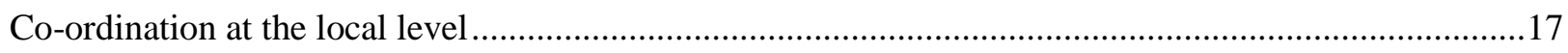

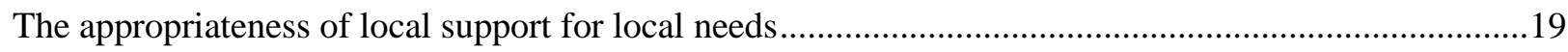

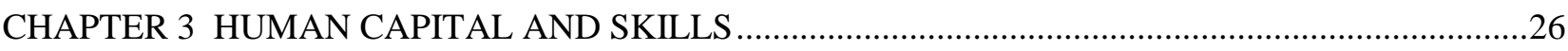

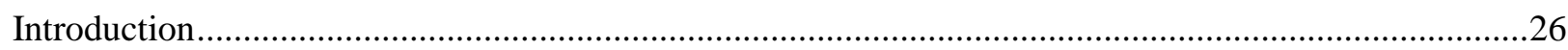

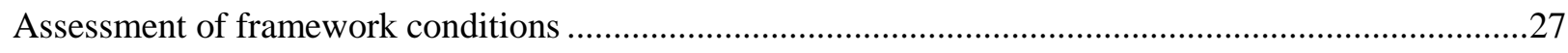

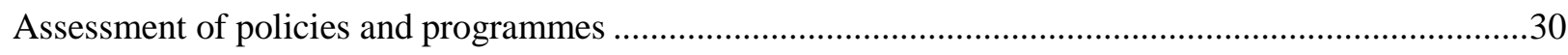

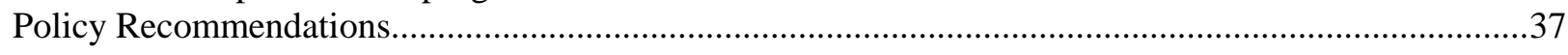

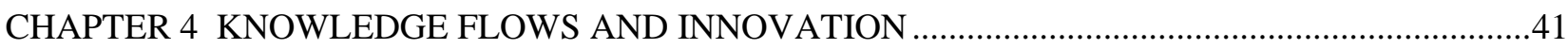

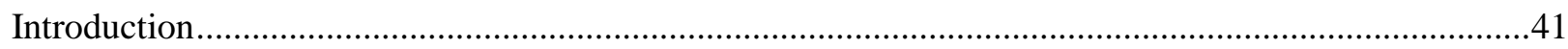

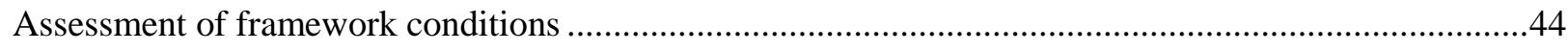

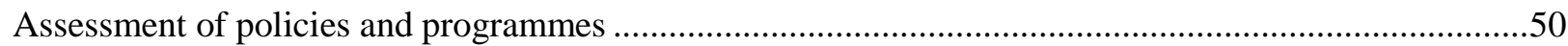

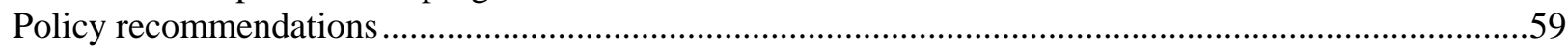

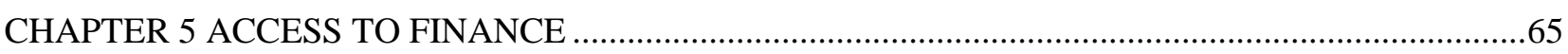

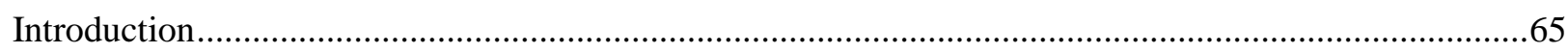

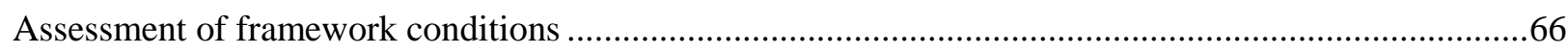

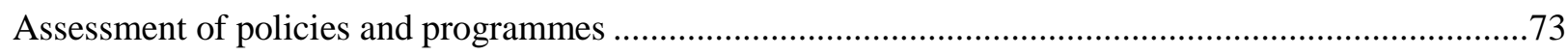

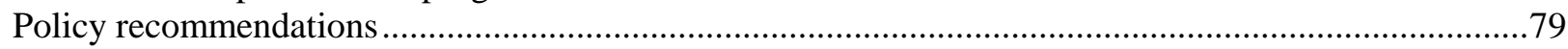

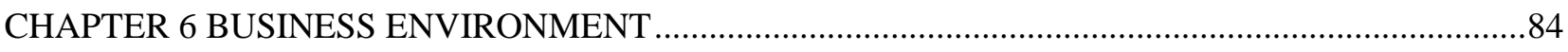

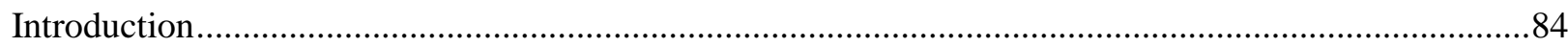

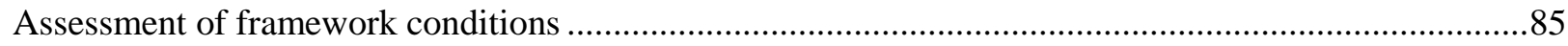

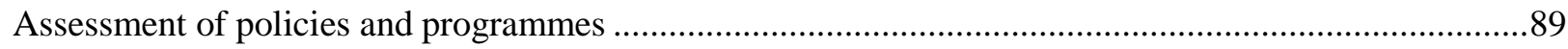

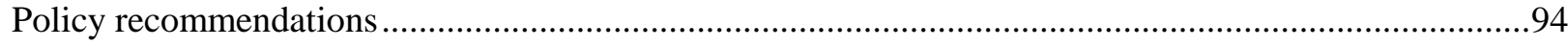

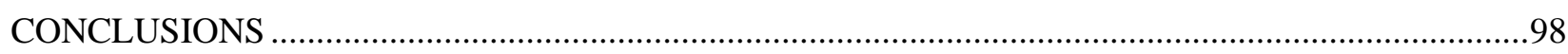

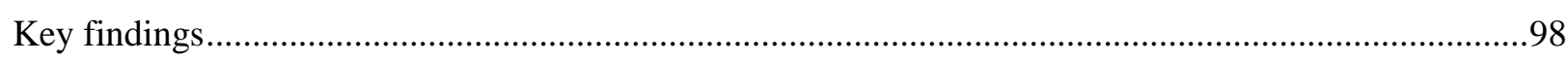

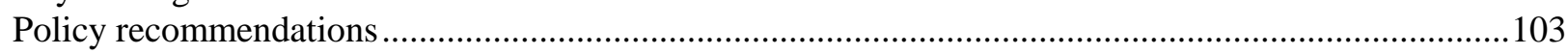

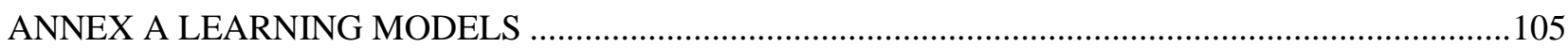

\section{Tables}

Table 3.1. Training provision and skills in Mexico compared to Latin America \& the Caribbean and

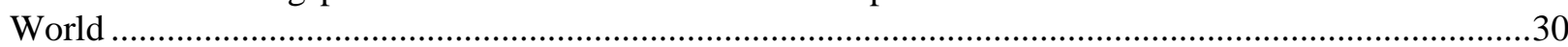
Table 3.2. Agencies involved in entrepreneurship skills and entrepreneurial human capital development

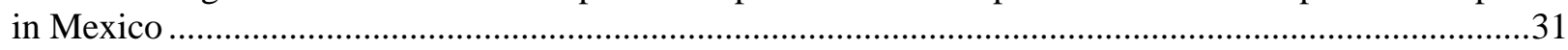

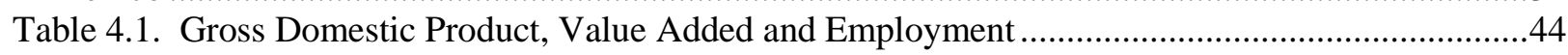

Table 4.2. The Mexican Innovation System in Comparison ..............................................................47

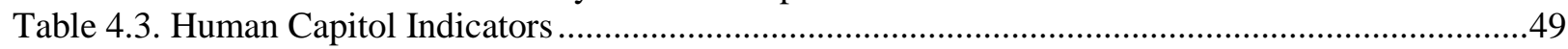


Table 4.4. Overall Science and Technology Investment in Mexico 50

Table 5.1. Business financing options by stage of business development .............................................66

Table 5.2. SPYME Programmes in the framework of Mexico Emprende...............................................69

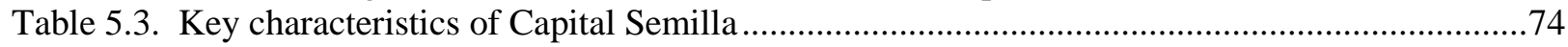

Table 5.4. Size (SME Fund contribution) and outreach of Capital Semilla.............................................74

Table 5.5. Annual interest rates applied to credit through Mexico's NGF by loan size ............................77

\section{Figures}

Figure 1.1. Gini coefficient of income inequality across OECD countries...............................................

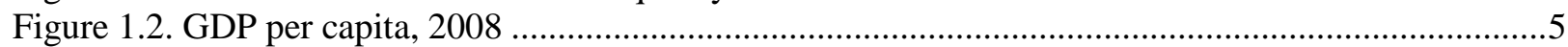

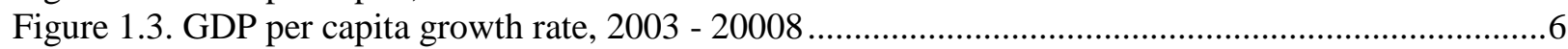

Figure 1.4. The relation between GDP growth rate and GDP per capita .................................................6

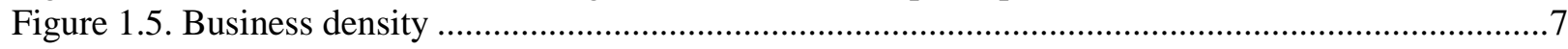

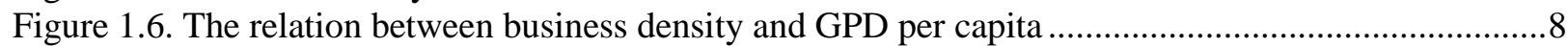

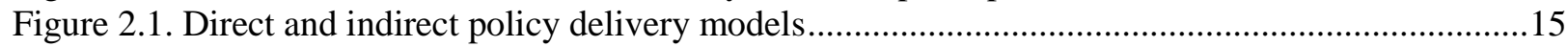

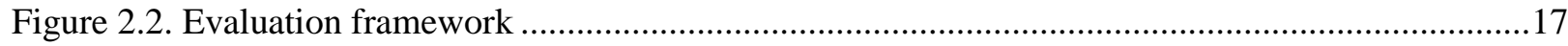

Figure 5.1. Evolution of business credit by commercial banks, 2000-2010 …..................................67

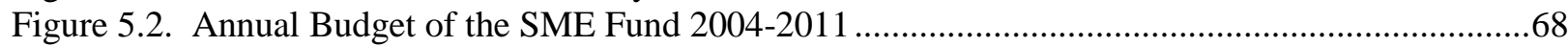

Figure 5.3. The evolution of the National Guarantee Programme of Mexico ……..................................76

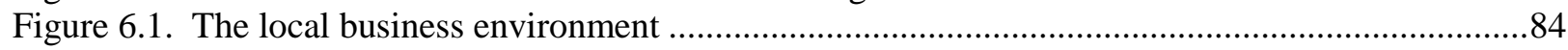

Figure 6.2. Product Market Regulation (PMR) in a sample of OECD countries, 2008 ..........................86

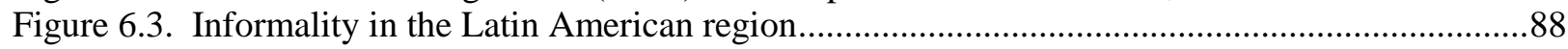

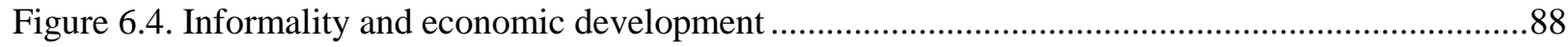

\section{Boxes}

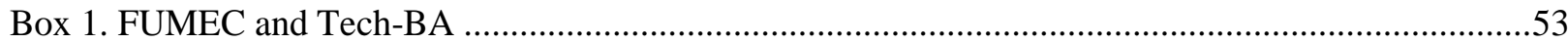

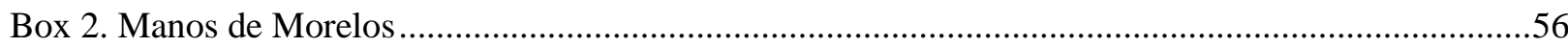

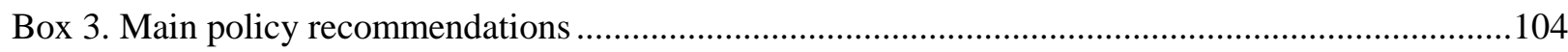




\section{CHAPTER 1 \\ REGIONAL DISPARITIES IN MEXICO}

\section{Regional disparities}

Mexico is a country of contrast. Within the OECD area it is the second most unequal country with regard to income distribution, behind Chile and far ahead of Turkey and the United States, although income concentration has decreased more recently, with the Gini index falling from 0.50 in the mid-2000s to the current 0.48 .

Figure 1.1. Gini coefficient of income inequality across OECD countries

( $0=$ lowest inequality $-1=$ highest inequality $)$

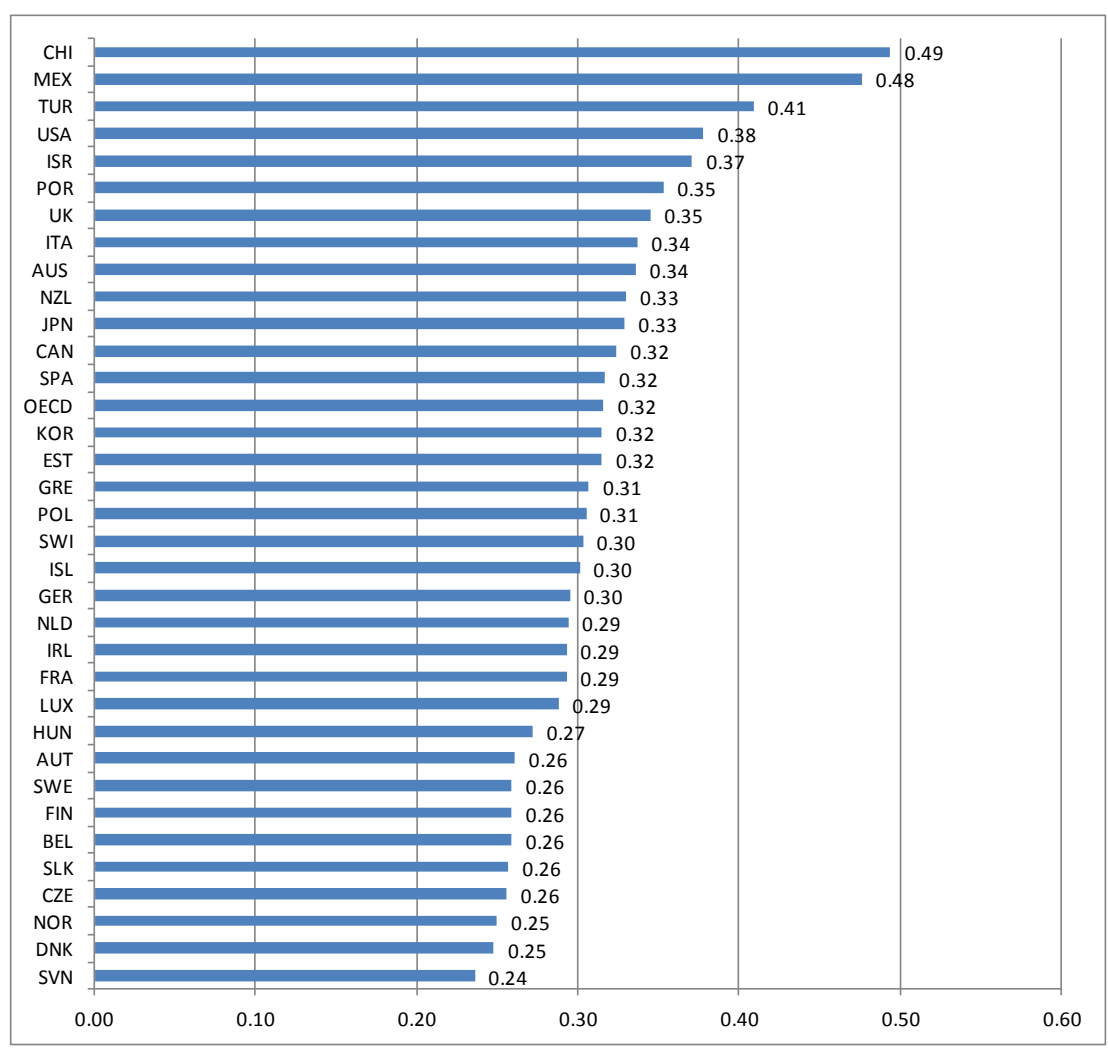

Source: OECD Income and Population Database

Welfare disparities are also evident across regions (Fig. 1. 2). GDP per capita is five times greater in the Federal District than in Chiapas, the poorest state of the country. Wealth is especially concentrated in the northern states bordering the United States, especially in the eastern part bordering Texas, and in the south part of Gulf of Mexico (Campeche and Tabasco). The former has benefited since 1994 from the NAFTA agreement and foreign direct investment (FDI) in low-tech manufacturing, whereas the latter is 
the most touristic region of Mexico and has also profited from foreign investment in this sector. States in the south Pacific coast (e.g. Chiapas, Oaxaca, and Guerrero) are the most stricken by poverty.

Figure 1.2. GDP per capita, 2008

MXN pesos, 2000 constant prices

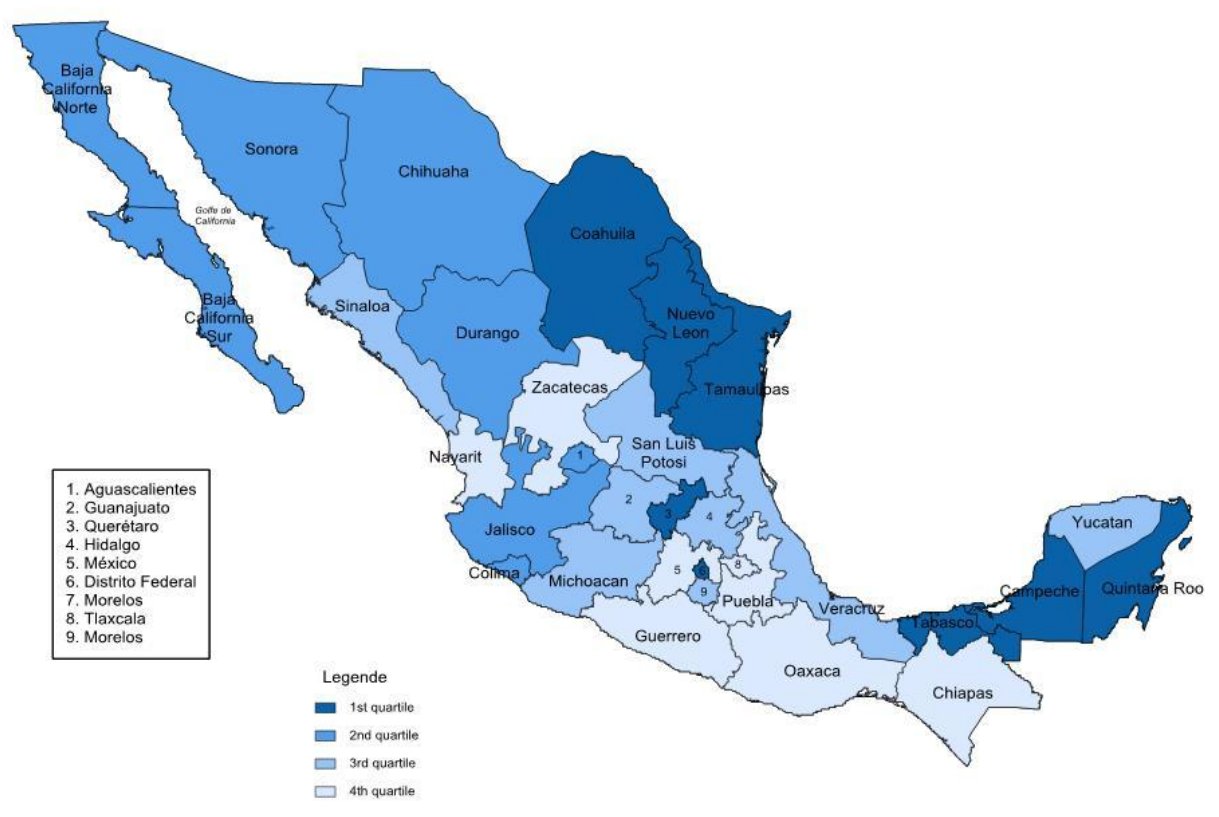

Over the period 2003-2008, the GDP per capita of the bottom quartile of Mexican states has grown by $21 \%$, whereas that of the top quartile only by $11 \%$. Of the seven fastest growing states over the same time period, two are found in the bottom quartile (Nayarit and Zacatecas), three in the second-lowest quartile (Hidalgo, Veracruz and San Luis Potosi), and only two in the top quartile (Campeche and Tabasco) of GDP per capita. In particular, the North has checked its growth, as the marginal benefits of trade liberalisation have diminished over time and organised crime dedicated to drug trafficking has become rooted at the border with the United States. Most of the South also continues growing comparatively slowly (e.g. Chiapas and Guerrero), although there are some exceptions such as Oaxaca. To sum up, there is a moderate process of economic convergence across the states of Mexico: the fastest-growing states between 2003 and 2008 have not corresponded to the traditionally affluent states of the country (Fig. 1. 3), which is confirmed by the positive but moderate relationship between recent growth rates and current economic welfare (Fig. 1.4). ${ }^{2}$

2. The states of Tabasco and Campeche have not been included, as they have much higher values than the average and represent, therefore, statistical outliers. 
Figure 1.3. GDP per capita growth rate, 2003 - 20008

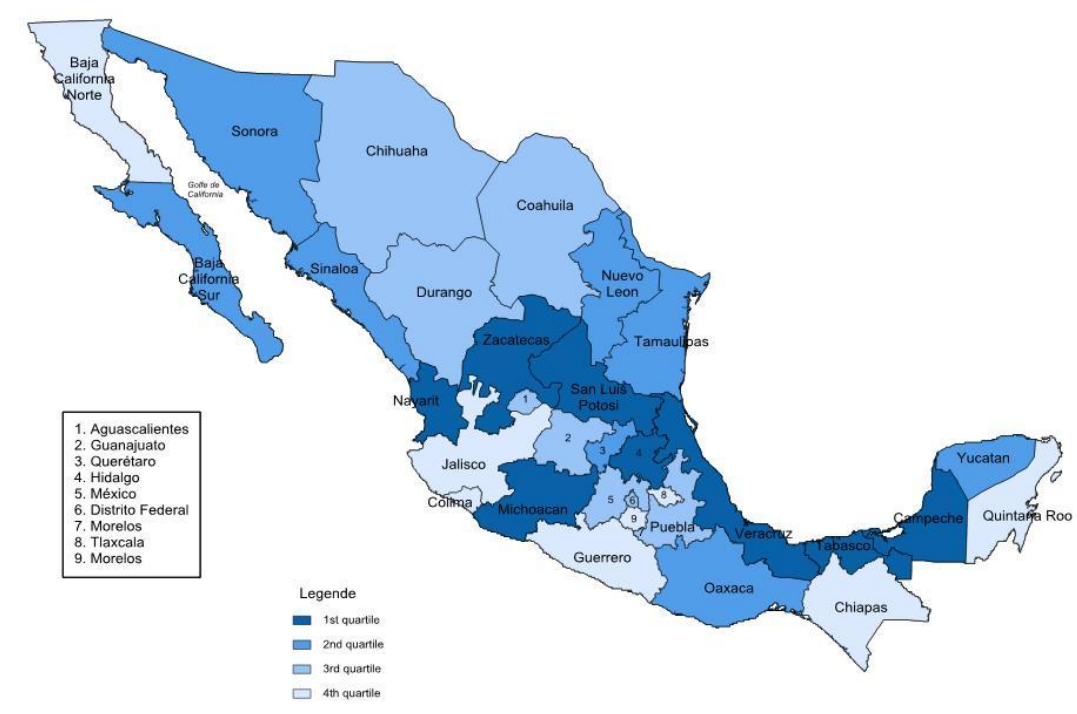

Figure 1.4. The relation between GDP growth rate and GDP per capita

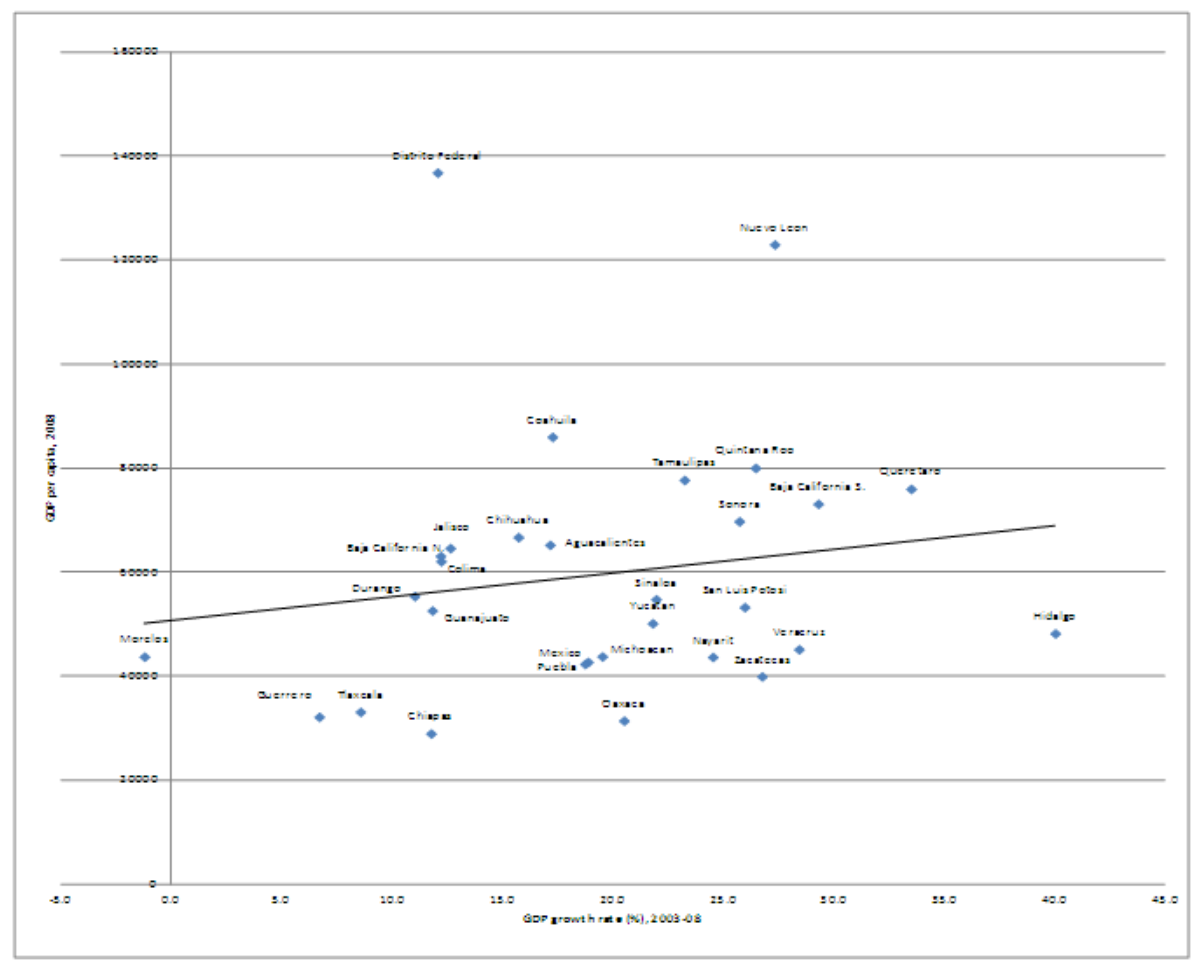

Source: Own elaboration based on OECD Regional Database 
From the viewpoint of entrepreneurship and SME development, it is relevant to look at disparities in business density and whether this affects economic development. Business density in Mexico as a whole is very low (i.e. 45.9), just slightly more than half of that in the United States, where it hovers around 80. This is in line with international empirical evidence that shows a U-shaped relationship between entrepreneurship and GDP, whereby entrepreneurial activity is the highest in low-income and high-income countries and the lowest in middle-income countries like Mexico that are primarily driven by a managed economy (Thurik, 2009).

Within the country business density is the highest in Oaxaca (62.2) and the lowest in Baja California (31). More generally, it is relatively high in the poorest states of the south Pacific coast (Oaxaca, Guerrero and Michoacán), where job opportunities are lower and business ownership largely corresponds to selfemployment and micro-enterprises in traditional sectors of the economy, while it is very low at the border with the United States, where the economy is dominated by FDI and large establishments, including maquilladoras (Fig. 1.5). Unsurprisingly, therefore, there is a negative relationship at the state level between business density and income per capita (Fig. 1.6), for the overwhelming majority of small businesses in Mexico are geared towards low-productive activities and the economically most dynamic states are driven by large multinational and national enterprises.

Figure 1.5. Business density

Number of firms per thousand population

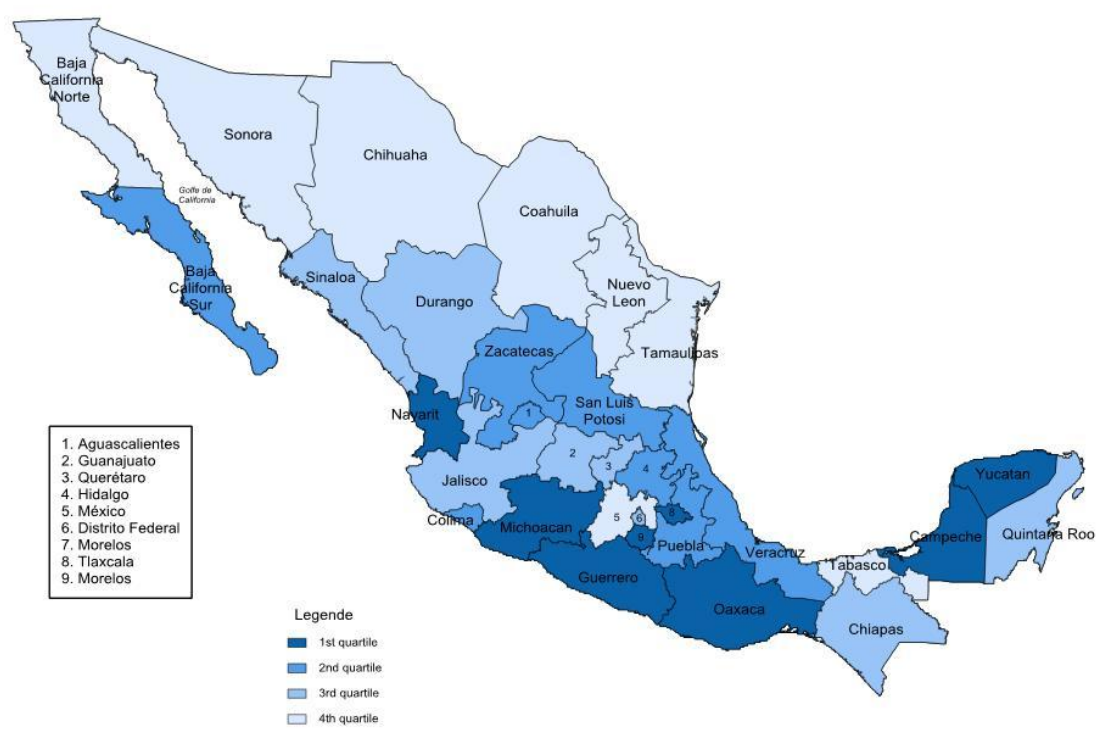


Figure 1.6. The relation between business density and GPD per capita

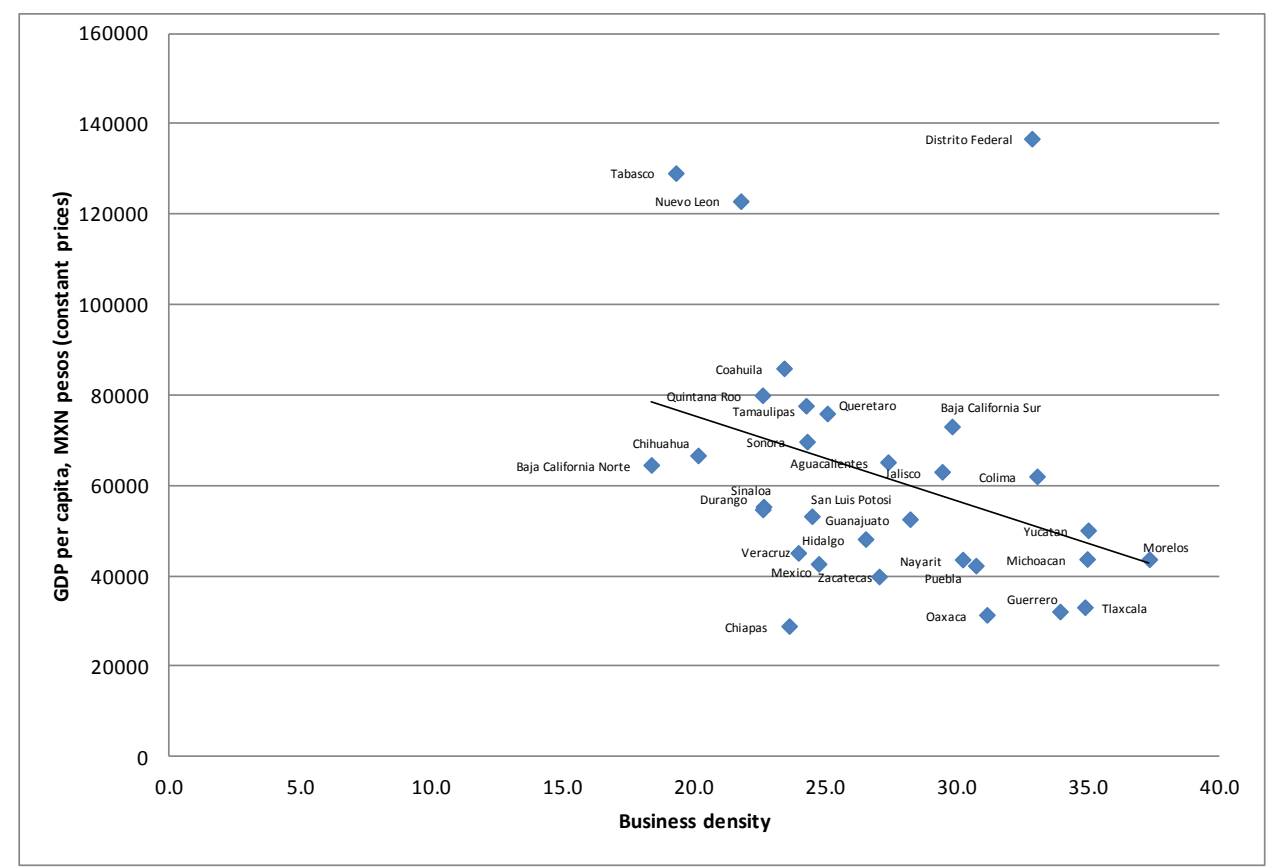

The challenge for Mexico is, therefore, to move in the coming years from a managed to an entrepreneurial economy, which is characterised by a stronger presence of innovative small businesses and is associated with the transition towards an upper-income economy. This is true both for its states that have extremely low business density, which need to nurture the local economy beyond the mere attraction of FDI through the promotion of FDI-SME linkages and corporate spin-outs, and for those which have relatively higher business density but which will have to promote not only self-employment but also opportunity-driven entrepreneurship.

Much, therefore, remains to be done in the field of entrepreneurship and SME policy, including at state level. The report analyses what states are doing in this field, based on the case studies of Morelos and Queretaro.

\section{A glimpse at Morelos's and Queretaro's economies}

Morelos and Queretaro are two small states in Central Mexico that are not representative of inter-state disparities across the country, but they have been chosen primarily to understand how entrepreneurship and SME policies are co-ordinated amongst different levels of government, how national policies are tailored to local needs, and the inter-play between programmes. Having two very different industrial structures, one harnessing its immediate closeness to the Capital city and based on services (Morelos) and the other hinged on traditional manufacturing and heavy industries (Queretaro), the two also provide a greater scope for learning on policy co-ordination and policy tailoring than in states with more identical features.

Morelos and Queretaro represent small contributions to the national economy of Mexico, which has been historically concentrated around the Federal District $(21.5 \%$ of national value added and employment) and, more recently, at the northern border with the United States. Morelos, with a lower GDP per capita (60\% of the national level) accounts for $2 \%$ of national value added but only $1.1 \%$ of national employment, while Queretaro has a higher GDP per capita than the national average while also exhibiting 
a greater share of national value added relative to employment. This signals the presence of high productivity industrial activity that is low-wage in Morelos and higher-wage in Queretaro.

The two states also display distinct specialisation patterns, even at a fairly aggregate level. Roughly a third of Queretaro's workforce is engaged in the industrial (secondary) sector. Employment in manufacturing is dominated by automotive, auto parts and other heavy industry sectors. A third of employment in Queretaro is in services, with the remainder in the primary sector. Thus, Queretaro's economy is diversified and balanced between these three sectors. Manufacturing plays a distinctly smaller role in Morelos, accounting for only 17\% of state GDP in 2006. Chemicals and pharmaceutical production are an area of focus, with $7 \%$ of national production in "personal care products" and $17 \%$ in pharmaceuticals, accounting for higher wages. Tertiary sector activities dominate the economy of Morelos, contributing to more than $50 \%$ of GDP. Tourism is prominent among these services and generates $12 \%$ of the state GDP, with a yearly growth rate of $3 \%$. 


\section{CHAPTER 2 POLICY COORDINATION AND POLICY TAILORING}

\section{Introduction}

This chapter analyses local co-ordination with the national level, co-ordination at the local level, and the appropriateness of local support for local needs in the area of SME and entrepreneurship policy in Mexico. The final section summarises the strengths and recommendations. Designing, developing and delivering public policy has become markedly more challenging and complex in recent years because of the emergence of new systems of government and governance that work across multiple levels - including the supranational, sub-national, regional and local - and involve multiple agents - including public, private and civic institutions. The broad stages of the policy cycle model - problem identification, research and evidence review, policy design, implementation and evaluation - become more difficult to manage in the context of different actors working at different geographical scales. The policy cycle model is especially challenging to use in areas of economic development such as SME and entrepreneurship policy, which have multiple aims and raise issues that cut across the boundaries of existing institutions, for example between economic and education policy.

The federal and state governments in Mexico have established a wide ranging framework for SME and entrepreneurship policy in the relatively short period of almost a decade since 2002. This first phase of policy development has put in place comprehensive programmes in an attempt to meet the needs of a wide range of different kinds of entrepreneurs, micro-businesses and SMEs across Mexico. While there has been some periodic integration and simplification of funding support through the 2000s, the next phase of policy development requires the institutional actors to undertake thorough evaluation and reflect upon which programmes have worked and which have not to inform strategic decisions about future priorities and the consolidation, streamlining and targeting of programmes.

\section{Local co-ordination with the national level}

Vertical co-ordination refers to the connection and alignment of policy frameworks upwards and downwards between the different levels in the governance system in order to provide effective and efficient support. In a multi-actor and multi-level system, however, vertical co-ordination is characterised by the search for the appropriate balance between centralised and decentralised approaches and institutional arrangements, as well as the resolution of issues concerning where policy leadership and responsibility reside. In the following analysis of Mexico, vertical co-ordination refers principally to the relationships and integration between the national federal government level and the local (sub-national) state government level and in some cases the level of municipalities.

\section{Strengths}

There are a number of notable strengths in the current arrangements for the vertical co-ordination of SME and entrepreneurship policy in Mexico. 


\section{National strategic planning framework}

Mexico has a National Development Plan (2007-12) and its axis for economic development seeks a competitive economy to generate 'more and better jobs, more and better enterprises and more and better entrepreneurs'. The plan sets the task for the Ministry of Economy to strengthen support to SMEs, foster productivity and competitiveness, strengthen the financial system and promote regional development. This central approach to balanced national development is important in setting the broad level priorities especially given the relatively high levels of spatial disparities in economic and social conditions and in the distribution of economic activities across Mexico (Rodríguez-Pose and Ezcurra, 2010). The National Development Plan establishes the frame of reference for state level policy and the potential for the alignment of aims between the national and state levels. The structured federal national framework has afforded substantial decentralisation to state level governments and municipalities (Silva-Ochoa 2009). The degree of alignment with the national framework therefore varies across the states and this allows for the tailoring of state-level policy to state-level needs. The National Development Plan affords a national perspective and grasp to policy initiatives for SMEs and entrepreneurship. Support programmes and their infrastructure are therefore typically designed with a national view to encompass all 31 states and the DFMexico City. In the first phase of policy development nationally, this has meant the establishment of centres with specialised services in segmented markets targeting specific groups - such as traditional, intermediate and high-tech economic activities - and business development needs at particular stages of development - such as incubators, Centros México Emprende, business accelerators, export development, the National Science and Technology Council (CONACYT) research centres and technological parks. As part of its national perspective, SME and entrepreneurship policy has clearly identified target groups linked to the stages of company growth - from potential and nascent entrepreneurs, self-employment and microenterprises, existing SMEs to high growth enterprises and 'Gazelles', and 'Tractors'. This policy targeting reflects a degree of sophistication in the approach taken in Mexico and mirrors practice in the longer established policy frameworks in more advanced economies (OECD, 2007). This categorisation of target groups also suggests the kinds of emerging prioritisation and rationales for intervention and support which will be integral in the next phase of development of the SME and entrepreneurship policy framework in Mexico. The comprehensive coverage and access provides a wide ranging policy framework seeking to address the broad array of SME and entrepreneurship needs across Mexico.

\section{Institutional focus and leadership}

Established in 2001, the Under Ministry for SMEs within the Ministry of Economy provides a clear institutional focus, lead and co-ordination capacity with authority and status within the Federal government in Mexico. Prior to 2001 the SME policy team provided co-ordination mechanisms and grants to facilitate access to training and consultancy through a network of 120 centres across Mexico. But since the creation of the Under Ministry and the specific SME Fund, the aim has been to establish a more comprehensive national network based upon intermediaries and to open up and develop the market for specialised services. The institutional arrangement based on the Under Ministry means there is little value in the Mexican context of exploring the establishment of the kind of separate arms-length specialised agency for SME and entrepreneurship policy which has been used elsewhere, for example the Polish Agency for Enterprise Development (PAED) in Poland (OECD, 2010). The formal status and authority of the UnderMinistry already provides the required institutional focus and leadership.

\section{Indirect policy delivery model}

The institutional arrangements for SME and entrepreneurship policy delivery are based upon intermediary organisations. This includes a wide range of different types of institutions such as state, local and municipal governments, private sector businesses, business associations, public and private universities, and civic associations. The philosophy has been to encourage intermediary and especially 
private sector institutions to enter the market to provide services as a means of developing market-oriented capacity beyond direct state provision and to build continuity into policy frameworks by disconnecting them from shifting priorities and change in the political cycle. While many of the intermediaries are private sector, most are not-for-profit organisations. To date, the system appears to be benefitting from the advantages of using intermediary organisations including flexibility, specialisation and responsiveness to market needs amongst local entrepreneurs and SMEs. As the system develops, fragmentation, duplication, overlap and competition will need to be addressed. Indeed, the Under Ministry for SMEs recognises such issues in setting up the first wave of Centros México Emprende and modules in 57 metropolitan zones nationally (covering more than $75 \%$ of economic units) to offer consultancy services and link entrepreneurs and SMEs to support programmes. The Under-Ministry expects a process of specialisation, rationalisation and consolidation to unfold amongst providers as the service delivery system develops and matures over time across the country.

\section{Effective joint working}

There is evidence of good quality working relationships between the national ministry and state governments and municipalities. Effective joint working is evident, for example between state governments and the national Federal Commission for Regulatory Improvement in simplifying and speeding up business registration processes through strong co-ordination. Initiatives have connected state level support with the national Tu Empresa website which provides information on all relevant Federal regulations in one place. In the state of Morelos, this initiative has been important in modernising the Public Registry of Business Properties and Commerce, moving to an electronic system, and reducing the bureaucracy and complexity burden on new start ups, and helped progress the formalisation of especially micro-businesses. Another example of effective national and state-level co-ordination is the Ministry of Economy Export Office, which works closely with state governments to provide additional resources and support for internationally-oriented entrepreneurs and SMEs. Co-operation and strong working relationships have enabled policy innovation between the national federal centre and local partners at the state government and municipal levels. As a means of addressing deep-seated structural problems which require long term and sustained support, the Under Ministry has appeared willing to innovate and experiment. Addressing the under-developed capital market in Mexico, for example, the Under Ministry for SMEs has developed a methodology to create investor clubs to foster networks between new enterprises and entrepreneurs to link to sources of capital. This initiative utilises consultants to evaluate projects and present them to potential investors. This represents an innovative form of institution building that is confronting directly the difficulties that investors face in assessing the risk and return of new projects and committing to involvement in smaller scale initiatives.

\section{Issues and recommendations for improvement}

Areas where some further attention and effort may help improve SME and entrepreneurship policy and its delivery in Mexico include:

\section{Clarification of the aims for intervention and the appropriate balance between different types of programmes}

There are a variety of different rationales for support amongst the various programmes for SMEs and entrepreneurs in Mexico. For some, there are clear economic objectives. Such programmes are guided by conventional rationales for intervention such as market failure, for example correcting information asymmetries in knowledge about market and technological development opportunities. While for other programmes, the economic aims are connected to broader social objectives and the needs of particular groups and areas. These programmes are not just about market failure. For example, Mi Tortilla has economic and social purposes in helping businesses, first, to develop sustainable strategies in a 
consolidating market shaped by larger scale producers; second, to help sustain economic activity, incomes and livelihoods for households and families; and, third, to deliver a core staple food source to the market for the wider population at affordable prices. Such initiatives contribute to the broader formalisation of the economy, bringing informal activity into the formal mainstream to contribute to the tax system and access service delivery such as micro-finance for business development. The strategic issue for overall policy is the need to articulate a clear and transparent set of aims for what all the various programmes are trying to achieve, and to explain how they relate to each other and what the appropriate balance should be between them. The question is not simply one of focusing upon either the quality or quantity of SMEs and entrepreneurs - that is either supporting traditional and micro-businesses or those with innovative and technological development and growth potential. Although micro-businesses constitute some $95 \%$ of companies, $45 \%$ of jobs and $15 \%$ of added value to GDP, public support cannot only focus on the needs of this group. Similarly, although innovative and high tech businesses are required for the future development of the Mexican economy support too cannot only address its particular requirements. The stage of economic development in Mexico means both types of support are appropriate for different economic actors in different parts of the country. The 'more and better jobs' concept from the National Development Plan already encapsulates this central idea. In the context of the overall and geographically differentiated levels of GDP per capita within Mexico, more jobs are needed and there are clear positive outcomes in linking economic and social rationales to provide livelihoods for households and reduce poverty especially through the support of micro-enterprises. Whether formalised or not, such activities provide coping strategies for individuals and families, reducing the demands upon the state for social provision. Better jobs are needed too that are involved in higher value added activities, delivering the higher productivity and higher wages that generate greater economic multipliers within the economy and underpin the enhanced competitiveness and sustainability of the businesses involved. Support here rightly focuses upon the creation of new activities in innovative intermediate and high-tech areas and upgrading amongst existing businesses.

Clearer aims and objectives for the policy framework and different programmes can underpin decision-making on the limits for publicly funded interventions. There is evidence that support is being taken up by individuals and businesses on upward development trajectories. This initiating and stimulating effect of public funds is welcome and positive. However, such successful recipients have sometimes continued to receive further and ongoing support. A strategic question for policy is therefore when this support should finish. When does it cease to be additional (i.e. funding things that would not happen without support) and become deadweight (i.e. funding things that would happen without support)? This depends upon its purpose: is the intervention to enable and facilitate only the initial efforts of entrepreneurs and SMEs to develop? Or is it intended to be ongoing throughout the life of the businesses, for example providing subsidised sources of fixed and working capital to defray operating costs? The risk with continued and repeat funding support lies in creating forms of dependency upon publicly funded programmes and displacing relatively scarce sources of support from other deserving recipients at earlier stages of development. As businesses become geared up and skilled in writing proposals and securing programme support, funding may end up flowing to those already successful businesses and entrepreneurs that have begun promising growth trajectories. Resources may then not be available to help other groups of entrepreneurs and businesses to get started on the development process.

Some of the programmes have confronted and attempted to resolve this issue. Reflecting international good practice (NESTA, 2008), the business incubation programme currently has guideline timeframes for the duration of support with some flexibility depending upon the kind of business and its progress (e.g. 6 months for a traditional business, 1.5 years for an intermediate tech business and 2 years for a high-tech business). An evolutionary approach to changing the type and duration of support was also evident in financing arrangements, with the longer term aim to move toward greater private sector involvement to allow government support to be of a different nature, shifting from subsidy (e.g. scrap bonds, productive projects) to quasi-direct financing (e.g. strategic projects) to credit guarantees (e.g. SME credits) to capital 
(e.g. equity, business angel clubs). The Centros México Emprende too, are working to business plans aiming for self-financing within 8 months. The Economic Development Ministry in Morelos is also trying to strike an appropriate balance between new and existing recipients for support. Striking such a balance is made difficult because successful existing recipients are often more likely to deliver more of the outputs and outcomes sought by the programmes and the intermediary institutions delivering them. This creates an incentive for providers to continue supporting existing successful businesses to deliver the target outputs and outcomes they seek. Guideline timeframes and criteria for limits to support may be something worth considering for the different types of support programmes for SMEs and entrepreneurs

\section{Management, co-ordination and capacity building of intermediaries}

As the SME Fund programme and its delivery system evolves a key challenge for the national federal Under Ministry for SMEs will be to guard against the fragmentation, duplication, overlap and competition that can arise in such indirect institutional arrangements for service delivery. Direct and centralised models can more readily control delivery channels while indirect and decentralised models rely upon effective incentive structures to shape and steer the system (Figure 1.1.). Characteristic of the early phase of policy framework development is the proliferation of intermediate institutions providing services funded by a growing and widening array of support programmes. Duplication and fragmentation can emerge that may undermine the overall effectiveness of the system. Robust and rigorous review will be required to contain the rising transaction costs from dealing with multiple layers of providers, the increasing costs of administration absorbing funds and reducing direct financial support to client businesses, and the bureaucracy and costs of provider certification. In addition, the tendency for programmes to become more complicated over time as incremental changes are made to their operation and eligibility needs to be guarded against.

In strategic terms, detailed research to provide a clear understanding of how the system as a whole is working and evolving would be useful in providing an overview for the under ministry and state governments to help shape the system's future development. System-wide issues include, for example, encouraging consistent quality across the range of providers, ensuring specialisation amongst key intermediaries, encouraging scale economies amongst intermediaries delivering more than a single element of the programme, and facilitating the exit of intermediaries providing services of insufficient standard.

There is evidence that this kind of system-wide approach is being undertaken in relation to the next phase of expansion of the national business incubators. Here the aspiration is to make the individual institutions more market oriented and to get them acting together more effectively as a system exchanging experience and knowledge as well as competing to improve quality and effectiveness. Where changes in the institutional arrangements have already been made these will need monitoring and assessment, for example placing the 51 PymExporta centres provided by intermediaries under the central control of the new specialised national agency ProMexico. 

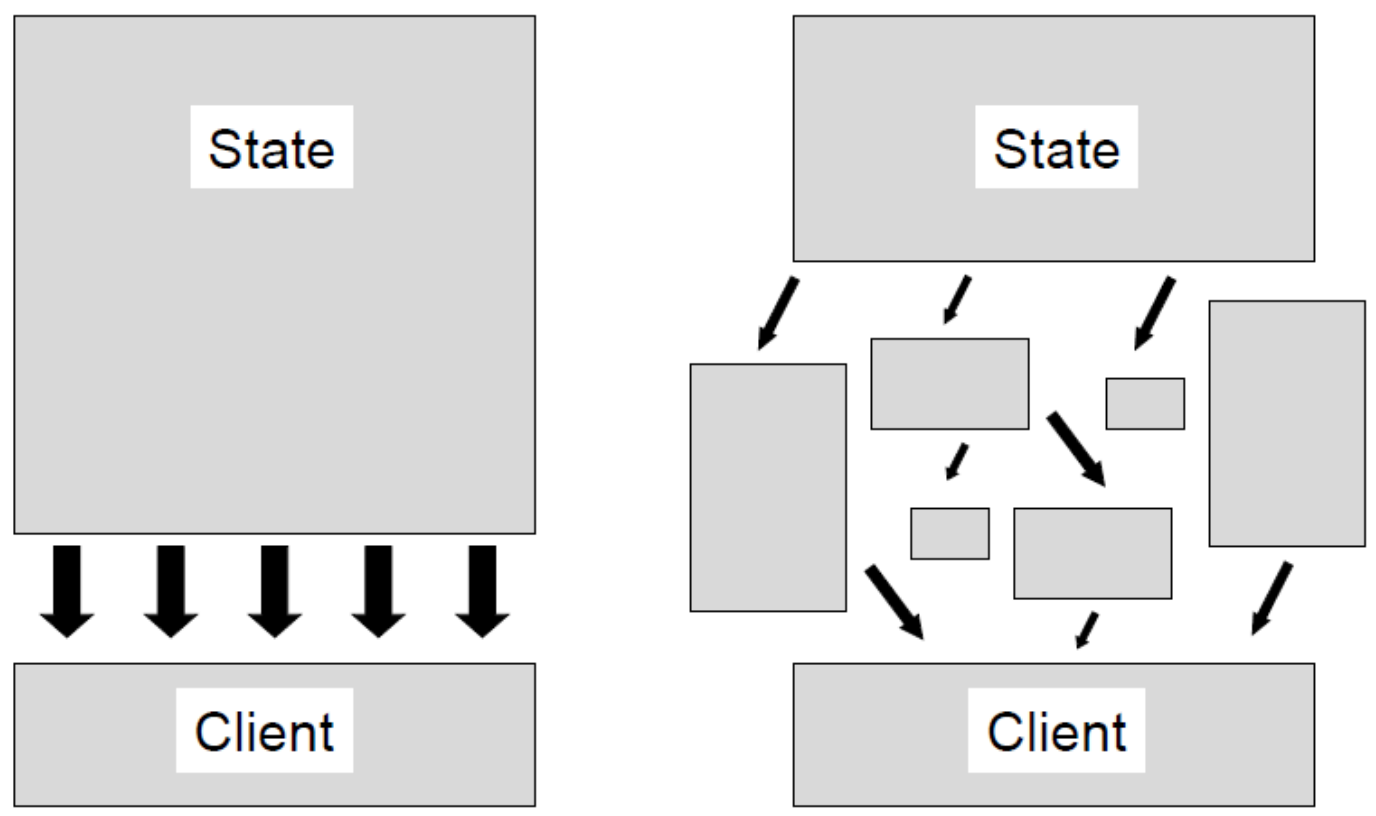

Source: Author

Reforming the operation of the SME Fund

At a more detailed level, potential reforms that can further streamline the SME Fund and make it more client-oriented and effective include:

- Changing from an annual 12 monthly cycle of certification of providers to a longer 24 or 36 month cycle to reduce the costs and efforts involved, supported by appropriate monitoring and reporting during the life of the contracts

- While some steps have been taken (e.g. the on-line system), further simplification and reduction of the reporting and verification requirements for delivery intermediaries should be explored while maintaining the necessary accountability, transparency and confidence in the use of public funds. One example could be introducing bi-annual rather than quarterly reporting. Evidence suggests that the reporting requirements have been increasing each year and becoming wider, for example extending from requesting information on the number of jobs to detailing the duration of each job. This additional information is useful and, indeed, further information such as the qualification and skill level of the job would help provide a better picture of support but this level of analysis may be more properly suited to formal assessment and evaluation of project outcomes and impact.

- Moving from standard rules to the differentiation of reporting requirements for different types of activities (e.g. high-tech, intermediate and traditional businesses) and the different kinds of employment models that activities operate (e.g. associations made up of freelance contractors rather than conventional single-employer businesses). This reform would then better reflect the different business development processes for different types and sizes of businesses, for example high tech firms employing freelance contractors that need long time periods to prove the viability 
of business ideas compared to traditional businesses that can be trading and directly employing people in much shorter time periods

- Shortening the timescale of the programme from proposing the initial projects through assessment and selection through to receiving and spending the funding and finally reporting the results in accordance with the initial project proposal. Some intermediaries have had to use bridging funding to enable projects to progress because of the delays in receiving the programme funding. Others, such as state governments and municipalities, have preferred not becoming intermediaries in some cases because of the delays involved, and have sought to find other ways to provide direct support to companies, albeit with less resources. State governments, for example, have in some cases sought to be agile enough to try and work at the same speed as industry, but feel the support of the national federal programme - while potentially enlarging the pool of funds - slows down their ability to respond to local business need. In addition, the programme funding often arrives late in the financial year and yet still has to be spent in that same financial year. For example, a project may be planned to start in March but it receives the funding in October and has to report on the results of the project in December - just over 2 months after receiving the funding. This creates problems for funding recipients in spending the resources appropriately within the calendar year. Further problems with timing have been experienced in relation to quotes for equipment purchases provided at the start of a calendar year for the bid proposal changing in their specification and price by later in the year when the funding is actually received. Longer term and more timely provision of programme funding would allow intermediaries more effectively to plan and schedule their activities

- While formalisation and registration of businesses with the tax authorities is part of the business support service requirements, the initial projects still have to go through this process and identify the creation of at least 4 employment opportunities even when there is uncertainty regarding whether the project is a viable business or not. Some kind of provisional, temporary and lighter touch tax registration may be appropriate for this kind of project that, if it proves viable, could be converted easily to full tax registration.

\section{Stronger assessment and evaluation of existing programmes}

This recommendation is linked to the earlier point about clear aims and rationales for intervention. It emphasises the feedback loop in the policy cycle model from delivery through evaluation and back to design, ensuring that policymakers have sound knowledge and understanding of what outcomes their policies are achieving and what kinds of impacts they are having. Critical here is not just the counting of inputs (e.g. staff, project finance), activities (e.g. R\&D support, manufacturing advice, marketing support, export networks) and outputs (e.g. companies assisted, spin-offs), but developing a better understanding of outcomes (e.g. levels of business R\&D, productivity rates) and impacts (e.g. Gross Value Added, enterprise culture) and how they are determined (Figure 2.2.) (Pike, 2010).

Amongst the programmes in operation, the tendency was to provide simple counts, for example of the number of companies helped and entrepreneurs participating in training programmes. Such stand alone output figures with no comparators to similar types of programmes or benchmarks at the state or national level provide only superficial snapshots of activities at specific points in time. There was some evidence of a shift toward a more outcome-oriented approach that could be built upon, for example in systematic surveys of users and beneficiaries to gather evidence on the appropriateness and effectiveness of support and its impacts and outcomes. Rigorous evaluation will also help to identify opportunities for the integration and simplification of multiple and overlapping programmes as part of the next phase of national policy evolution and development. Robust assessment and evaluation systems need to build upon rather than add to the existing monitoring and reporting requirements. 


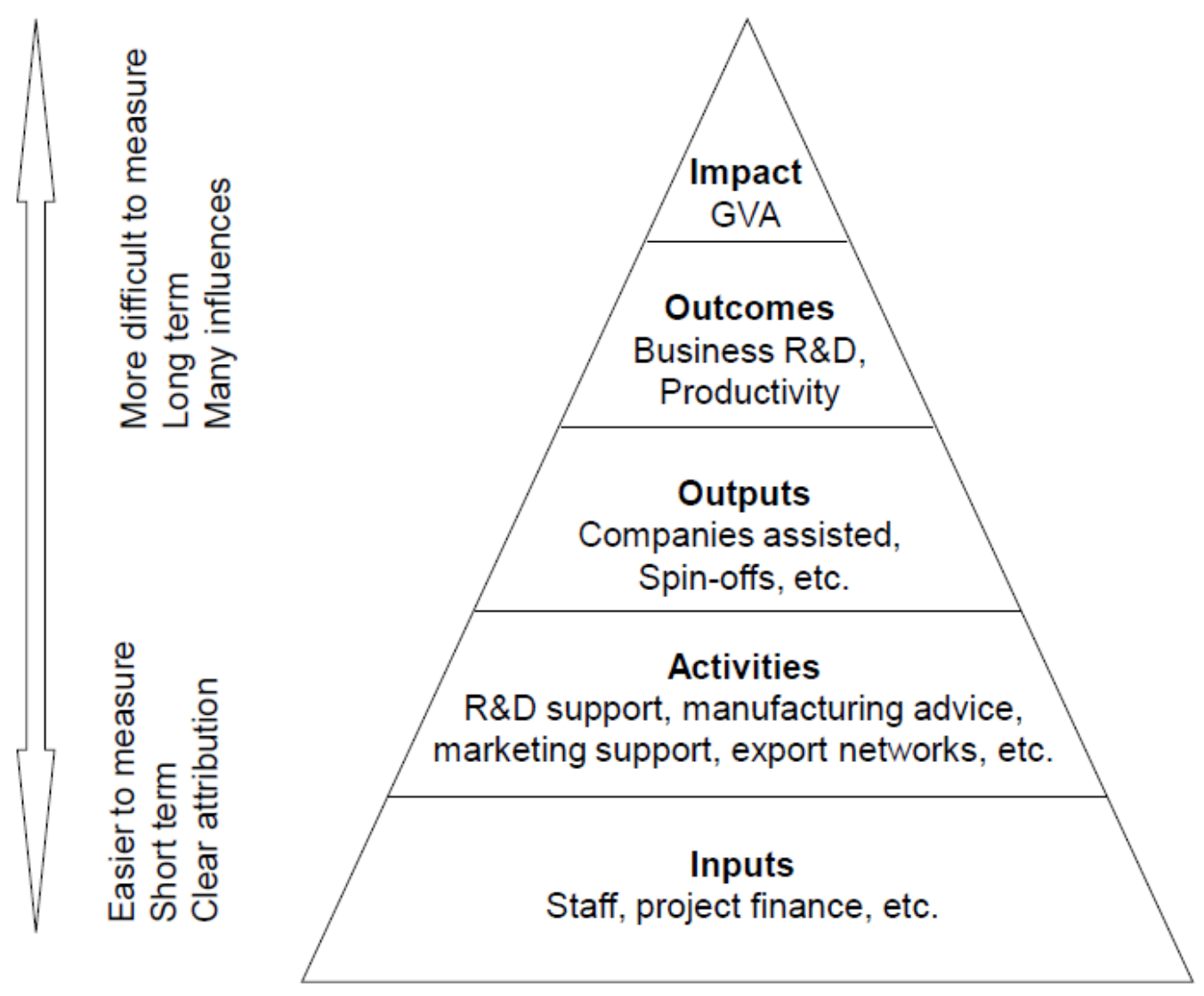

Source: Adapted from Neil MacCallum (2006) Office of Project Advice and Training, London, UK, OECD LEED Evaluation Workshop, Trento

\section{Co-ordination at the local level}

In the SME and entrepreneurship policy framework in Mexico, horizontal co-ordination at the local level involves state governments, local governments especially at the municipal level, and other local institutions acting as intermediaries in delivering services funded by public programmes including private businesses, business associations (e.g. Chambers of Commerce and Industry), public and private higher education institutions (e.g. universities and technical colleges), and civic organisations (e.g. not-for-profit trusts).

\section{Strengths}

Co-ordination at the local level demonstrates a number of strengths in its horizontal organisation of SME and entrepreneurship policy in Mexico:

\section{State government authority and legitimacy within the federal government structure}

State government provides a clear and strong leadership role in setting strategy and determining priorities for support at the state level. This level of government has the autonomy and legitimacy within 
the national federal system to identify priorities and to tailor policy to needs, and each state has a direct and structured relationship with federal national government ministries. To ensure state participation in the SME Fund, for example, the Ministry of Economy signs annual co-ordination agreements with each state government. In some cases, the state government has established highly effective working relationships with local business and service delivery partners enabling them to bring together up to date local knowledge on needs and to match business and service providers. The state government role is critical for SME and entrepreneurship policy and economic development more widely in the decentralised system in Mexico because municipalities can provide only limited attention and resources, for example through training programmes and job fairs, unless they become intermediaries for the delivery of national programmes. The main horizontal and vertical co-ordination comes through the state government, linking outwards to the local partners and upwards to the federal national level.

\section{Close networks and effective working relationships amongst local institutions}

Local level arrangements have been put in place in some states that are very effective at feeding into decision-making for the national programmes. For example, the local level committees for the SME Fund involve stakeholders, including the private sector, in the review and analysis of projects presented for submission to the national level for final decision. The local co-ordinating institutions can be local arms of national level institutions working with local partners, especially the State Economic Development Offices, and the state-level Councils of Science and Technology. The Councils of Science and Technology are often working at the state level to develop stronger communication between research institutions with industry and government to increase private and state investment in science and technology, and to provide more attention to local industrial and social problems.

\section{Institutional focus and integration locally}

The Centros México Emprende network is a new national initiative that has been established relatively quickly as a 'one-stop shop' focus for SME and entrepreneurship policy services. Within the national and decentralised indirect framework for policy delivery, the Centros are designed to be led by local intermediaries, including Chambers of Commerce and Industry such as CANACINTRA and business associations such as COPARMEX, and connect to local partners. The Centros provide a local institutional focus, lead and physical infrastructure to integrate public support programmes and private services to ensure businesses receive appropriate support for their development. They also provide the hub and signposting to other programmes rather than direct delivery of services. The aspiration is that the Centros will become self-financing with a phasing out of support after 8 months to ensure a market-oriented focus for services and enable public support to be routed direct to businesses and entrepreneurs.

\section{Issues and recommendations for improvement}

Several issues can be identified at the local level for the improvement of horizontal co-ordination of SME and entrepreneurship policy:

\section{Strengthening the capacity of Federal Delegates of the Ministry of Economy working at the state level}

Some Federal Delegate Offices are currently isolated and are not providing an effective connection and co-ordinating mechanism between, first, the federal national ministries and the state government level and, second, between the federal national ministry, state governments and partners at state level. There is evidence that this is because the federal delegates lack knowledge of developments and concerns at both the federal and state levels. Where this is the case, the Federal Delegate Office becomes an additional step in the process of developing and delivering policy which in some cases adds little value in terms of making for better projects or overcoming any bureaucratic barriers. Where the Federal Delegate Office is weak, the 
State Economic Development Secretaries (SEDECOs) have linked directly to the Federal Ministry of Economy and bypassed the Federal Delegates Office. There needs to be improved communication between the delegates and their domicile national federal ministries, as well as between the delegates and their partners at the local level, especially the state governments. Greater clarity in their role might focus upon their ability to provide, first, the 'eyes and ears' of federal government at the state level, relaying information up to the national ministries to inform the effectiveness of federal government policy. Second, their role is to provide an effective co-ordinating mechanism for federal government ministries in concert with state government ministries and local actors at the state level. Clarification of their role and upgrading their human capital to enable effective delivery are key steps to ensuring better and more effective knowledge transfer between Federal Ministries, state government and other local partners.

\section{Strengthening state government and university relationships}

To connect the research and technological development institutions with SMEs and entrepreneurship policy seeking to stimulate economic development at state level, relationships between universities and state governments could receive more attention and support. A common concern expressed at state level was the need, first, to reform the contracts and incentive structures for staff pay and promotion to increase the recognition and status of applied and industry-oriented research and, second, to revise the Intellectual Property regulations within especially the public federal national universities better to incentivise commercialisation activities based upon research. The current system was deemed inflexible and seen to inhibit close interactions at the state level. However, staffing and IP structures in universities are Ministry of Education's responsibilities over which state governments have limited influence. Exploration and resolution of such issues through the responsible Federal Ministries could enable the building of more effective relationships at state level.

\section{Standing committee on SMEs and entrepreneurship policy}

Within the Association of State Economic Development Secretaries (AMSDE) it is worth exploring whether a standing committee might be established focusing specifically on SME and entrepreneurship policy. As Mexico moves into a new phase of policy refinement, integration and streamlining, there may be scope for a temporary or more permanent standing committee to address issues of co-ordination. This institutional innovation could draw together representatives from responsible institutions from across the states to construct contact networks, share good practice, provide co-ordination and, where appropriate, to address cross-state boundary issues. For example, in co-ordinating linkages between SMEs across state boundaries through supplier development and certification programmes in one state connecting to the 'Tractors' of inward investments in other states. Examples of such initiatives are already developing as the automotive parts cluster in Queretaro is linking to the new car assembly plant investments by Honda and Mazda in the neighbouring state of Guanajuato. This kind of initiative contributes to national development objectives of import substitution and the promotion of domestic manufacturing capacity. The experience of working across state boundaries could be learnt from and shared. Cross border working may also ameliorate zero-sum forms of inter-territorial competition between states in the context of the National Development Plan aspiration for balanced national development.

\section{The appropriateness of local support for local needs}

The effectiveness of the design and delivery of policy for SMEs and entrepreneurship is shaped by its ability to identify and address local needs at the state level often by adapting broader national programmes to meet particular local requirements. Framework conditions - such as economic structure, business stock, supply chains, access to finance, educational attainment and skill levels - vary geographically and directly shape the potential for entrepreneurial and SME activity (Potter, 2005). Balances need to be found between the top-down aspiration for the scale economies and efficiencies of 'one-size-fits-all' generic policy and 
the bottom-up desire for differentiated 'made-to-measure' policy tailored to the concerns of particular local circumstances. Recent research has emphasised the ways in which the integration of top-down and bottomup approaches are better able to develop the kinds of 'place-based' approaches tailored to particular local development policy concerns (Crescenzi and Rodríguez-Pose, 2011).

\section{Strengths}

Notable strengths in the tailoring of SME and entrepreneurship policy for local state level needs are evident in the following areas:

\section{State government autonomy}

The federal system of government and its further decentralisation in recent years provides for substantial autonomy in economic development strategy and policy at the state government level. This has meant state governments have a relatively high degree of capacity to design and develop economic development strategy appropriate to local needs. This kind of strategic autonomy enables state governments to prioritise SME and entrepreneurship policy as part of broader economic development strategies. The decentralised institutional arrangements allow strategy to be developed to address local circumstances, even when local conditions require a degree of divergence from the National Development Plan. For example, if the economic structure in a state is dominated by industrial businesses in established international supply chains then they can constitute the focus of policy support through supplier development programmes linking SMEs to Tractor firms. Local businesses are supported through quality accreditation (e.g. ISO 9000), technological upgrading and organising events for established transnational companies to meet potential new suppliers within the state and beyond. In Queretaro, such initiatives have involved local SMEs with the white goods manufacturing plants of Whirlpool (Tijuana), Electrolux (Ciudad Juarez) and Bosch (Monterrey) as well as Samsung locally. In the state of Morelos, more generally, the aim is to create enough jobs that are well paid and allow local people to access jobs and better living conditions. This aim is progressed through 4 local strategies that seek to address the deficits in local economic infrastructure, improve the business environment, reorient economic activity to segments with greater added value and technology, and promote the capacities of SMEs

\section{Comprehensive, flexible and targeted programmes}

The range of programmes within the national SME and entrepreneurship policy framework provides a wide coverage and eligibility for specific groups which afford substantial flexibility for local actors to propose projects that address particular local needs. Funding programmes are mixed and connected at state level, sometimes including federal, state and municipal resources, as well as those of other organisations from the national or local levels. This provides further flexibility in developing appropriate responses to local needs. As noted above, the National Development Plan sets only the broad frame of reference. States tailor development strategies to local needs and welcome the flexibility of national programmes to support their use in local strategies. This flexibility has been welcome for states in the wake of the global financial crisis where, for example in Queretaro, funds have been targeted at SMEs in industry and micro-businesses in services to help them 'get back into the game' and support local economic recovery. In addition, there is some evidence that support programmes are proving additional, for example in ensuring that projects are initiated and developed at larger scales than could have been achieved without state government funding.

The flexibility in federal programmes allows them to be used by local institutions to address the different needs of each state with specialisations in different economic sectors, size of business, functions and goods and services. This tailoring of local support can be at a broad level. In Guadalajara and Morelos, for example, support programmes have been focused upon innovation and technological development; for example the national resource has been adapted for the local purpose of expanding the institutional and 
physical infrastructure better to connect SMEs with research centres and universities in the city of Cuernavaca. The adaptation to local needs can also be targeted at the development of particular specialisations. For example, Yucatan specialises in agro-food products while Queretaro and Chihuahua are building their presence in aeronautics. Experience with particular indigenous plant varieties with specific qualities in Morelos is linking state university pharmaceutical departments and biotech businesses to work with the properties of indigenous plants with commercial health, food and homeopathic medicine development potential.

Programme targeting allows for the tailoring of support to the needs of local client businesses. This includes the 5 key sectors identified within the broader SME Fund. It is also evident in more specific institutional settings such as the national system of 500 business incubators across 190 cities in Mexico. The incubators are targeted at 3 different kinds of businesses: traditional commerce and services, intermediate with higher knowledge level and high-tech for highly specialised sectors such as biotech and nanotech.

\section{Connecting external networks and local development}

Policy initiatives seeking external networks and export orientation have sought to tailor their programmes to maintain and develop local productive activities. This is especially evident in support for high-tech and innovation-based SMEs and entrepreneurs. For example, FUMEC's (The United StatesMexico Foundation for Science) focus upon specialised incubation and market niches has sought to connect to international high-tech clusters to promote innovation across borders and use international collaboration as a mechanism for the growth of innovation-driven SMEs in Mexico. FUMEC uses its 3 main programmes - SATE (technology and entrepreneurial consultants), Sectoral Co-ordinator and TechBA (technology business accelerators) - to address local needs. This has involved introducing Mexican companies into locations and networks in Austin, California (Silicon Valley), Madrid and Montreal. Crucially, while commercial spin-off businesses and representative offices have been opened, the productive base has been retained in Mexico as the focus for investment and job creation. Funded by the State of Morelos's SEDECO and the federal SME Fund, FUMEC is also hosting an international congress - 'Bio-connect 2011' - to foster business in health technologies, involving businesses from Morelos and across Mexico and those from international clusters where its Tech-BAs are based (America, Canada, Germany and Spain). External orientation is likely to become increasingly important in SME and entrepreneurship policy, especially to elsewhere in Latin America and other emerging markets in Asia, beyond the longstanding focus of businesses in Mexico upon the American market following the global financial crisis, recession and weak recovery there from 2008.

\section{Institutional flexibility and innovation}

The model of programme provision through intermediaries provides for a variety of institutions which is capable of tailoring policy to local context, mobilising local knowledge and experience to design and deliver effective services and support. This model means that the map of institutions in each state is different and can reflect differentiated local demands for types of services and delivery models. State governments are also pragmatic in using direct forms of institutional arrangements where considered appropriate, for example in not-for-profit financing institutions to enable them to offer more attractive lending rates than commercial banks. The SME and entrepreneurship policy in Mexico displays openness to institutional innovation and policy learning from international practice and adaptation to particular local circumstances. For example, the Centros México Emprende and modules were developed from the 'one stop shop' and 'single window' principle following the review of experience and visits to Country Enterprise Boards (Ireland), Small Business Development Centres (US), Technical Co-operation Service (Chile), Directions Regionale de l'Industrie (France) and Canada Business Services Centre (Canada). 
Assessment and review of the national system of incubators too drew upon national and international good practice to prepare its evaluation framework.

\section{Issues and recommendations for improvement}

There are several areas where some reflection and improvement may be generated in tailoring policy to local needs.

\section{Stronger incorporation of the views of other actors in strategy and policy for SMEs and entrepreneurship}

Opening up the strategy making and policy development process at state government level to involve the expertise of local 'non-state actors' provides one way of facilitating the articulation and incorporation of local needs (Pike et al., 2010). The local knowledge of policymakers can be widened and deepened by engaging more closely with local economic actors especially SMEs and entrepreneurs. It might require building the kinds of institutional linkages to help local partners become more involved and take a greater stake in the local economy, expressing their views and adapting programmes more effectively to local needs. For example, as mentioned above, a temporary or standing group or panel on SME and Entrepreneurship Policy could be established at state level and involve state and local government as well as the private and civic sectors. In a decentralised system it can also help clarify strategic priorities and the direction of evolution of the overall support system. Guarding against the problems of elite capture and vested interests will be a key issue in designing and implementing such governance structures for SME and entrepreneurship policy.

\section{Instilling a culture and practice of upgrading toward higher value added economic activities}

Given that the high levels of job creation amongst SMEs is not matched by their contribution to GDP growth, the National Development Programme emphasises 'more and better jobs' and the strategy is based upon added value, differentiation, productivity growth and competitiveness. This approach acknowledges the need to move businesses in Mexico away from reliance upon a low cost, low technology, low productivity and lightly regulated competitive footing toward a higher cost, higher technology, higher productivity and better regulated model - especially given the low cost competition from Asia and specifically China (Fabre and Smith, 2003). In the context of the global financial crisis, this upgrading needs also to consider the potential to shift business models in a more sustainable direction in economic, social and ecological terms.

The focus upon upgrading needs to reflect upon two issues. First, the understanding of innovation needs to be broadened especially given the context of the stage of evolution of Mexico's economy. In one sense, this means an acceptance that some activities may be carving out specialisms in inter-mediate or even relatively low-tech market niches, for example IT companies providing software solutions and contact centre functions. While such activities may not be considered to be at the very top end of high-tech, cutting edge and new technology development, they may still be worthy of support in the context of learning by doing and potential upgrading of their sophistication and value adding over time. Another area where local upgrading might focus is upon support for services for industry - for example in IT services, maintenance and distribution - that complements and builds upon the typical current focus upon direct materials. Larger firms typically outsource such services to large providers which can shut out local service firms. In Queretaro, for example, the longer term strategy is focused upon development of a multi-modal logistics hub by capitalising upon the local airport and rail connections and investments by international companies DHL and Fedex to stimulate further investment and business development opportunities, linking too with the maintenance potential of the local aerospace cluster. 
Second, the focus upon upgrading may require a further shift from the reactive policy model of providing only the kinds of support demanded by local entrepreneurs and businesses - albeit tailored to what they perceive to be their needs - toward a more strongly proactive and developmental policy model that seeks to diagnose and upgrade businesses and potentially identifies forms of support formerly not considered or requested by the local businesses. For example, a SME might perceive its major barrier to growth lies in achieving appropriate quality levels for its goods and services whereas specialist diagnosis from a service provider and customer feedback may reveal that its quality is sufficient and its key concern should be timely order processing and fulfilment. Identifying unmet or poorly articulated needs as well as issues that remain unknown and outside the perception of local businesses is a key task for the strength of the overall system of intermediaries. A purely market-led solution - for example intermediaries emerging only in response to perceived or articulated market demand - may confront market failure but not be sufficient to provide the stimulus to upgrading and the capability to identify service needs for businesses which they did not recognise or perceive.

There are signs that this issue is being acknowledged within the Under Ministry for SMEs. It is seeking to stimulate demand for services that companies did not perceive to promote step changes in performance. Programmes targeted at gazelle companies, for example, provide specialised consultancy to add value to products and to their organisation and management systems and provide mentoring to identify and establish positions in national and international markets and technology hubs. The Centros México Emprende too are developing a diagnostic approach to identifying appropriate support to improve productivity and competitiveness, diagnosing business needs and channelling businesses to appropriate support programmes.

\section{Refining and strengthening programme targeting}

Further refinement and stronger targeting could be worked through the next phase of programme evolution in Mexico. In terms of fine tuning policy to emerging local needs, in Morelos, for example, the strategy for science park development has sought to attract large Tractor companies - both Mexican and foreign-owned. However, the policy has tried to focus upon getting Tractor companies to establish their R\&D and development centres rather than just setting up operations that may employ more people but offer lower quality and lower skilled jobs. In ITESM's business incubator in Querétaro they are retaining their focus upon high tech projects that can lead to patents or copyrights even though in the wake of the economic crisis the highest level of demand for incubation services locally are for more traditional business projects. In addition, institutional providers in the local incubation system in the state are beginning to specialise to be better able to serve the segmented local demand for traditional, intermediate and high tech projects.

\section{Better tailoring of national education and training programmes to local context}

Enabling national frameworks better to reflect local needs can be explored to maximise their effectiveness and contribution to local SME and entrepreneurship development. The National Programme for Entrepreneurs (Programa Emprendedores), for example, is currently a generic training framework that can be adopted and delivered by local institutions. But within the programme there is currently only limited capacity for adaptation to local needs due to the need to maintain the consistency of the core curriculum. Ways might be found of better connecting course material with local case examples, for instance in new business ideas in particular sectors relevant to the local context or recognising the achievements of successful local entrepreneurs and SMEs. 


\section{References}

Bourgogne, P. (2002) Regional Foresights and RIS Processes: The Study of 2 French Regions: Lorraine and Auvergne, DG Research: Brussels.

Crescenzi, R. and Rodríguez-Pose, A. (2011) "Reconciling top-down and bottom-up development policies", Environment and Planning A, 43, 4, 773-780.

Department of Innovation, Industry, Science and Research (2011) Evaluation of the AusIndustry Regional Managers Network, DIISR: Canberra.

Department of Innovation, Industry, Science and Research and IP Australia (2011) Annual Report 20102011, DIISR: Canberra.

DG Enterprise and Industry (2005) Consultation with Stakeholders in the Shaping of National and Regional Policies Affecting Small Business, Final Report of the Expert Group, CEC: Brussels.

Fabre, F. and Smith, R. (2003) Building an Entrepreneurial Culture in Mexico, Paper for Nacional Financiera: Mexico City

Minister for Innovation, Industry, Science and Research (2008) "Connecting Australian business: government launches \$250 million enterprise connect network", Press Release, 21 May 2008, http://minister.innovation.gov.au/Carr/MediaReleases/Pages/CONNECTINGAUSTRALIANBUSIN ESSGOVERNMENTLAUNCHES\$250MILLIONENTERPRISECONNECTNETWORK.aspX

Musson, S., Tickell, A. and John, P. (2005) "A decade of decentralisation? Assessing the role of the Government Offices for the English Regions”, Environment and Planning A, 37, 8, 1395-1412.

NESTA (2008) Business Incubation in Challenging Times, NESTA: London http://www.nesta.org.uk/library/documents/Business-incubators.pdf

OECD (2007) Framework for the Evaluation of SME and Entrepreneurship Policies and Programmes, OECD: Paris.

OECD (2009) OECD Reviews of Innovation Policy: Mexico, OECD: Paris.

OECD (2010) OECD Review of SME and entrepreneurship issues and policies at national and local levels in Poland, OECD Local Economic and Employment Development (LEED) Programme, OECD: Paris.

Performance and Innovation Unit (2000) Reaching Out - The Role of Central Government at Regional and Local Levels, PIU: London.

Pike, A. (2010) Understanding and Measuring the Governance of Local Development Policy, OECD LEED: Paris.

Pike, A., Tomaney, J., Torrisi, G. and Tselios, V. (2010) Non-State Actors in Local Development Governance, OECD LEED: Paris.

Potter, J. (2005) "Entrepreneurship policy at local level: Rationale, design and delivery", Local Economy, $20,1,104-110$. 
Rodríguez-Pose, A. and Ezcurra, R. (2010) "Does decentralization matter for regional disparities?: a crosscountry analysis", Journal of Economic Geography, 10, 5, 619-644;

Silva-Ochoa, E. (2009) "Institutions and the provision of local services in Mexico", Environment and Planning C: Government and Policy, 27, 141-158. 


\section{CHAPTER 3 \\ HUMAN CAPITAL AND SKILLS}

\section{Introduction}

A country's economic recovery is predicated on its educated, enterprising and skilled people. Skilled people are more productive: they are more innovative and they build stronger businesses (BIS, 2009). A high education level of the regional workforce and the wide availability of labour are positively related to the contribution of new businesses to regional employment (Fritsch and Schindele, 2011). Government policies can therefore influence the supply of input factors into entrepreneurship, for example through improving the availability of qualified labour. Public policy may also be used to improve individuals' and employers' incentives to invest in human capital (OECD, 2003).

The focus on enterprise education, a key element in Mexico's economic strategy, can provide a number of important outcomes (Storey, 2008; Karlsson and Andersson, 2009), which address particular market failures. The first is to raise the awareness of an individual to the possibility of becoming a business owner as a career option: many individuals do not realise the private benefits of starting a business. By explicitly including business and entrepreneurship within educational curricula (at schools and colleges as well as at higher education institutions), this may increase the supply not only of entrepreneurs, but also of entrepreneurs who already have a sound understanding of business. National and regional governments can influence the demand side by increasing the number and type of entrepreneurial opportunities.

A second potential benefit of enterprise education is that it may improve the performance of businesses, overcoming the market failure of many owners of small firms not fully appreciating the private benefits to their business of taking certain courses of action. Course content which includes for example, marketing, management, financial control and business planning, may enable better businesses to be established. Policies can also directly target the values and attitudes of potential and actual entrepreneurs, for example towards markets and growth. A lack of entrepreneurial skills leads to a lack of awareness of the competitive requirements in the market to which the firm is related, and a difficulty in developing or finding an information system that helps in relating to new potential clients and business opportunities (OECD, 2011a).

At the regional level, there is a strong and positive correlation between labour productivity and educational attainment in OECD regions. For the regions within Mexico, the correlation has been found to be even stronger. Recent studies have confirmed that education contributes significantly to economic growth. This is specifically through certain variables such as average schooling years, number of tertiary education graduates, total expenditure in education, and especially expenditure in primary education institutions (OECD, 2009a).

This chapter assesses what measures have been introduced with respect to the upgrading of technical skills in the workforce through vocational education, student placements in industry and the development of higher level skills through continuing professional development (CPD). This goes hand-in-hand with developing an entrepreneurial culture nationally and regionally, by changing attitudes towards starting a business. 


\section{Assessment of framework conditions}

Mexico's education and training system nationally and regionally is being increasingly geared to address weaknesses in the country's skill base, including a very high level of micro-enterprises in the economy, low overall levels of skill, a lack of vocational education and of continuing professional development (OECD, 2011b).

There is also a very high percentage of self-employed. In 2008 it was over $30 \%$ of the workforce, far higher than the OECD average (OECD, 2010). Despite the recognition of its importance and the major efforts undertaken over the last 20 years to expand education services, by OECD standards the country still performs poorly in data on quantitative and qualitative formation of human capital at all stages of education, from primary schooling to life-long learning (OECD, 2009a).

The demography of the country is a critical part of framework conditions, affecting the levels of entrepreneurs and skilled people. Mexico has experienced a boom in younger people: 60 million out of a total population of nearly 114,000 million are aged between 13-39 years old, with a very high percentage of younger people. This is associated with the rapid rise in population from 40 million in 1960. This is important because it shows that the nation is travelling through a period where the population size of productive stage has reached its highest relative weight with respect to inhabitants in dependant age, resulting in what is known as demographic bonus (Partida-Bush, 2005). Hence Mexico's potential competitive advantage will need to be harnessed through its educational system and through the extent to which entrepreneurship education and vocational training is integrated from schools through to higher education.

\section{Building the skill base: the Mexican education system}

Mexico's education system is organised into four levels: preschool (K1-K3), compulsory basic education (grades 1-9), upper secondary education (grades 10-12), and higher education. At school level, many students enter the workforce with low levels of education. Enrolment of children of primary school age is high in basic education (grades 1-9) although it varies by level. It is very high in primary schools (grades 16) (93\%), but lower in lower secondary schools (grades 7-9) (86\% of lower secondary school age). These rates mean that out of every 100 students entering the first grade of primary school in Mexico, around 68 of them will complete all nine years of basic education. Thirty-five of these will go on to graduate from upper secondary. States with higher completion rates provide a better environment for workforce skill development and entrepreneurship education. For example Morelos is one of few states with very high levels of participation in basic education in elementary schools (99.4\%). Queretaro has higher average scores in the quality of tertiary and school level education contributing to its human capital and the value added of the workforce (OECD, 2009a).

As governance is centralised at the national level through the Secretaria de Educacion (SEP), the ability of states to customise their provision of training in schools is limited. Overall, teachers and school administrators have little autonomy in the system. This affects the ability to make decisions with respect to entrepreneurship awareness and education. However, some states such as Morelos have identified opportunity areas working with the Ministry of Economy on entrepreneurship education at school, college and higher education. 


\section{Vocational education and training}

Provision of vocational education and training (VET) in Mexico is patchy. ${ }^{4}$ In contrast to other OECD countries, Mexico has put much less emphasis on vocational tertiary education (tertiary-type B level programmes) during the last two decades, with an entry rate of just $2 \%$ for these programmes in 2005 , well below the OECD average of 15\% (OECD 2009a). VET has been targeted in Mexico mainly through the National College of Technical Professional Education (CONALEP). This was established in 1978 to train middle-level technicians for the industrial and service sectors of the economy. It is represented in every state and is funded in part by federal funding through the Ministry of Education, and by each state. The programme is equivalent to high school education, or further education in the UK, and awards technical professional qualifications. Students join at 14/15 and are educated for 3 years. A key strength is that each college designs courses according to its region's skills needs.

VET is particularly important in cluster development as it underpins the productive capacity of SMEs and their position in supply chains. Morelos, for example, promotes four clusters: ICT, advanced manufacturing, health technologies (medical devices, clinical trials, new pharma techs, etc.) and food technologies. Queretaro specialises in IT, machine tooling, food and beverages, maintenance of motors and aircraft, mechatronics, industrial chemistry and electronics. State level funding for training is particularly important for companies in lean manufacturing and for certification, which is generally higher than in other Mexican states (OECD, 2009c). Here the state subsidises the cost to companies, for example by training grants or scholarships for employees to undertake degrees.

\section{The Higher Education System}

For higher-level skills, Mexico has an extensive set of public and private higher education institutions (HEIs). The HEI system consists of universities, technological institutes and state educational institutions. Public higher education in Mexico is offered through various subsystems:

- Public federal universities; 8 national institutions that are funded by the federal government such as the National University of Mexico (UNAM) and the National Polytechnic Institute (IPN). During the 2009-2010 cycle, these had 13.6 percent of national registrations;

- Public state universities located in all 31 states, accounting for $28.3 \%$ of total registrations. They receive mixed public funding from both the federal and the state governments, with relative contributions subject to an agreement between them and the individual institution;

- Technological institutions, both federal and state. Depending on their vocation they are classified into Industry, Agriculture, Ocean Sciences and Forestry;

- 83 technological universities represented in 26 Mexican states. Morelos for example has only one. As compared to federal or state universities, technological universities have a more hands-on approach to training. They provide two levels of education: higher technical college ( 2 years) and engineering degrees (4 years). When they were first established, courses were offered mainly at higher technical university level, although they recently expanded into bachelor degree programmes;

- $\quad 32$ polytechnic universities which are decentralised institutions that belong to state governments.

4. VET is any formal, post-compulsory education that develops knowledge, skills and attributes linked to particular forms of employment, and develops practical and technical skills that have the potential to enhance the performance of enterprises. 
HEIs collectively have a student body of around 450000 students, in 2807 HEIs. In the private sector, the Technological Institute of Higher Studies of Monterrey (ITESM) is a private non-profit nationwide university system.

While private universities have no specific mandate for regional engagement, they are often engaged because of their business model. ITESM is the most important. It has expanded to 33 campuses spread throughout 26 Mexican cities providing a unique case in active regional engagement across the country (OECD, 2009a). Its campuses help develop their regions by establishing technology parks, such as in Queretaro. Its curriculum is designed to meet local industrial needs. It coordinates its own network of incubators, as do technical universities and technological centres with their own incubators.

\section{Recent trends}

In spite of this range of institutions, a major national weakness (although this varies by state) is that, in spite of a rapid rise in the number of student enrolling in higher education, Mexico has a low proportion of the population with higher level qualifications compared to other countries. Only $8 \%$ of the population aged 18 and older in Mexico holds a bachelor's degree, compared to 30\% in the US, and $13 \%$ in Italy. However, efforts to improve the supply of graduates with industry-relevant skills nationally have paid off in some respects even if the achievements need to be put in perspective given the small percentage of students enrolling in tertiary education. Mexico's share of science and engineering graduates in all newly awarded tertiary degrees is above the OECD average; the number of doctorates awarded, while quite small by international standards, has doubled since 2000 and more than trebled in engineering and technology (OECD, 2010).

A particular issue, however, is that of coverage. Every year thousands of potential undergraduate students are rejected because of lack of available places. A further problem relating to the extent and quality of workforce skills is that of balance of subjects studied. In Morelos, for example, the Technological University Emiliano Zapata (UTEZ), a small technical and regional public university located in Cuernavaca, identified a problem of missing competences due to the lack of enough engineers in the state. This is related to the career choice of the prospective students because of high saturation of certain options such as accounting, business management, law, and others. This suggests that there should some thought as to how to incentivise students to take more industry-relevant subjects.

Smaller technical universities and the private universities are at the forefront of industry-relevant VET. The formal participation of employers and representatives of industry as external members of institutions' governing bodies is a phenomenon largely limited to technological universities and some technological institutes and polytechnic universities. In other institutions, in particular autonomous institutions, their presence in governing bodies is scarce (OECD, 2006; OECD, 2009a). For example at UTEZ, the educational model is that of career development relevant to productive sector. It specialises in informatics, electronics, telecoms, industrial engineers, business administration and management. It has a certificated software development centre and one for biotechnology. It hosts the Cisco regional academy, and a systems agreement for accreditation with Cisco. It provides training and qualifications, diplomas for people in companies on IT tools, with short courses for people who want to start a business, workshops, conferences. The university is able to make a course suitable for industry in the state e.g. in informatics or engineering. Programmes are usually successful with a high percentage of students placed in industry for which they were trained.

At the regional level, the "third mission" of HEIs to support regional development, although improving, is as yet underdeveloped in Mexico. Some states such as Morelos and Queretaro, however, are targeting higher education as an economic growth strategy to overcome such barriers and work with local industry in designing course, including on provision of entrepreneurship education at tertiary level. 
In Morelos, in 2006, its public universities enrolled 9000 graduates. By 2011 this had risen to 18000 , rising to 19000 in 2012, with an overall target of 25 000. Alongside ITESM and UTEZ are other higher education and research institutions with responsibilities for entrepreneurship and training include the Autonomous University of Morelos, and the high-tech incubator and patent centre and the technology centre, CEMITT - Centro Morelense de Inovacion y Transferencia Tecnologica. In Queretaro, entrepreneurship education and training are integrated into the higher education systems with major institutions providing incubation, entrepreneurship education and industrially relevant training including the Autonomous University of Queretaro (UAQ) and ITESM. In UAQ in their final term, all student majors must work within a company to solve specific problems, while ITESM makes as a requirement for graduation that each student must present a project to be used by companies.

Related to the increasing levels of provision of entrepreneurship education and training identified above is evidence of a growing propensity for training by firms. A survey of 1480 firms in 8 states of Mexico shows that a large share of Mexico's industrial base already has a training culture (IFC, 2010). Positive and negative aspects of national and regional framework conditions for training provision are shown in the table below. This shows that Mexican SMEs, as well as large firms have a higher propensity to engage in training compared to those in other countries in Latin America and worldwide. This is the case across all size bands, but significantly in the smallest size band. Mexico has a small percentage of unskilled workers out of production workers in medium and large sized firms. A striking feature of the figures is that the percentage of firms identifying an inadequately educated workforce is much higher for medium-sized firms, which would include some gazelles, than elsewhere. This suggests that training programmes need to target this particular type of firm, particularly though vocational education.

Table 3.1. Training provision and skills in Mexico compared to Latin America \& the Caribbean and World

\begin{tabular}{|c|c|c|c|c|c|c|c|c|c|}
\hline & \multicolumn{3}{|c|}{$\begin{array}{l}\text { Percent of firms offering } \\
\text { formal training }\end{array}$} & \multicolumn{3}{|c|}{$\begin{array}{l}\text { Proportion of unskilled } \\
\text { workers (out of all } \\
\text { production workers) (\%)* }\end{array}$} & \multicolumn{3}{|c|}{$\begin{array}{l}\text { Percent of firms identifying } \\
\text { an inadequately educated } \\
\text { workforce as a major } \\
\text { constraint }\end{array}$} \\
\hline & Mexico & $\begin{array}{l}\text { Latin } \\
\text { America } \\
\& \\
\text { Caribbean }\end{array}$ & World & Mexico & $\begin{array}{l}\text { Latin } \\
\text { America } \\
\& \\
\text { Caribbean }\end{array}$ & World & Mexico & $\begin{array}{l}\text { Latin } \\
\text { America } \\
\& \\
\text { Caribbean }\end{array}$ & World \\
\hline Small & 42.4 & 33 & 25.8 & 31.3 & 31.5 & 28.3 & 30.7 & 37.9 & 32 \\
\hline Medium & 57.2 & 53.9 & 41.3 & 32.7 & 43.9 & 36.4 & 51.4 & 38.2 & 29.9 \\
\hline Large & 89 & 76.2 & 63.5 & 32.9 & 42 & 38.4 & 23 & 34.6 & 25.8 \\
\hline Average & 50.8 & 43.7 & 35.4 & 31.9 & 37.7 & 32.6 & 30.9 & 35.8 & 27.4 \\
\hline
\end{tabular}

Source: Adapted from Neil MacCallum (2006) Office of Project Advice and Training, London, UK, OECD LEED Evaluation Workshop, Trento

\section{Assessment of policies and programmes}

While a proliferation of bodies responsible for delivering training provision might be seen as resulting in an unnecessarily complicated set of resources, nevertheless at the early stages of provision, this is strength as it means that many agencies are covering many targets. It is later that consolidation will enhance efficiency.

To summarise the educational framework structure, the table below shows the range of national and regional agencies that are responsible for entrepreneurship education and entrepreneurial skills. For some, it is the primary function. For others it is a secondary but still very important activity. For both types, there are overlaps across each target area. None of the national funds, even ones such as Prosoft which is 
targeted at the IT industry, are aimed at tractor firms. However, as is shown below, larger firms benefit from the training provided to SMEs in their supply chains.

The policy assessment focuses on four areas: vocational education; specialised training for SMEs; incubators and accelerators; and entrepreneurship awareness.

Table 3.2. Agencies involved in entrepreneurship skills and entrepreneurial human capital development in Mexico

\begin{tabular}{|c|c|c|c|c|c|c|c|c|}
\hline & $\begin{array}{l}\text { Ministry of } \\
\text { Economy } \\
\text { SME fund }\end{array}$ & $\begin{array}{l}\text { Joint progs } \\
\text { with other } \\
\text { bodies e.g. } \\
\text { FUMEC } \\
\text { TechBa }\end{array}$ & $\begin{array}{l}\text { Ministry of } \\
\text { Education }\end{array}$ & Conacyt & $\begin{array}{l}\text { Public } \\
\text { univ's }\end{array}$ & $\begin{array}{l}\text { Private } \\
\text { univ's }\end{array}$ & $\begin{array}{l}\text { Other } \\
\text { Ministries } \\
\text { e.g. } \\
\text { Tourism }\end{array}$ & $\begin{array}{l}\text { Sector } \\
\text { specific } \\
\text { Prosoft }\end{array}$ \\
\hline Entrep's & $x$ & & $x$ & & $x$ & $x$ & & \\
\hline $\begin{array}{l}\text { Micro } \\
\text { firms }\end{array}$ & $x$ & & & & $x$ & $x$ & $x$ & \\
\hline SMEs & $x$ & $x$ & & $x$ & $x$ & $x$ & $x$ & $x$ \\
\hline Gazelles & $x$ & $x$ & & $x$ & $x$ & $x$ & & $x$ \\
\hline Tractors & & $x$ & & $x$ & $x$ & $x$ & & \\
\hline
\end{tabular}

\section{Vocational education}

Where SMEs in Mexico receive significantly less support than in other countries is in vocational education. This is particularly so at college and university levels. At high school level, Mexico has introduced the school-based secondary VET, the Mexican Technical Baccalaureate, which provides technical education and training. Students typically start at age 15 after completion of lower secondary education (OECD, 2009b). Another form of upper secondary skills training is CONALEP. The latter is central to cluster development by providing training for SMEs per se and particularly those working with a region's tractor firms. For example, CONALEP was established in Queretaro in 1996 and now has four campuses. It targets the state's strategic sectors, which are dominated by tractor companies.

CONALEP provides training for small and micro companies as well as larger firms. Courses are subject to a local feasibility study vetted by the Federal office. Numerous channels of communication with state offices give information about which companies are present in the state and which ones are arriving, and courses can be based on specific needs of a company which requests training.

CONALEP provides apprenticeships in the form of internships, which last for 360 hours (Federal law) and which earn a diploma. Students study in CONALEP for two years. In their third year they spend time with a company, developing "professional practices". The programme is successful in matching students with employers: some $60 \%$ are recruited by the company. A specific example of skills development is the maintenance of motors in small aircraft. The company Eurocopter approached CONALEP to include a specific module on helicopters.

Where CONALEP's effectiveness could be improved is twofold. First, it could be improved by having more teaching in English, thus increasing opportunities for placements in multinational companies. Second, co-ordination of efforts between the Secretaries of Economy and Education at state level to decide strategy and funding would also improve effectiveness. In Queretaro, for example, currently there is no collaboration on sets of skills needed between the Secretaries of Economy and Education at state level. Steps to improve coordination would be based on an identification of skills sets needed in specific sectors and where there are gaps and overlaps in provisions. From this, a committee which represents industry, the 
ministries, CONALEP, other vocational education providers and the universities should be established to oversee a programme of delivery which integrates provision of training.

This is beginning to happen in Queretaro and involves CONALEP and the new university in aeronautics, the National Aeronautics University of Queretaro (UNAQ). They will share equipment and facilities on a joint campus, but CONALEP will train technicians while higher technical subjects will be taught at UNAQ. A type of licence, which is essential for employment in this technological area, will be developed. The rationale for this collaboration is that the state has some 43 companies in this sector, which comprises an integrated cluster of academia, industry, R\&D, design and engineering. Human capital is generated at five levels: Basic technician, Upper Level technician, Engineer, Masters and PhDs. In 2011 there are more than 2,300 aerospace graduates and this is expected to rise to 6,500 by 2016 .

The Technological University Emiliano Zapata (UTEZ) provides another example of good practice of responsiveness. It provides training and qualifications, diplomas for people in companies on IT tools, with short courses for people who want to start a business, workshops, conferences. It hosts the Cisco regional academy, and a systems agreement for accreditation with Cisco. When a programme is opened, for example when industry locates in the state, the university will, based on competences and evaluation of skills needs, introduce a suitable course, e.g. in informatics. Programmes are successful as a high percentage of students are placed in the industry in which they are trained.

While these are good models, universities could do more to develop vocational education through a number of routes such as co-operative programme at undergraduate and master's levels, continuing professional development (CPD) for employees, and teaching company programmes.

The co-operative education model, now found in over 60 countries worldwide, is not well developed in Mexico. Co-operative education is an educational model that formally integrates academic studies with relevant work experience, which provide a student with high levels of training. They are offered at undergraduate and postgraduate levels. Students alternate periods of school and work in appropriate fields of business, industry, government, social services, or the professions. Work periods are usually four months long. Some of the largest programmes include the University of Waterloo in Canada and Northeastern University in the USA. A recent development is the formation of accreditation bodies for Cooperative programmes for example in the USA and Canada as well as the World Association for Cooperative Education (WACE). Where programmes have been used extensively there is evidence that students and the university as well as the host firms benefit from the two-way transfer of knowledge. The learning model of North-eastern University in the USA addresses this topic (see Annex on Learning Models).

Some universities in Mexico do offer a form of this programme, organising internships for example where students spend time in industry. Internships generally differ from cooperative education programmes in that they usually have a single work assignment, which usually does not take place during term time and students receive less supervision than in a co-operative programme. For example, the Polytechnic University of Morelos has an internship programme in which students stay for 4 months in the last stage of their university career in industry to develop a product. The return is good: close to $85 \%$ of students find jobs with the company, $10 \%$ pursue postgraduate studies and less than $5 \%$ do not have jobs.

Continuing professional development (CPD) is the means by which people maintain their knowledge and skills related to their professional lives. This kind of training for higher level skills is generally insufficiently addressed in Mexico. In Morelos this was identified as a gap in the training system. A problem relates to policy jurisdictions. The SME fund does not cross into CPD as it is outside of the fund, it being the responsibility of the Ministry of Education. It was reported in Morelos that there are barriers to such study in Mexico, relating to the timing of diploma courses; for example if time has to be taken off 
work to attend classes during afternoons. Mexico has recognised the gaps and is addressing the challenges faced by a series of recent initiatives. For example, there are good examples of collaboration between VET schools and employers, such as the Playa del Carmen project which links public and private resources to improve worker preparation and training in the tourism sector in the Mayan Riviera (OECD, 2009a).

Finally, teaching company schemes are designed to facilitate the transfer of knowledge, technology and skills to which company has no access through the part-time employment of a graduate who is supervised by a university and is acquiring a higher qualification. The knowledge transfer partnership in the UK provides an example (see Annex on Learning Models).

\section{Specialised training for SMEs}

Specialized training and consultancy to SMEs is provided through a number of routes. For example, the objective of the Programme COMPITE is to raise standards of quality and social responsibility. The Ministry of Economy, through COMPITE, provides training in topics such as: Reengineering and process optimization workshops; ISO 900; Quality Training for the optimum performance of the company's human resources.

Ministries other than the Ministry of Economy have a secondary role in provision of training. For tourism, companies are promoted and supported through an agreement between the Ministry of Tourism and the Ministry of Economy through the Modernization Programme (Programa Moderniza). The Ministry of Tourism has policy responsibilities regarding SME firms in the tourism sector, and the instruments of these policies are operated through Programa de Apoyo a la Competitividad de la Micro, Pequeña y Mediana Empresa Turística (Competitiveness Support Program for Touristic SMEs) (OECD, 2011).

Specialist programmes such as Prosoft, a federal programme established in 2002, have a secondary but very important role in the training provision for specialist skills. This programme provides funding for training, certification, and product/project development. It is financed $25 \%$ by the federal level, $25 \%$ by the state level, and $50 \%$ by the private sector. Morelos was the first state to apply for the programme. A beneficiary, a gazelle employing 130 people, received training paid for by Prosoft, and was then certified by IBM on open software technologies after 12 months of full time courses. A strong point of the programme is its high additionality. In this case a supported company was able to bring at the local level global and cutting edge competences such as those of IBM. Certification is expensive, so that without Prosoft it would have been nearly impossible to obtain.

A weakness in skill provision in this sector, even with Prosoft, is the lack of links with educational centres which provide training in IT. Currently all programme are supported by Ministry of Economy and few educational programmes by the Ministry of Education. There should be more overlap and provision.

\section{Business incubators and accelerators}

\section{Business incubators}

The rationale behind the vast network of business incubators is that there is an insufficient number of firms in Mexico. Incubators in Mexico have existed for over 35 years but under the SME fund the number and range of functions have accelerated. This is a national model: all incubators have a committee in which the Ministry of Economy, the state government, the chambers of commerce, etc. participate and together make decisions on project approvals and future strategies. The process is highly subsidised. In 2011, the cost to the Ministry of Economy was between 25 000-65 $000 \mathrm{MXN}$ pesos per participant. Its strengths are targeting across all three types of firms (traditional, medium-tech and high-tech sectors) and the use of the universities, public and private, in incubator programmes. 
The number of incubators has expanded rapidly. In 2011, 500 business incubators were in operation. Of these the majority were supporting traditional (217) and medium-tech (262) businesses with a minority towards high-tech (21). Over $70 \%$ of the incubators are in a university or other forms of education institute. The scale of support achieved for supporting entrepreneurship would have not been possible without the SME Fund.

Consultants funded by the SME programme provide training to micro and small firms in areas such as process and quality systems. They play a particularly important training role in the international certification process in management and technical standards (ISO). Certification of this sort is very important as it enables small firms to get into the production chain. Multination and large Mexican companies require their suppliers to be certified as meeting international standards. For example, a supplier to the automotive sector in Queretaro was trained in quality certification ISO/TS16949:2009. This is demanded by the automotive sector as an indicator of quality but is also accepted in other sectors.

Where the programme needs to be improved is in the degree of flexibility at the regional level, linking incubators to accelerators and greater support for training trainers. First, although the programme does allow for regional differences in targets, states could be given stronger decision making powers to tailor incubation processes. At the regional level, State Development Agencies cannot design their own entrepreneurship programmes through the Federal budget. State Technical Committees can make changes provided that they follow the procedures established in the rules of operation for such cases. Adjustments have to be ratified by the National Board of Directors of the SME Fund.

States, however, do vary in the number and types incubators and have their own incubator programmes, such as in the Morelos Centre for Entrepreneurial services. For example, of the five incubators in Morelos, 3 belong to universities, 1 is private, and 1 belongs to the state of Morelos (IATCEMITT) (Morelos Centre for Innovation and Tech Transfer). The State Council of Science and Technology of Morelos (Consejo de Ciencia y Tecnologia del Estado de Morelos - CCyTEM) is also involved.

The Technological Institute of Monterrey (ITESM) plays a particularly valuable role and demonstrates the importance of the private sector in the provision of incubator-based training, particularly for high tech firms. For example it is the only university in Queretaro with programmes for high-tech companies. The modality is that many students from different programmes want to start their own firms. The campus has created a club as a way of making a network of entrepreneurs, and encouraging new entrepreneurs to join. The technology park, established in 2010, runs two entrepreneurship clubs: one each for the accelerator and the incubator. However, it would be more effective to join the two together.

The ITESM campus is also part of the process by which tractors come to the state to use 'landings': inward investment by Mexican and foreign companies such as from Spain, US and Brazil by linking SMEs to multinational enterprises (MNEs). ITESM does this by supporting clusters in automotive, health, and IT, working with the US-Mexico Foundation for Science (FUMEC) which manages the business accelerator programmes on integrating local SMEs into global supply chains. The campus can offer subsidised rent funded by state government for companies on the condition that there are links with the school, focus on IT, airspace, automobiles, IT.

Moreover, it could be argued that the incubator programme is lacking in key respects. The first is that the importance of networking and building communities of practice which are essential soft skills in entrepreneurship (Nativel, 2006) are under-estimated. What appears to be happening in Morelos in public universities is that incubators are being built without social spaces in which entrepreneurs can meet and develop contacts. 
The second is that expectations of the extent to which entrepreneurship programmes can by themselves play a significant social policy role through job creation are unrealistic. This is particularly the case with the target for student entrepreneurs: the ambition is to create 10000 student start-ups, which is linked to the high percentage of incubators in universities. However, an issue is the quality and sustainability of student start-ups. Research by the OECD LEED programme (forthcoming) has suggested that student enterprises have very high mortality rates due to the typical barriers of youth entrepreneurship, for example lack of prior work experience, difficult access to external finance and limited social networks. Worldwide the pattern is that the number of spin-offs is increasing with more surviving albeit from a low base. However, most remain small or take many years to grow. In contrast, spin-offs from existing firms have a high propensity to survive and grow. This finding is consistent across developed countries such as the, Canada, Italy, Sweden, the US and the UK (Harrison and Leitch 2010, Lawton Smith et al., 2011).

In Mexico, although students are particularly targeted, the success rate is low. The number of companies being incubated is increasing but employment generated is low. In 201024 companies generated 109 jobs and in 2011 there were 30 companies for 105 jobs. Mexico's universities could increase support for student entrepreneurs alongside the incubation process through developing student-led networks.

In universities, particularly public universities, there is a lack of incentives for academics to get involved in spin-off activity. In public universities, faculty engagement with the private sector is limited by employment legislation, identified by state organisations and universities in Morelos. Employment legislation in universities falls within the remit of the federal government even for state universities which are still funded at the federal level. The consequence is that often academics are only offered an acknowledgement as co-workers for a project. An alternative model considered in the incubator in the state university of Morelos is for a university to pay the teachers to incubate innovation-based projects to provide incentives for academics to get involved in translate ideas from the universities into profitable businesses as part of developing an entrepreneurial culture. Finally, there is a need for standardisation to improve the quality of trainer in incubators. In Queretaro it was proposed that the Ministry of Economy creates a national programme, based on a US model, to ensure quality. Business accelerators

The business accelerator programmes, Tech-BA, is designed by FUMEC through national funding from the Council for Science and Technology (CONACyT), focusing on where Mexico has opportunities based on its research base, for example health and clean technologies in Morelos. The market failure arguments for supporting gazelle firms lie in their role in direct job creation, in generating new economic activity and in stimulating competition. It is present in 20 states in Mexico and operated by partnerships with U.S. organisations in order to ensure best practices and access to the entrepreneurial and financial ecosystems of key US technological regions such as Silicon Valley in California, Austin in Texas, Phoenix-Scottsdale in Arizona, the Detroit region in Michigan, as well as Montreal in Canada and Madrid in Spain.

Tech-BA has worked with innovative companies related to high technology sectors with a strong presence in global technology markets, such as: Information and communication technologies, Aerospace and automotive, Life Sciences, Electronics, including Microsystems and Robotics, Advanced Materials, Multimedia, Animation, Digital Content and Educational Services, Biotechnology related to agricultural and food industries, Alternative Energies and Sustainable Technologies.

In 2011 there were 50 business accelerators, both national and international. This appears to be successful policy initiative. Since 2005, they have integrated 321 companies through pre-acceleration and acceleration processes. As a result of this effort, companies have accumulated more than 56 million dollars in commercial transactions or investment attraction, and have created more than 3,600 new jobs. 
One point of strength of the FUMEC programme is its cluster development function with its emphasis on human capital development. In SATE (a specialised technological and entrepreneurial consulting system) growing clusters are identified, by bringing in a consultant (articulator) who makes an inventory of the companies in the sector, interview each company and build a profile of the company and its needs. "Sector Coordinators", another FUMEC's initiative, look out of the state, bringing in consultancies and experiences that are not available locally, building a network of specialised consultants. Morelos is committed to three clusters; health technology, ICT and advanced manufacturing. Specialisations include medical devices and cloud computing. ${ }^{5}$

In Morelos in the local accelerator programme activities are undertaken such as company profiling; workshops on trends and opportunities; action plans; management tools; innovation strategies; assessing technical and marketing readiness; and identification of companies with interest and capacities to join Tech-BA. Good practice takes the form of working with start-ups from incubation and helping existing companies migrate to better value markets through specialised incubation and acceleration. It does this by focusing on niches, for example in ICT, where there is a cluster of 59 companies in software and mobile devices. Support is provided by an analysis of global trends based on markets and technology and conducting studies of specific opportunities for example in medical devices or micro-electronic devices looking for a critical mass of companies to develop clusters in each niche. Opportunities for developing partnerships with companies in other locations are explored.

Success in the programme is illustrated by an alliance with Microsoft through an accelerator in Seattle. FUMEC trains the company in developing the business model for the company to become global. Microsoft has officially recognised the programme. The strength of this programme is that it recognises that, especially in cutting edge areas, competencies may be very specific and unavailable internally.

Where the programme could be improved is in developing management skills. The companies have technical strengths but limited management skills. It is here that the universities could be involved in the acceleration process through the use of the skills of their management departments and business schools. Although in Morelos there is some indication that there are connections between the incubator and accelerator programmes, a weakness of the programme generally is the lack of formalised connection to incubator programmes. In turn it is crucial that incubators do not operate in isolation from the accelerator programmes, to increase the possibilities that gazelles are developed and are supported in training and entrepreneurial skills through exposure to specialist expertise, international best practice and international markets.

\section{Entrepreneurship awareness}

'Entrepreneurship awareness' designed to improve entrepreneurial cultures in different sections of society including younger people, women, students, housewives and the unemployed, is a key element in the SME Fund.

For example, in the Caravan dos emprendedores programme, an itinerant van is used, often located in a university campus, for around a day and a half to give presentations, invite speakers from each region and potential entrepreneurs. It is used as a tool to reach out to remote localities and inform them about the programmes of the Ministry of Economy. It is not necessarily capital cities that host the events. So far, over 100000 people have participated. Some states such as Jalisco were already undertaking similar activity but now all of these local initiatives are grouped under the umbrella of this programme.

5. Cloud computing is a recent development in computing which allows users to use a variety of devices such as their own personal computers, laptops and smart phones to access remote services such as programmes, storage and applications over the internet. 
An improvement in public policy identified in Morelos would be for funding on entrepreneurship awareness and education also to be focused on elementary schools, and for women and different ethnic groups. The Ministry of Education will need to work with the Ministry of Economy on this as the school curriculum is decided at national level.

It is important for Mexico that women are targeted as it has an increasing share of younger women in the workforce who are now being trained in what were traditional male occupations. Ernst and Young (2011) reported that a failure to integrate women fully into the workforce is costly in terms of GDP, arguing that it is clear that women can add incrementally into a developing nation's economy. This is also being recognised in the UK, for example the University of East London in 2011 established the Centre of Excellence for Women's Entrepreneurship. Although Mexico has no exclusive programmes for women in the national system of employment, it is beginning to happen, for example in Queretaro. In 2008, the incubator of the Autonomous University of Queretaro (UAQ) worked with a group of women identifying demand with the department of sustainable development for the local municipality. The group mainly included artisans, for example bakers and women working with leather goods.

\section{Policy Recommendations}

From studies and data on Mexico and from the interviews in the two regions, three recommendations are made. These relate to different components of the skill base.

\section{More emphasis needs to be placed on vocational training and continuing professional development}

Although there are good examples of HEIs and industry working together at state level, at the national level, there is a lack of coherence in approach to both school and university level training for students and employees. Both forms of training directed at SMEs and gazelles are relatively underdeveloped in Mexico. What is needed is a better infrastructure for both which integrates federal and regional programmes. Particularly, investment needs to be made at college (high school) level.

The steps that the government could take are threefold. First, although the SME fund has provided a very high level of support for entrepreneurship education, it could work far more on workforce development. The SME fund should look into training issues at skill sets for those in work in SMEs to identify elements of the system that are missing. Second, the Ministry of Economy and the Ministry of Education could establish a national forum where representatives of business and industry can contribute to the development of tertiary education policy. Third, vocational education needs be more widespread throughout colleges and universities.

Mexico could emulate Brazil's model. The National Program for Access to Technical Education and Employment, established in April 2011, is intended to create 8 million new vocational training opportunities by 2014 for those who require professional qualifications. The objective is to further promote the integration of young students and workers in the professional market. The measure aims to expand and democratise the offer of technical courses and mid-level professionals. The offer of initial training courses and continuing technical education to men and women working in the country is also a key feature of the programme. For such a programme to work in Mexico, different ministries (Economy and Education) need to work together in order to address confusion of responsibilities due to multiple agencies.

\section{The current framework for skills needs to be better targeted.}

A more integrated approach is needed across ministries at Federal level (Economy, Education) and at regional level to develop a coherent national skills strategy focussed on growing firms that can be adapted to local needs. The incubator and accelerator programmes need be closely integrated. Although the specialist programmes such as Prosoft provide valuable training, they could also be more closely linked to 
both. A first step would be to produce a policy document that identifies market failures and provision of entrepreneurial skills for SMEs to enable more of them to become gazelles. A second step would be to improve communication between the states and government on training needs. A third step would be for the Ministry of Economy to find opportunities to involve the private sector more in training provision. At all levels, there is a need for training to be self-sustaining and at low cost with reduced dependence on government.

More generally it is important that training policies in each state are geared towards emerging global and local sectors so as to develop skills that are missing. They should also be directed towards growing businesses. Morelos for example shows a weakness in both respects. It is also important that states develop entrepreneurship education programmes outside of the universities.

There needs to be better targeting to balance growth in low and high quality jobs.

The targeting of balance between low and high quality jobs and social groups such as women, younger people, unemployed and ethnic groups is under-defined, and the impact of programmes is not yet systematic although some programmes are beginning to develop them. A first step is therefore to make this a requirement. Profiles of employment have implications for future training needs, particularly in the development of more specialised skills for SMEs and gazelles in order to develop strategic companies for each region and for the country. The overall pattern of which sets of firms in each segment benefit is not transparent. A second step would be therefore to use available information to make sure that this gets translated into training for each of the five target groups, determining how those are related to regional entrepreneurial skills strategies. 


\section{References}

BIS (2010), Skills for Sustainable Growth, http://www.bis.gov.uk/skillsforgrowth

Ernst and Young (2011), Women in the workplace: Unleashing the Power of Women Entrepreneurs, http://www.ey.com/GL/en/Industries/Government---Public-Sector/Women-in-the-workplace--Unleashing-the-power-of-women-entrepreneurs

Feldman, M.P (2003) "The Locational Dynamics of the US Biotech Industry: Knowledge Externalities and the Anchor Hypothesis", Industry and Innovation 10, 3, 311-328.

Freel, M S (2003), "Sectoral Patterns of Small Firm Innovation, Networking and Proximity", Research Policy, 32, 5, 2003 751-770

Fritsch, M. and Schindele, Y. (2011), "The Contribution of New Businesses to Regional Employment—An Empirical Analysis", Economic Geography, 87, 2, 153-180

Karlsson, C and Anderson, M (2009), Entrepreneurship Policies: Principles, Problems and Opportunities. CISEG Working Paper No.7, http://ideas.repec.org/p/hhs/hjiseg/0007.html

Harrison, R and Leitch, C (2010), "Spin-off companies, the Entrepreneurial System and Regional Development in the UK", Regional Studies 44, 9 1241-1262

International Finance Corporation/World Bank (2010), Enterprise Surveys: Mexico Country Profile 2010, http://www.enterprisesurveys.org/Data/ExploreEconomies/2010/mexico\#workforce--size

Lawton Smith, H Chapman, D Wood, P, Barnes, T and Romeo, S (2011) "Entrepreneurial academics and regional economic development: the case of spin-offs in London's triple helix region", paper presented at the Triple Helix IX International Conference "Silicon Valley: Global Model or Unique Anomaly?", 11-14 July 2011

Nativel C. (2006), "From Welfare-to-work to Welfare-in-work: Concepts and Policies", in OECD, Skills Upgrading: New Policy Perspectives, OECD Publishing, Paris.

OECD (2003), OECD Employment Outlook 2003: More and Better Jobs, OECD Publishing, Paris

OECD (2006), Thematic Review of Tertiary Education: Mexico, OECD Publishing, Paris.

OECD (2009a), OECD Reviews of Regional Innovation in 15 Mexican States, OECD Publishing, Paris.

OECD (2009b), Systemic innovation in the Mexican VET system: Country Case Study Report, OECD Publishing, Paris.

OECD (2009c), Learning for Jobs: OECD Reviews of Vocational Education and Training, OECD Publishing, Paris.

OECD (2010), Factbook 2010: Economic, Environmental and Social Statistics, OECD Publishing, Paris.

OECD (2011a), Economic Surveys: Mexico, OECD Publishing, Paris.

OECD (2011b), Entrepreneurship, SMEs and Local Development in Andalusia, Spain, OECD Publishing, Paris. 
OECD (forthcoming), Local Policies for Entrepreneurship and Small Business Development, OECD Publishing, Paris

Partida-Bush,V. (2005) "Demographic transition , demographic bonus and ageing in Mexico", http://www.un.org/esa/population/meetings/Proceedings_EGM_Mex_2005/partida.pdf

World Bank (2010), Impact Evaluation of SME Programs in Latin America and Caribbean, World Bank, Washington DC.

http://siteresources.worldbank.org/INTLACREGTOPPOVANA/Resources/Impact_Evaluation_SM E Programs ENG Final.pdf 


\section{CHAPTER 4 KNOWLEDGE FLOWS AND INNOVATION}

\section{Introduction}

The market introduction of new and economically valuable ideas - innovation - is a direct determinant of economic growth. The ability to translate new ideas into traded products that address market opportunities is a source of wealth generation for a country's economy. Economies also grow when their firms and workers absorb and master existing ideas that have been produced in other locations and contexts; in a word - learning. Especially in less-advanced economies, learning from others and building upon ideas created elsewhere are likely to be as significant a driver of growth as innovation. But innovation and learning are both widely acknowledged as a crucial mechanism through which to materially elevate the well-being of an economy's workers.

This chapter assesses the effectiveness of existing policies aimed at stimulating innovation and learning in the small and medium-sized enterprises (SMEs) in Mexico. It also recommends amendments to improve these policies going forward. It focuses on such policies in the context of two central Mexican states: Queretaro and Morelos. The chapter begins by summarizing the current state of research on the economic impact of innovation and learning as well as the state-of-the-art thinking on policy aimed at SMEs. It then outlines conditions on the ground in these two states, as well as in Mexico more generally, that bear on capacities for innovation and learning. This is followed by a description of the policies put forth by the Mexican Ministry of the Economy and other bodies, implemented in a decentralized manner by State economic development administrations through a host of intermediary organizations. After identifying a set of existing strengths and unexplored policy opportunities, the chapter concludes with recommendations illustrated by three learning models.

\section{Innovation and learning lags in Mexico}

The last quarter century witnessed the consensus swing toward the economic impact of knowledge, after decades during which academic economists sought the roots of economic growth in the accumulation of labor and physical capital. It is now widely held that development is driven by productivity-enhancing creation of new and economically important ideas, as well as the absorption of existing knowledge (Abramovitz, 1986; Aghion and Howitt 1992; Bell and Pavitt, 1993; Klenow and Rodriquez Clare, 1997; Easterly and Levine 2001; Klinger and Lederman, 2006). To the extent that regions and countries differ in these capacities to create and absorb knowledge, they will be richer or poorer.

A comparison of the development of Mexico and South Korea since 1960 emphasizes this point. In 1960 South Korea was considerably poorer than Mexico; today, however, South Korea is far richer. To understand the causes of these changes, Chen and Dahlman (2006) decompose changes in each economy's per capita gross domestic product (GDP) to reflect contributions from (i) productivity growth and (ii) the expansion of labor and capital. Growth in total factor productivity - which is another way of describing the accumulation of knowledge - accounts for the bulk of South Korea's expansion. Rather than due to investments in capital and labor, South Korea's rise is largely due to their successful investments in 
innovation and learning that have increased productivity. By implication, Mexico's relatively slow development is a function of its lesser performance in innovation and learning.

\section{The Promise of innovation and learning}

One immediate difference between Mexico and South Korea lies in the distribution of firm sizes. In contrast to South Korea, where there are many large, multinational firms, in Mexico, 99\% of all firms are micro, small or medium-sized enterprises. These businesses employ nearly three-quarters of the workforce and produce half of the nation's output by value (World Bank, 2010). SMEs are different from larger firms in ways that have material implications for their engagement with innovation and learning. Importantly, small firms are generally less productive than larger ones, and the difference between the SME share of employment and value of output in Mexico suggests opportunities for increasing efficiencies and realizing economic gains. Furthermore, SMEs themselves come in different forms, with different foci and potential. It is therefore worth considering the opportunities for knowledge acquisition that pertain to each segment of this heterogeneous SME sector.

At the lower end of the distribution of firm size and (often) sophistication are micro-enterprises, defined as having less than 10 employees. Mexico has a very large number of such firms. They tend to have low productivity levels, due in part to low levels of training and education. There is a great deal of potential for productivity upgrading among firms, transforming habitual satisfying behaviour into more optimal methods of production, adopting modern technologies, as well as improving marketing, administration and other business functions.

At moderate and higher levels of sophistication, learning can permit existing SMEs to integrate with international supply chains. This integration offers not only growth opportunities in terms of employment, but in a circular manner it also creates ongoing opportunities to absorb ideas by being exposed to global best practices. The adoption of global firm level production techniques among the Mexican firms, including just-in-time inventory methods, quality control measures, and job rotation could induce productivity growth. Successful participation in global supply chains integrates Mexican firms as essential partners with multinationals, who, as relationships and trust develop over time, are likely to invest in both upgrading the capacity of their suppliers and also build proximate facilities to ease transaction costs. ${ }^{6}$

At the highest sophistication levels, firms have great potential to innovate. These innovations could take one of two forms. The first is the development of new products uniquely suited to the developing domestic market, such as affordable high-efficiency appliances. Such innovations can address societal obstacles in Mexico and could additionally be exported to other developing countries. The second is innovations at the technological frontier that would be developed for global exports. Advanced finished goods, for example in consumer electronics or robotics could be developed and produced in Mexico for global export. Through such innovations there is the potential to create 'gazelles': firms that quickly increase their size and profitability; though this potential varies from sector to sector, and is by no means necessarily an automatic outcome.

6 The automotive company Delphi provides an illustrative example. Initially manufacturing in Mexico, in 1995 Delphi established an engineering center in Ciudad Juarez. This center is primarily involved in doing research, design and development activities and currently employs over 1000. According to Carrillo and Hualde (1996), the firm cut development costs by $60 \%$ and delivery time by $20 \%$ during the first years of operation. Delphi's website notes that several hundred patents have been issued to its Mexican engineers. 
While innovation and learning in SMEs have the potential to spearhead considerable economic development, such upgrading is not automatic. Knowledge, while quasi-public in nature, is not ubiquitously available. Firms need to invest in developing absorptive capacity in order to be able to use knowledge and benefit from learning (Cohen and Levinthal, 1990). New and complex ideas tend to be bound up in social networks and clustered in space. These networks work best when there is trust among the participants and a high degree of local involvement. It takes time and effort to identify relevant knowledge and to be in the right place to seize upon it. Small and medium-sized firms in particular may lack the resources to adequately identify the value of investments in external knowledge. SMEs may also be constrained by needing to focus on the immediate concerns of making payroll rather than engaging in learning and devoting resources to riskier future investments. As such firms may under-invest in knowledge upgrading and the discovery process.

This potential market failure prompts a role for policy: Effective policies aimed at fostering innovation and harnessing economically important knowledge have the potential to enhance revenues, productivity and employment growth. In the absence of such policies, these beneficial outcomes may well go unrealized. There is no single set of agreed upon best practices to stimulate innovation and the absorption of knowledge. Much depends on local context and requires continuous investment over time. But experts agree on basic ingredients to perform in the knowledge economy, including having the right institutions and incentives; an adequate supply of appropriately skilled workers; an effective communication infrastructure; and an suitable innovation system composed of firms, research centers, universities and other organizations (Chen and Dahlman, 2006).

Moreover, the literature points to some commonly accepted 'channels' for learning that policies can exploit. One channel to exploit is the natural tendency for industrial clustering, whereby regional concentrations of firms in a sector can learn from one another through the circulation of workers, social networks and observational effects. Through mutual trust and complementary expertise, firms can engage in collaboration while simultaneously working towards the common goal of creating economic value. Universities and research centers represent another channel for knowledge flows. These institutions generate a great deal of new ideas, but incentives and resources are not always in place for creators to commercialize their ideas. Much collaboration occurs with local universities where faculty members and students can be easily engaged and ideas can flow from the lab to the company, while the company can suggest new problems that require creative solutions. Firms may also learn by engaging in exporting activities, which can expose firms to new ways of doing business in the international arena. Another potential channel is learning and upgrading through vertical supply-chain relationships (Gereffi, 1999). In addition, SMEs can also gain access to valuable knowledge flows by getting trained and certified in global best practices, such as ISO 9001 and 14001, as well as sector-specific certifications. These various channels are by no means mutually exclusive, but they represent distinct foci of policy.

Nonetheless, the transformation of an economy rooted in more routine forms of production to one where learning and innovation are central remains possibly the greatest challenge facing developing countries around the globe. Indeed, the transition from unsophisticated producer to moderately advanced economy is better understood in policy terms than the climb from moderate sophistication to true participation in the global knowledge economy at the highest level. This is chiefly because this shift requires, in addition to modifications to concrete economic processes that demand considerable investment and carefully managed policy, a transformation from one kind of society to another. It demands sufficient trust and social capital to harness knowledge and stimulate a delicate balance between private and social gains from knowledge. This can be especially difficult to cultivate, in part because these may not be those societal characteristics most crucial for the initial industrial transition. Ultimately, these are no small hurdles, and many economies are simultaneously attempting to make the leap forward. 


\section{Assessment of framework conditions}

Though the Mexican economy has experienced considerable economic development and is increasingly integrated into the global economy, it remains less wealthy and less productive than many OECD member countries. Table 1 presents a baseline gauge of the levels of economic well-being and sophistication of the broader Mexican economy, as well as of the states of Morelos and Queretaro that are the focus of this chapter.

Queretaro has income levels that are slightly larger than the average found in Mexico as a whole, while per capita GDP in Morelos is only $60 \%$ of the national level. Table 3.1 provides comparative gross domestic product and percentage of value added and employment. Both Morelos and Queretaro represent fairly small contributions to the Mexican economy, which has historically been particularly concentrated in the region around Mexico City (21.5\% of national value added and employment). Queretaro and Morelos each contribute around $2 \%$ to national value-added, and account for only a small portion of the national workforce. Morelos, with lower GDP per capita accounts for $2.0 \%$ of national value added but only $1.1 \%$ of national employment, while Queretaro has a higher than the national average GDP per capita while also exhibiting a greater share of national value added relative to employment. This indicates the presence of high productivity industrial activity that is low wage in Morelos and higher wage in Queretaro.

The table below also indicates that there is great potential for improvement in Morelos, Queretaro and Mexico on the whole, as compared with the OECD average. Importantly, both Morelos and Queretaro are growing faster than the country of Mexico in aggregate, and considerably faster than the rate of economic growth in the OECD. To the extent that GDP per capita and other aggregate measures of economic performance indicate a readiness for innovation and frontier-leading knowledge creation, the next section investigates sources of variation between these two states.

Table 4.1. Gross Domestic Product, Value Added and Employment

\begin{tabular}{|l|r|r|r|r|}
\hline & GDP/cap & \multicolumn{1}{|c|}{$\begin{array}{c}\text { \% GDP } \\
\text { growth }\end{array}$} & $\begin{array}{c}\text { \% of Natl. } \\
\text { Value Added }\end{array}$ & $\begin{array}{c}\text { \% of Natl } \\
\text { Employment }\end{array}$ \\
\hline Morelos & $\mathbf{9 , 2 8 4}$ & $\mathbf{3 . 3 1}$ & $\mathbf{2 . 0}$ & $\mathbf{1 . 1}$ \\
\hline Queretaro & $\mathbf{1 6 , 1 3 7}$ & $\mathbf{4 . 5 8}$ & $\mathbf{2 . 6}$ & $\mathbf{2 . 2}$ \\
\hline All Mexico & 15,291 & 3.20 & 100 & 100 \\
\hline DF and Estado de Mexico & 16,592 & 2.91 & 21.5 & n.a \\
\hline All OECD & 33,936 & 2.70 & n.a. & \\
\hline
\end{tabular}

Source: State GDP data from OECD Regional Database, extracted November 16, 2011. National GDP data from OECD Statistics from A to Z. Value added and employment data from Ruiz Duran (2008)

Note: Per capita GDP data in nominal US\$ in 2008; GDP growth rates from 2005

\section{The Importance of industrial structure}

Certain sectors are more prone to innovation than others - for this reason we see large investments worldwide in promising fields such as biotechnology, advanced materials and renewable energy. At the same time, even within these sectors there is a wide range of activities with greater or less opportunity for innovation and learning, depending on the presence of regional capabilities. It is important to understand industrial structure and the degree of specialization and the potential for identifying promising investment opportunities.

Queretaro and Morelos present distinct specialization patterns, even at a fairly aggregate level. Roughly a third of Queretaro's workforce is engaged in the industrial (secondary) sector, made up mostly of manufacturing work (Queretaro economic yearbook, 2010). Employment in manufacturing is dominated 
by automotive, auto parts and other heavy industry sectors. A third of employment in Queretaro is in services, with the remainder in the primary sector. Thus, Queretaro's economy is diversified and balanced between these three sectors.

Manufacturing plays a distinctly smaller role in Morelos, constituting only 17\% of state GDP in 2006. Chemicals and pharmaceutical production are an area of focus, with $7 \%$ of national production in 'personal care products' and $17 \%$ in pharmaceuticals, accounting for higher wages. Tertiary sector activities dominate the Morelos economy, contributing more than 50\% of GDP. Tourism is prominent among these value-generating services, owing to a combination of natural amenities and proximity to Mexico City. Tourism generates $12 \%$ of GDP, and has recently grown at a rate of $3 \%$ a year. A major challenge is to diversify the rural economy to replace the income and jobs in agriculture as the sector continues to decline and to make the most of the inherent comparative advantages linked to a large extent to the natural environment that attracts tourism.

\section{Science and technology infrastructure as the foundation}

As discussed above, conditions for innovation and learning are stronger when regions host an ecosystem of firms, research centers and other organizations that interact, compete, share ideas and are generally engaged in the production of knowledge and technology. While it is hard to adequately measure the 'process' elements of an innovation system, we can go some way to gauge its effectiveness by examining indicators of scientific and technological output and resources. Table 4.2 presents data on select aspects of Mexican science and technology infrastructure and compares them with Brazil, Chile and Argentina, as well as China and South Korea. Comparing Mexico with other Latin American powers should shed light on Mexico's relative status in the region. The comparison with China is intended to differentiate these two developing economies that are continuing to compete to export goods to the United States market. The comparison with South Korea is intended to provide insight into the levels of investment in innovation that have been achieved by technology-led development success story. While specific information on this topic in Queretaro and Morelos is desirable, it is, unfortunately, largely unavailable. However, aggregate data on Mexico should provide a useful basis to consider the two regions in question.

Table 4.2 illustrates the wide variety of pathways that innovation systems can follow. Nevertheless, Mexico is not leading the pack amongst Latin American comparison economies, and it is underperforming relative to China, and lies far behind South Korea. Though it was roughly the same level of researchers per capita as Brazil, it has far fewer researchers than other comparison economies. At $0.47 \%$ in 2005, its share of R\&D expenditures in GDP was troublingly low - almost half that of Brazil, the next-nearest economy. On a more positive note, gross $R \& D$ investment accounted for only $0.37 \%$ in 2000 - it has grown considerably over a fairly short period.

The quality of Mexican scientific institutions appears somewhat weaker, though broadly in line with comparison economies. Links between university R\&D and industry are less strong in Mexico than in China and Korea, but somewhat superior to those found in Brazil. Patenting activity is in line with Brazil, but is notably lower than in the other comparison countries, while royalty payments are considerably lower than all but China. Venture capital, which can support the development of new, innovative SMEs, is less available in Mexico than in China and Brazil, though more than in Argentina and Korea - though this also reflects qualitative institutional differences that may not directly bear on innovative capacity. An assessment of the degree to which foreign-country multinational corporations (MNCs) are engaged in a wide range of local activities indicates a degree of breadth that resembles Latin American comparison economies, but a notably narrower range of value chain activities than that found in China and Korea. All in all, Mexico appears to have an innovation system that is somewhat weaker than leading Latin American economies, though it does not appear to be far behind. Based on these indicators, however, Mexico appears 
considerably behind China. This middling performance is a fact that the Mexican government is explicitly trying to ameliorate through policy interventions to be described below.

Mexico produced a somewhat larger number of scientific and engineering articles than China on a per capita basis, though fewer than Brazil, Chile and Argentina, as well as Korea. There are data on intranational variation here: Morelos appears to be an outlier on this front, with 360 articles per million inhabitants (Morelos Secretaria de Desarollo Economico, 2011). 
Table 4.2. The Mexican Innovation System in Comparison

\begin{tabular}{|c|c|c|c|c|c|c|}
\hline & Mexico & Chile & Brazil & Argentina & China & Korea \\
\hline Researchers in R\&D per million population, 2006' & 464 & 833 & 461 & 895 & 927 & 4162 \\
\hline R\&D to GDP ratio, $2006^{\prime}$ & 0.47 & 0.67 & 0.82 & 0.49 & 1.43 & 3.23 \\
\hline Quality of Sci. Research Institutions (1-7), 2011" & 3.9 & 4 & 4.1 & 4.2 & 4.3 & 4.8 \\
\hline University-industry R\&D collaboration (1-7), $2011^{\text {III }}$ & 4 & 4.1 & 3.6 & 3.9 & 4.5 & 4.7 \\
\hline Royalty Payments and Receipts (US\$/pop), 2007' & 6.5 & 30 & 13.5 & 28 & 5.21 & 144 \\
\hline Venture Capital availability (1-7), $2011^{\text {III }}$ & 2.5 & 3.1 & 2.8 & 1.9 & 3.5 & 2.2 \\
\hline Value Chain Breadth (1-7), 2011 I'I & 3.8 & 3.7 & 3.6 & 3.3 & 5 & 5 \\
\hline
\end{tabular}

Source: (i) World Bank Knowledge for Development Knowledge Assessment Methodology database; (ii) 2011 Global Competitiveness Report.

Notes: S\&E refers to science and engineering. USPTO refers to the United States Patent and Trademark Office. University-company collaboration results indicating whether collaboration is $1=$ minimal or nonexistent, all the way to $7=$ ongoing and intensive. Countries receive higher value chain breadth scores as exporting firms report being involved in a broad range of activities, such as design, manufacturing and marketing as opposed to a primary emphasis on resource extraction. 
Queretaro and Morelos host a wide variety of universities. These school include large state schools; smaller technical junior colleges offering two-year degrees; and branches of major national research universities, such as Tecnologico de Monterey, and Universidad Valle de Mexico. Postgraduate degrees are offered by a select group of schools, as well as by research institutes. These institutes come in various forms: the majority are affiliated with universities, some are fully private, and some are part of a public system maintained by the national public body charged with the development of science and technology: National Council on Science and Technology (CONACyT). CONACyT funds 27 Public Research Centers addressing three areas: natural sciences; social sciences; and technological development. The Federal District, Aguascalientes and Guanajuato host a large number of these centers, and they are unevenly distributed across other states. Queretaro hosts three centers, each in the area of technological development. CIATEQ focuses on advanced manufacturing, scientific measurement and energy. CIDESI emphasizes industrial automation, tooling and assembly. CIDETEQ is focused on electrochemistry and environmental technologies, including alternative energy and nanotechnology. These centers perform applied research, offer consultancy services to private industry, and also provide Master's and doctoral degrees.

CONACyT also maintains program qualifying research excellence as measured by various criteria, including generating publications in international peer-reviewed journals. Researchers who attain SNI status are provided with additional salary. They are ranked from 1 to 4 , with 4 indicating the highest level of research quality. In 2009, Morelos had 762 SNI researchers across all levels, or $4.9 \%$ of the national total, while Queretaro had 347, or 2.2\% (Foro Consultivo Cientifico y Tecnologico, AC, 2009). The Federal District and the State of Mexico accounted for nearly half of all SNI researchers in 2009, and almost $70 \%$ of researchers at level 3 (ibid).

Technology parks have been one policy used successfully to stimulate industrial activity. The Ciudad de Industria Cuernevaca (CIVAC) is located in Morelos. CIVAC was built in 1966 and is the largest development center in Mexico. Among the major companies in CIVAC include: Roche, Unilever, Baxter, Alucaps, Givaudan, Glaxo Smith Kline, NEC Corporation, GlaxoSmithKline, Fibrolub Mexican Mayekawa Mycom, Nissan, as well as 150 other companies. The presence of large multinational in CIVAC has created global linkages, provided higher wages while allowing Mexican workers to gain skills and experience.

\section{The contribution of a skilled workforce}

An appropriately skilled workforce is crucial for innovation and technological learning. Labor embodies skills that provide a competitive advantage. Sufficient human capital resources will shape an economy's ability to produce globally competitive goods and services. Moreover, evidence indicates that technological learning is not automatic. It requires investments in absorptive capacity, in which human capital plays an important role in the ability to appreciate and adapt information (Kemeny, 2011). Skilled labor can involve formal education but may also involve learning-by-doing and experience on the job.

The table below provides selected indicators of human capital for Morelos and Queretaro, and compares these with Mexico and the OECD average where possible. Workers in both states stay in school slightly longer than the Mexican average, though overall attainment is considerably below the OECD norm. Moreover, Mexican levels of upper secondary and tertiary educational attainment are quite low by OECD standards. Morelos and Queretaro have larger shares of their populace who hold graduate and professional (2-year) degrees, and fewer high school dropouts as compared with Mexico on the whole. On standardized math and science tests, Mexico is well below the OECD average. The main lesson from the data is that Morelos and Queretaro are moderately higher mean human capital as compared with Mexico on the whole, though this standard is fairly low in comparison with the entire OECD. 
Table 4.3. Human Capitol Indicators

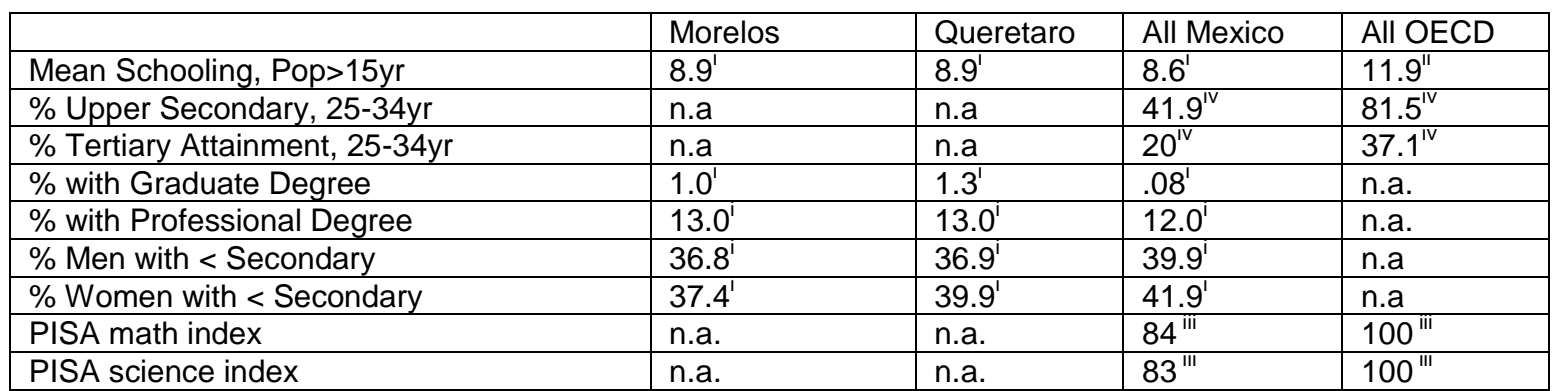

Source: (i) Instituto Nacional de Estadistica y Geographia (INEGI), collected via different survey instruments. Most data in this table is from 2010. (ii) OECD Educational database, 2010 (covering the year 2004). (iii) Author's calculations from OECD PISA database, 2009. (iv) OECD Education at a Glance 2011.

Notes: Graduate degree refers to completed postgraduate studies terminating in either a Master or PhD. Professional degrees follow completed high school and undergraduate degrees. Share of men and women with less than a high school degree are calculated among the population 15 years old or older.

\section{Leveraging multinational corporations and foreign investment}

It is commonly argued that developing countries learn and increase productivity levels by hosting multinational corporations (MNCs). MNCs are typically at the global technological frontier, and the accumulated knowledge they carry with them can, under the right conditions, beneficially spill over into the host economy (Borenzstein et al, 1998; Coe et al, 2008). In national terms, the share of stocks of foreign direct investment (FDI) in GDP is around 25\% (OECD, 2009b). As much as 60\% of foreign investment inflows are geographically concentrated around the Federal District (Jordaans, 2009). According to data for the period 2000-2005, around 1.2\% of national FDI inflows are situated in Queretaro, while less than $1 \%$ are in Morelos.

The nature of FDI activities is also a crucial determinant of the potential for knowledge spillovers (Javorcik, 2008). Specifically, there may be much less potential for the diffusion of productivity-enhancing knowledge when MNCs conduct only low-cost, less sophisticated activities like component assembly or the manufacturing of simple parts, as opposed to high-value activities like R\&D and design. Though there is variation by industry, Mexico has typically fit into the global economy on the basis of low cost competition, combined with low geographical trade costs to the United States market. FDI has been mostly aimed at lower sophistication activities, even in sectors that involve highly advanced technology and knowledge, such as automobiles and pharmaceuticals.

The potential to incentivize greater foreign investment offers a means to upgrade the Mexican economy. Brown (2008) offers examples of how American and Canadian companies are upgrading operation in Mexico and concludes that Mexico holds an advantage over China as a supplier for multinationals that require just-in-time delivery, customized products, and frequent design changes.

\section{Moving forward}

In conclusion, the innovation system in Mexico reflects an economy that, though certainly gaining in sophistication, still remains primarily focused toward cost competition, small, inefficient local-serving enterprises, and remains largely limited to leveraging its comparatively low geographical trade costs in relation with the large U.S. market. Within that general framework however, Queretaro and Morelos differ significantly. Morelos has what we might think of as a 'new economy' industrial structure - focused in part on knowledge-intensive activities that have cheap inputs but valuable output like pharmaceuticals and software, while being 'dualistic' in the sense of maintaining a large proportion of employment in lowerwage service activities like tourism. This combination explains the state's combination of low levels of 
GDP per capita and comparatively high levels of value added per worker. Given the overall situation in the state, the main challenge in Morelos is to continue to spur growth in its knowledge-intensive sectors, while broadening the base of well-paid jobs.

Queretaro, on the other hand, appears more 'old economy' - focused on heavy machinery and related capital-intensive technology sectors. This makes Queretaro potentially more vulnerable to deepening globalization unless its firms can successfully upgrade and move up the value chain, as China and other comparatively cheap countries encroach on Queretaro's specialization in the less-sophisticated segments of the automotive and other machine-intensive sectors. On the other hand, Mexico's proximity to the U.S. will no doubt mitigate this weakness in part, given continued medium-term significance of trade costs.

\section{Assessment of policies and programmes}

Mexico began its formal policy efforts to stimulate innovation with the creation of CONACyT in 1970. At its inception, CONACyT operated in two areas: scholarship programs and the creation of an infrastructure of public research institutions (OECD, 2009b). After the peso crisis in 1982, Mexico liberalized its economy, becoming increasingly open, both internally and externally. Along with this process came the gradual realization of the importance of policy intervention in the creation and diffusion of knowledge. The role of CONACyT, as well as that of other government programs aimed at innovation, has expanded accordingly. In recent years, Mexican policies focused on innovation and learning has continued to evolve. Emphasis has increasingly been put on the creation of linkages between industry and scientific institutions; on training and human capital development in the sciences; on scientific infrastructure and on funding innovation (ibid). It is not clear, however, that sufficient resources have been dedicated to these tasks. A 2002 Science and Technology (S\&T) law set an R\&D expenditure target of $1 \%$ of GDP, with a greater share of funding coming from the private sector; however, this goal has yet to be attained. National spending on all forms of science and technology amounted to $0.78 \%$ of GDP in 2006, with R\&D spending accounting for just over half that amount. By contrast, the OECD average share of gross R\&D expenditures in GDP is $2.25 \%$ (OECD, 2011c).

Table 4.4. Overall Science and Technology Investment in Mexico

\begin{tabular}{|l|l|l|l|l|l|}
\cline { 2 - 6 } \multicolumn{1}{c|}{} & $\begin{array}{l}\text { Federal } \\
\text { Government }\end{array}$ & $\begin{array}{l}\text { State } \\
\text { Government }\end{array}$ & $\begin{array}{l}\text { Higher } \\
\text { Education }\end{array}$ & $\begin{array}{l}\text { Private } \\
\text { Sector }\end{array}$ & Total \\
\hline$\%$ of S\&T investment & 45.7 & 0.9 & 7.7 & 45.6 & 100 \\
\hline$\%$ of GDP & 0.36 & 0.00007 & 0.06 & 0.36 & 0.78 \\
\hline
\end{tabular}

Source: CONACyT Programa Especial de Ciencia, Tecnología e Innovación 2008-2012

Notes: Data from 2006

Motivated by the preponderance of small firms in the Mexican economy, there is a new focus on policy efforts to directly stimulate technological upgrading and innovation in small and medium sized firms. Though a variety of science and technology programs and policies will have an indirect bearing on small and medium sized firms, traditionally only a small share of Mexican government support in this area has targeted innovation and knowledge diffusion in SMEs. Until recently, most federal science and technology investment has targeted larger and more established firms.

This has begun to change. In 2001, the Mexican federal government made SME support for technological learning and innovation among the foci of the 2001-2006 national development plan. In the current national plan, which covers 2007-2012, the emphasis for SME policy has shifted toward offering a comprehensive set of services, ranging from training and consulting, financing, support for commercialization and innovation. The role of innovation among SMEs has also been enshrined in recent policy statements, including the Special Programme for Science, Technology and Innovation (PECiTI). 
Several major policy efforts in this area are worth describing in detail, most notably the SME Fund and the Innovation Fund.

\section{The SME Fund (Fondo PyME)}

Policy efforts aimed at innovation in SMEs have been led by the Ministry of the Economy (ME) and CONACyT, as these organizations have come to view SME development generally, and in particular their efforts at innovation as being foundational drivers of regional and national economic growth. Learning and innovation play an important role in the most significant program on behalf of SMEs: the Ministry of the Economy's SME Fund (Fondo PyME). The SME Fund, created in 2004, was the result of a consolidation of a variety of different SME-oriented programs into one singular policy effort. In its first year, the SME Fund provided MXN\$2.8 million in support. By 2009, the Fund had expanded to provide MXN\$5.5 billion in support nationwide, with over half that amount coming directly from the Ministry of the Economy. As with much Mexican policy, efforts tend to be focused on Mexico City and the surrounding state of Mexico. On average, around two-thirds of annual SME Fund support between 2004 and 2009 was allocated to Mexico City. Both Morelos and Queretaro averaged around $0.8 \%$ of total annual program funding, though each contributes just over $1 \%$ to national GDP.

Among the major SME Fund objectives, the fund seeks to stimulate technological development, by which it means chiefly to stimulate innovation, as well as to assist SMEs to integrate into national and international production chains. Other primary goals of the Fund include training, business management, commercialization and financing. In 2009, only $6 \%$ of SME support provided to the SME Fund by the Ministry of the Economy was allocated to technological development, constituting 41 out of 492 projects. Nearly $90 \%$ of the technological development projects were focused on 'gazelles,' which the Mexican government defines on the basis of both annual sales and membership in a sector that the government considers 'strategic'?

The SME Fund operates in a highly decentralized manner. To achieve its aims, the SME Fund makes funding available to intermediary organizations, which include universities, state and municipal governments, research centers and chambers of commerce. These intermediaries then create programs that meet the needs of local SMEs. This devolution of program management and implementation to agents operating closer to the ground should, in principle, avoid a one-size-fits-all problem, which had plagued past policy approaches in an economy with a great deal of economic variation from place to place. The use of intermediaries also offers the promise of continuity and stability in a changeable political environment.

In order to stimulate knowledge production and spur innovation, the SME Fund provides support for the creation and maintenance of business incubators, whose primary goal is to produce prospective entrepreneurs with viable business plans, and 'accelerators' that seek to make existing firms more competitive. $70 \%$ of incubators are housed inside universities and technical colleges, as a means to harness knowledge flows as well as to incentivize entrepreneurship among the student body. Incubators focus not only on high-technology sectors, but also on harnessing economic potential and the diffusion of knowledge among firms embodying medium technology levels as well as traditional sectors. Incubators are evaluated and supported based on the number of registered firms they generate.

Accelerators are focused more narrowly on technology development. They are fairly selective in finding client firms, with acceptance rates in 2007 of between 10-15\% of firms that are scouted (Storey, 2008). Both incubators and accelerators are primarily consultancy-focused, bringing to bear expertise in various areas of business and technology development toward the end of improving the sophistication and

$7 \quad$ The OECD defines a gazelle as a firm that sustains $20 \%$ annual growth in employment of turnover over a three-year period. 
effectiveness of the participant firm. The ME defines 'excellence' for accelerators on the basis of increasing sales by $20 \%$ and the creation of six new jobs, all over the course of 10 months. Box 3.1 provides an example of the application of the SME Fund toward the provision of incubation and acceleration services in Mexican regions. SME Funds are also applied toward the construction of industrial science parks, whose goal is to lure 'tractor' firms - whether Mexican or foreign-owned that can anchor value chains and spur knowledge spillovers that will, ideally, raise the productivity of related gazelles and other SMEs.

Queretaro and Morelos have each used the SME Fund to advance SME learning and innovation in different ways. At present, the state government of Morelos has prioritized the construction of technology infrastructure. Since 2007, they have constructed several technology parks, including one housed in the Cuernevaca campus of the well-regarded technical university Instituto Tecnológico y de Estudios Superiores de Monterrey (ITESM), and another focused on digital services. Each of these have been supported by substantial state funding and some degree of support from municipal government and the private sector, in addition to federal SME Fund support. Funding for infrastructure accounts for nearly three quarters of the SME funds in Morelos, with the remainder being split between SME financing, business and export promotion. Above and beyond the distribution, however, SME Fund support remains quite small in the state, amounting to just over $0.1 \%$ of state GDP in $2008 .{ }^{8}$

Queretaro has taken a distinct approach to the leveraging of SME Fund support toward the goals of technological upgrading and innovation, one that reflects its industrial structure. A considerable proportion of SME Fund support is aimed at micro-enterprises and entrepreneurs, often in the form of grants aimed at basic skill development and income maintenance. Other efforts are dedicated toward linking SMEs to international anchor firms in the auto and auto parts sectors, in which the state has been specialized since the 1960s. Additional focus has been on the transposition of knowledge of heavy manufacturing processes gained from the automotive toward expansion of the aerospace sector, which the state government has identified as a growth opportunity in the region, with the Canadian firm Bombardier as an anchor firm. To support SME participation in both automotive and aerospace, SME Funds have been applied toward supporting smaller firms in obtaining international certification, including quality management certifications such as AS9100 in aerospace, and ISO 9001. These certifications tend to be costly, and small firms believe they could not easily obtain the necessary funds to get certified. The participation of state and municipal economic development commissions also provides confidence that, having obtained certifications, small firms are more likely to successfully create links with larger tractor firms.

$8 \quad$ Authors' calculations based on average annual total allocation of SME Fund support from 2004 to 2009, as a share of state GDP in 2009. Average SME Fund amounts are used since allocations fluctuate considerably from year to year 


\section{Box 1. FUMEC and Tech-BA}

FUMEC, the U.S.-Mexico Foundation for Science, is a 20 -year-old not-for-profit organization aimed at maximizing cooperation between the two countries toward innovation-led economic development.

As part of this broader strategy, FUMEC partners with state economic development administrations, including SEDECO in Morelos, with the aim of identifying and leveraging regional industrial strengths and areas of opportunity. Selected firms in the identified clusters, ranging from incubator graduates to experienced entrepreneurs with 'gazelle' potential, enter into a 'pre-acceleration' process, during which they are provided with assistance on both technical matters as well as market positioning, with the goal of helping these firms to develop the capabilities required to competitively offer their products and services to global markets.

In addition to these intensive consulting services, participating firms are placed in TechBAs - accelerators located in a variety of industrial hubs around the world, including Silicon Valley, Montreal, Austin and Madrid. These locations are chosen on a cluster-specific basis. In these locations, Mexican firms are provided with office space, while they receive further consulting and are linked to successful firms in these dynamic industrial ecosystems. By learning to operate in these environments, firms can master what it takes to perform at the global technological frontier.

At present, more than 600 firms have participated in various stages of the process. Between 80 and 100 firms have set up permanent offices in far-flung localities, though the majority have remained headquartered in Mexico. These firms have generated roughly US $\$ 168$ million in sales.

The SME Fund supports the TechBA program, as well as the cost of migration and office setup, while states provide the funding required for the initial regional analysis.

In the state of Morelos, FUMEC is trying to exploit potential in several industrial sectors: health technologies, including clinical trials, medical device production and indigenous plants; information technology; and advanced manufacturing.

Efforts to link gazelles to tractors in machinery sectors have been coordinated with local incubators whose construction and ongoing operating costs have been supported by the SME Fund, including a high technology incubator affiliated with the Queretaro campus of ITESM. The state government has also created an aeronautical university, offering courses that range from 2-year technical degrees to Masters programs. According to state officials, the explicit goal of these efforts is to create an ecosystem of small, though highly sophisticated firms acting as suppliers to Bombardier and other lead firms. Thus far, 10 local firms have become suppliers in the aeronautics sector. Each of these firms employs approximately 20 workers. As in Morelos, overall SME Fund support in Queretaro remains quite small in relation to overall levels of economic activity in the state, representing around $0.05 \%$ of the state GDP. ${ }^{9}$

\section{The Innovation Fund}

Founded in 2007, the Innovation Fund (FIT) combines resources from CONACyT and the Ministry of the Economy toward the goal of stimulating innovation. Federally administered, the Innovation Fund offers direct grants of support primarily to SMEs defined broadly to include also entrepreneurs as well as larger firms that involve SMEs in proposed projects.

$9 \quad$ Authors' calculations based on average annual total allocation of SME Fund support from 2004 to 2009, as a share of state GDP in 2009. Average SME Fund amounts are used since allocations fluctuate considerably from year to year 
To receive funding, prospective firms respond to a call produced annually based on specifications determined by the fund's technical committee, which is chaired by a representative of the Ministry of the Economy, and additionally includes representatives of CONACyT, the SME undersecretary, and several other members. The fund supports three types of projects: those aimed at producing product, process, material or service innovations; those seeking to create or strengthen centers or teams with a focus on engineering, design and technological development; and projects in technology-focused startups that support pre-commercialization activities, such as pilot testing. The technical committee agrees upon sectoral targets. The most recent available targeted industries, from 2007, were as follows: agribusiness; aeronautics; automotive and auto parts; leather, footwear and tanneries; pulp and paper products; electrical and electronic, pharmaceuticals and health sciences, metallurgy; capital equipment; chemicals and petrochemicals, information technology, and textiles. This is a very inclusive list, encompassing a great deal of the industrial base of Mexico, as well as most industrialized economies. It is also noteworthy that, other than information technology, these sectors are primarily oriented to manufacturing rather than advanced service provision. Because the fund provides direct funding from the federal level, there is no explicit attempt to exploit regional differences, though given the broad 'target' sectors, neither does it appear likely to exclude regions.

In 2007, the fund supported projects accounting for a total of MXN\$500 million, while the pool of applicants requesting nearly MXN\$3.2 billion for project funding. This highlights the possibility that there may be a rationale for enlarging the scale of this intervention - though this certainly depends on the quality and adequacy of the firms that were not selected to participate in the program. Certainly the volume of applications and the request for funding suggests that there is unmet demand from the private sector.

\section{CONACyT programmes}

The National Council for Science and Technology (CONACyT) also provides support for innovation and technological learning to SMEs. FOMIX, or mixed funds, are aimed at promoting learning and innovation, though not explicitly aimed at smaller firms. FOMIX priorities are determined in collaboration with states, whereby potential recipients respond to state-specific requirements, with supporting jointly provided by CONACyT and state funds. Three different S\&T programs were created in 2009, replacing a tax credit system that previously supported technology projects in primarily larger multinational firms (OECD, 2009c): INNOVAPyME, INNOVATEC AND PROINNOVA. INNOVAPyME is a grant program aimed at increasing investment in research and development and upgrading value-added in small and medium sized entities by complementing company investments in learning and innovation. The program also supports the creation and strengthening of links with educational institutions and research centers. INNOVATEC aims at supporting large firms. PROINNOVA supports links between research and enterprises among organizations of all sizes. In 2010, INNOVAPyME provided nearly MXN\$700 million in support to over 100 firms (CONACyT, 2011a), while all three programs combined served over 1500 firms, providing over MXN\$6 billion between 2008 and 2011.

CONACyT also funds a system of research centers spread around the country, each sectorallyfocused. As mentioned earlier, the state of Queretaro hosts three such centers: CIATEQ, CIDETEQ and CIDESI, while Morelos has no CONACyT-affiliated research centers. These centers engage in R\&D activities, and take on industrial clients seeking their expertise. A variety of the centers in this network also offer specialized postgraduate degrees, and CIATEQ and others engage with graduate students in other universities, providing them with lab space and mentoring in exchange for their efforts on consulting projects. It should be noted, however, that these programs do not constitute the central focus of CONACyT. The majority of CONACyT's total budget is dedicated toward the maintenance of the national system of researchers (SNI), and secondarily to scholarships. The possibility that the program might be expanded to include firms in partnerships with academic is a logical extension that will be explored in the learning model section of this chapter. 


\section{PROSOFT}

In 2001, the national government declared that software was a strategic area for national economic development. In part to fulfil this aim, in 2004 the PROSOFT fund began supporting projects that developed information technology capabilities in Mexico. Specifically, the goals are to strengthen the local IT industry to serve domestic needs, to render itself a more attractive destination for the growing market for software service offshoring, and to produce globally competitive IT exports to the global economy.

Funding for PROSOFT has risen from MXN\$135 in 2004 to MXN\$650 by 2008. As with the SME Fund, support is disbursed through a competitive bidding process, with funds contributed by not only the federal Ministry of the Economy, but also the state government as well as participant firms, with government funds not to exceed 50\% of project budgets. Unlike the SME Fund, responsibility for project approval lies at the Federal level. Funds are not restricted to use by Mexican firms: MNCs can also receive support for projects located in Mexico. Though some funding has been awarded to small firms, precise estimates of the distribution of recipient firms sizes is not currently available. Universities have been part of the process as well, in particular the National Association of Institutions in Computer Education (ANIEI), which has been awarded funds to develop the needed human capital.

PROSOFT has sought to incorporate global best practices, including the Carnegie Mellon-developed Capability Maturity Model Integration (CMMI), which seeks to improve organizational processes in the name of producing high-quality deliverables. In 2008, the ME launched PROSOFT 2.0, which re-defined some of the targets, including an ambitious expansion of IT spending $1 \%$ in 2006 to $2.3 \%$ in 2013, as well increase IT employment and revenues.

\section{Strengths and weaknesses in current policy}

\section{Strength: Comprehensiveness of Scope}

Several strengths and weaknesses have been identified on the basis of the desk and field studies that underlie this analysis. A major strength of the current SME innovation policy regime is its comprehensiveness. In particular, the Ministry of the Economy has taken a broad view of learning and innovation, both in terms of apparent technological sophistication as well as of a wide range of needs for firms of different sizes and stages of development. To a considerable degree it has also been thoughtful in identifying the supports that each different target requires.

To less-sophisticated entrepreneurs and micro-enterprises, the focus is on the diffusion of basic business skills, support for equipment purchases and training to raise productivity, and the development of a more entrepreneurial culture in Mexico, each of which they support through Mexico Emprende as well as the common practice of placing incubators in college campuses. At the same time, having incubators that specialize in the development of business ideas that can involve traditional, medium- or high-technology sectors suggests that 'innovation' is being understood not simply as the result of scientific research centers, but also involves leveraging site- and tradition-specific knowledge toward further economic development. 


\section{Box 2. Manos de Morelos}

The Tourism employs a significant share of the workforce in the state of Morelos, largely a result of domestic tourists, especially those from close-by Mexico City. In addition to the hotels, restaurants and other services consumed by tourists, visitors commonly seek out traditional crafts produced by skilled artisans. Manos a Morelos is an association of craftsman, formed and supported through a combination of the SME Fund and state-level funds, bringing together artisans from around the state.

Craft production is typically produced and sold by individuals in outdoor markets. Manos a Morelos began in 2008 as a craft exhibition, supported by the state economic development agency (SEDECO) as a means to promote local artisans. From there, however, artisans organized themselves into a group. The state has continued to support the organization in several ways. First, they have provided basic business training, as well as training on workplace safety (Empresa SOL - Seguridad, Ordernado, Limpio). They have also received consulting assistance to increase productivity, and to learn to export their goods. With funding from the state, they have purchased new equipment. They will also open a permanent gallery for their work in a large mall in central Cuernevaca.

The benefits of institutionalizing what is typically a fragmented group of unrelated producers goes beyond training and consulting, however. One important outgrowth of the organization has been the development of a recognizable brand - Manos a Morelos - that distinguishes their work from those of others, and to which notions of quality and tradition can be attached. Equally, cooperation creates learning opportunities. In the words of one artisan, "One earns much more by sharing information than by keeping it." Craftsmen collaborate and share new ways of producing and finishing products, as well as new designs, and these innovations can command higher prices.

At the highest level of both formal technological sophistication as well as firm development, we have accelerators aimed at gazelles that have strong potential to be able to produce innovative goods and services that can serve global markets. SME Fund support is also being used to link smaller firms to larger production chains, though certification and other strategies. Equally, the Innovation Fund is supporting the creation and commercialization of new technologies that will be crucial to the further development of the Mexican economy.

Hence, the breadth of scope in policy efforts, from support for patenting scientists by CONACyT to the diffusion of basic business skills in micro-enterprises, suggests that the government has understood both the challenges and opportunities that it faces in seeking to stimulate development through learning and innovation.

\section{Strength: Building on Existing Competencies}

A second evident strength is the ongoing tailoring of program support to leverage existing strengths on the ground. This tailoring occurs primarily at the state government level, whereby economic development agencies explicitly target sectors and industrial clusters, while also identifying and pushing toward perceived emergent opportunities. This tailoring process, while not formally built into the governance structure of SME programs, is most apparent in the application of the SME Fund. In Queretaro, the SME Fund has enabled the deepening of the historically-significant specialization in auto and auto parts sectors and value chains, as well as the attempted transposition of mechanical expertise knowledge into the nascent aeronautics sector in the region. This entails careful consideration of the existing knowledge base in the region, and the process has been sensitive to the need for firms to possess sufficient 'absorptive capacity' (Cohen and Levinthal, 1989) in upgrading efforts. In Morelos, an analogous targeting process is occurring through the development of pharmaceutical research centers and technology parks, while the state economic development department (SEDECO) also supports organizational and development strategies of traditional handicrafts workers. Current participant firms in these regional 
sectors may or may not prove to be highly innovative motors of the regional economy, however the underlying analysis put forth by state agencies, premised on existing industrial strengths and emergent opportunities, stands on strong footing.

\section{Strength: Organizational and Geographical Decentralization}

An important strength of the SME Fund in particular, is its distinctive geographical and organizational devolution of authority to intermediaries. As stated above, this devolution was in part an attempt to make these programs more stable in the face of political change. It also permits those directly engaged in grantmaking and other means of support to be sufficiently close to the ground to be able to properly assess the immediate context. Geographical sensitivity seems particular key here, given that many ostensibly national programs, with regard to innovation as well as a broad range of other economic subjects, have tended to be geographically concentrated around Mexico City. While a certain degree of concentration makes sense in an economy in which the conurbation of Mexico City contains around a fifth of the national population and contributes just over the same share of national GDP, there surely would remain a great population of SMEs that would be underserved given a Mexico city-centric program. Nonetheless, despite structural decentralization of the SME Fund, if not all SME-specific supports for innovation and learning, a large share of disbursements remain concentrated in and around the capital. Both Queretaro and Morelos, on the other hand, receive an even smaller share of funding than is warranted on the basis of both their population and their contribution to GDP, and despite their generally stronger-than-average innovation systems.

One open question is to determine the extent to which greater decentralization of funding for SME projects is desirable going forward. Peripheral regions in Mexico are considerably less sophisticated than many of those in the core, and as a result, investment in innovation in these locales may well be less productive. Based on the evidence above, this does not appear to be the case for Queretaro and Morelos, however it is surely true for a host of far-flung states. Given this reality, funding for SME innovation may well be more optimally concentrated in certain regions, at least for certain high-technology and researchbased forms of innovation. Greater emphasis on policy instruments aimed at knowledge diffusion might be more effective in the context of less-advanced Mexican regions. At this point, this kind of targeting lies more in the hands of intermediaries, though more might be done to strengthen such directives at the federal level.

\section{Weakness: Weakly Articulated Role of Universities in Innovation System}

Through placement of business accelerators and incubators in university settings, as well as through various CONACyT-led funding sources, the Mexican SME policy framework indicates the importance placed on appropriating and exploiting knowledge produced in the academy. Nonetheless, the mechanics of exploiting the university as a strategic site of knowledge could be improved.

One recurring theme in field studies was the absence of clear and meaningful incentives to spur links between academia and industrial players in order to commercialize inventions, as well as to disseminate knowledge. This is a weakness that has been noted in prior OECD studies of Mexico. In particular, university faculty researchers lack clear incentives to participate in activities that may lead to commercialization. Their primary incentives are toward membership and rankings in the SNI system, which primarily privileges the production of research publications in internationally-recognized journals. At best, incentives to share ideas are uneven. In some technical colleges, for instance Universidad Technologica Emiliano Zapata in the state of Morelos, policies are being put in place to reward researchers with additional salary for participation in technology development projects. But in many cases, the requirements for faculty are primarily to teach, advise, publish and administer - not to be involved in knowledge dissemination to industry and the outside world. Interviews also indicated some cultural distinctions in the university hierarchy: among professors at technical colleges, industry work was common 
and uncontroversial, whereas among researchers at the national university, rewards earned through collaboration with the industrial sector was seen as 'dirty money'. The situation could be improved with the establishment of clear rules of the game that provide appropriate stimulus to this sort of collaboration, along with a concerted effort to shift the culture to value such work. Some progress appears to have been made with the amendment to the Science and Technology law in 2009 to prioritize university-industry linkages (chapter 1, article 5) as a means of developing the Mexican innovation system. Some improvements have recently occurred, in part as an outgrowth of the amendment. Technology transfer offices have recently been created, such as the Intermediary Institutions and Knowledge Transfer Units (UVTC), as well as CONACyT's Strategic Alliances and Innovation Networks Program (AERIS), that supports projects that involve research units and firms. It is not clear how many participant firms in these programs have been SMEs. Ultimately, much more needs to be done to strengthen these collaborative links, while also acknowledging that such links must be only a part of the broader technology strategy: universities are likely to follow, rather than lead in the pursuit of innovation.

By placing incubators in institutions of higher education, policymakers have rightly seized upon the university as a site of valuable knowledge. Less clear is their bet that incubators can gather viable entrepreneurs directly from the student community. Entrepreneurs are typically informed by their prior professional experience; effort at generating viable incubator participants would likely be better placed outside the student body.

\section{Weakness: Insufficient emphasis on horizontal linkages}

At present, there is insufficient emphasis on linkages between firms in the same industry and region. Though policymakers have identified industrial 'clusters' in Queretaro and Morelos, as elsewhere in Mexico, the use of this term in this context does not necessitate a great degree of meaningful cohesion and collaboration among the firms. Yet, to fully achieve the benefits of clustering and yield 'collective efficiency' (Schmitz, 1999, Pietrobelli and Rabellotti, 2004), firms must not simply coexist - they must interact. This goal has not been made explicit as a pathway to greater innovation and the diffusion of knowledge. However, state policymakers in some contexts have attempted to push for collaboration among SMEs. Field studies revealed that attempts to actively link firms sharing a sector and region often failed due to the lack of perceived value among the participant firms. Gazelle firms did not see the return to interaction and collaboration with other SMEs, instead they solely sought links with tractors. This situation points to the need for work at multiple levels. On the one hand, the development external economies should be made a priority at a high level. Second, greater levels of trust and mutuality ought to be cultivated among firms in 'clusters'.

\section{Weakness: One-size fits all requirements}

Governing the wide array of support mechanisms for SMEs, including a large and highly decentralized program involving hosts of intermediaries is difficult, and the Ministry of the Economy has largely acted with care to ensure consistency and transparency. There is, however, room for improvement. Field studies indicated widespread discomfort with some of the requirements imposed by the Ministry of the Economy for SME Fund support. Burdensome reporting between recipients, intermediaries and federal government cause problems and delays the provision of funds, made especially problematic because of rules specifying that funding must be spent within the year during which it was applied.

Existing rules present particular problems for innovative firms. Innovation is one target among several of the SME Fund and other programs geared toward SMEs, including job creation - itself a primary plank of President Calderon's larger policy efforts. These two goals may well be complementary in most ways. However, although the SME Fund distinguishes between firms in traditional sectors, as opposed to medium- and high-technology firms, it fails to take into account these distinctions when it comes to 
requirements placed on participants in incubators and accelerators. As with other participants, firms in high-technology incubators and accelerators like those found in Parque Tecnologico in the Queretaro campus of ITESM are expected to generate at least 4 new jobs. Nonetheless, many high-technology entrepreneurs require only a very small workforce, though they may end up generating considerable value to the Mexican economy down the road. At present there is little distinction between these kinds of firms and those for which job creation may be a more sensible metric of success. For many high technology startups, additional labor may be more of a burden than a help, at least initially. There is thus an opportunity to sharpen policies on this front to better differentiate between innovative firms and those that are more likely to rapidly generate jobs. Equally, there may be an opportunity to better measure job quality, rather than simply a head count. Though job creation and innovation are both important, in this case they are not entirely consonant goals.

\section{Weakness: When to turn off the spigot?}

At present, SME programs focused on innovation and learning allow participant firms to cycle through the program repeatedly, with no formal mechanism to determine when the spigot ought to be turned off for a particular SME. There are good reasons why a particular firm might make productive use of successive rounds of funding over the course of several years. Small Mexican firms face an insufficiently developed private credit sector and ongoing informational and other market failures. However, there is the potential for at least two problems associated with the absence of limits governing ongoing government support. First, in the absence of such limits, programs risk creating a culture of dependency on public support. This could impede the development of suitable private investment vehicles aimed at satisfying the needs of small firms. Second, given a reality in which the scale of investments in programs like the SME Fund is likely to be considerably smaller than optimal, there is an opportunity cost to continued funding for a small subset of firms. Repeated funding for 'proven players' risks taking away opportunities for needy, potentially innovative startups. Ultimately, there ought to be well-developed criteria to determine whether a firm that has already received support from the SME Fund, PROSOFT, or other programs can receive support from that program again. Formal criteria should balance ongoing obstacles facing repeat-SMEs, potential rewards for support, the availability of private funds, and the availability of new, deserving applicants to these programs.

\section{Policy recommendations}

The Mexican government, both at the Federal and state levels, has strongly expanded and sharpened policy instruments aimed at stimulating innovation and learning in SMEs. Nonetheless, there remains room for improvement. Certainly, the scale of intervention needs to be increased if Mexican SMEs are to truly become engines for regional and national economic development. Learning and innovation may also need to play a larger role in broad policy efforts on behalf of small firms. More strategically, we offer three specific recommendations, which are supported by the learning models in the annex.

\section{Recommendation: Incentivizing productive links between industry and the academy}

Universities are sites of both theoretical and applied knowledge that can, under the right conditions, match effectively with the needs of industry. As discussed above, the present system of rewards and incentives does not effectively harness potential synergies. The incentive system for university researchers needs to be recalibrated toward rewarding cooperation and interaction across the entire higher education system in Mexico. Just as the SNI has effectively stimulated international-quality scholarship, so should there be a system incentivizing collaboration across academic disciplines and with industry. 
Key suggested reform:

In a manner akin to Brazil's Sectorial Funds (described in a Learning Model in the annex), a subset of the Mexican SME Fund should be explicitly dedicated toward fostering partnership projects between firms of various sizes, universities and research centers. A crucial dimension of such a policy is the creation of meaningful incentives for university researchers to participate in cooperative ventures with private sector agents. In addition to bonuses for scholars who achieve international visibility for their peer-reviewed work, researchers should be offered benefits for participating in viable cooperative projects that are supported by a 'collaborative fund'.

\section{Recommendation: Stimulating greater collective efficiency in clusters}

When firms undertake related activities in close geographic proximity, both the immediate environment and the firms themselves are likely to change to become more productive and more innovative. The environment begins to adapt to the presence of the firms by attracting customers, traders, workers with related skills, individuals and firms wanting to offer services, and still more enterprises anxious to benefit from the markets being created. Policy intervention is required to begin the initial process by providing opportunities for collaboration and joint investment.

Key suggested reform:

As part of the SME Fund, Mexican policy efforts should be dedicated toward the creation of collaborative linkages between SMEs in related sectors (as well as those who are additionally co-located). These links have the potential to raise productivity, generate innovation, among other key benefits. By making this kind of interaction a policy priority, and by dedicating funds toward it, the Ministry of the Economic and state economic development agencies can signal to SMEs that these links have considerable potential to spur economic development. Making such links contingent on a particular proposed project, as with Chile's PROFO program (documented below in a Learning Model), will ensure that interfirm linkages are for productive purposes.

\section{Recommendation: Basic reform to encourage entrepreneurship}

Policy makers often prefer support packages and incentives to basic reforms, as support packages are more visible and do not conflict with established interest groups. New initiatives and programs while certainly appealing, address conditions at the margin. For instance, changes to the regulatory framework or the education system would certainly encourage innovation and entrepreneurship however may not address more fundamental concerns about trust, legitimacy and culture. Moreover, smaller reforms may weaken demands for more fundamental and transformational reform. While policy-makers may be tempted to pick single firms and then promote them as 'gazelles', the public sector is notoriously inefficient in identifying successful firms. Policy intervention is required to ease the barriers to entrepreneurship and increase the ability of individuals to capitalize on knowledge flows. It is incredibly difficult to predict where good ideas may come from and which firms may be successful. The probability that innovation and entrepreneurship will yield economic growth is increased when the underlying incentives are stable. Individuals are only willing to undertake risk and dedicate their time to innovative activity when they have confidence that their efforts will be rewarded and their actions will be able to achieve the desired results.

Key suggested reform:

1. Knowledge flows are only possible when trust, equality of access to opportunity and well-defined appropriability regimes exist. Fundamental regulatory and banking reform and increased funding for all levels of education will encourage innovation and entrepreneurship. 
2. Create policies that distinguish the determinants for success among recipient firms, in order to delineate between innovative firms that may not generate large employment growth, and other kinds of firms in sectors where employment growth is more likely. Greater sensitivity to capitalto-labor ratios and other sector-specific factors material to the development of successful firms will ensure that successful firms are recognized as such, and that prospective participants are not discouraged from entering SME Fund accelerator programs.

3. Generate policy guidelines regarding repeated participants in SME Fund and other innovationand learning-focused programs to ensure that firms can achieve self-sufficiency as quickly as possible, while making programs available to the widest array of potentially suitable participants. 


\section{References}

Abramovitz, M. (1986). "Catching up, forging ahead, and falling behind", The Journal of Economic History, Vol. 46, No.2, pp.385-406.

Alarcón, C. and G. Stumpo (2001). Policies for small and medium-sized enterprises in Chile. Cepal Review 74: $167-82$.

Becerra-Rodríguez, N. (2011). Is There A Trade-Off Between Academy-Industry Linkages and Scientific Productivity? Empirical Evidence From Mexican Researchers. Paper presented at the DIME-DRUID ACADEMY Winter Conference 2011.

Benavente, J. M., and G. Crespi. (2003). The Impact of an Associative Strategy (the PROFO Program) on Small and Medium Enterprises in Chile.University of Sussex, SPRU Electronic Working Paper Series Paper No. 88.

Benavente J. M. and Maffioli A. (2007). —Evaluating the Effects of R\&D Subsidies on Firm Competitiveness: Evidence from Chile Working Papers, Inter-American Development Bank, Office of Evaluation and Oversight (OVE).

Borensztein, E., J. De Gregorio and J.W. Lee (1998) "How does foreign direct investment affect economic growth?” Journal of International Economics Vol.45, No.1, pp.115-135.

Brown, Alan S. (2008) “Mexico Redux" Mechanical Engineering, January. Retrieved December 292011 from: http://memagazine.asme.org/Articles/2008/January/Mexico_Redux_2.cfm..

Chen, D.H.C. and Carl J. Dahlman (2006) "The knowledge economy, the KAM methodology and World Bank Operations", World Bank Institute, Washington DC.

CONACyT (2011) "Programa de estimulo a la investigacion, desarrollo tecnologico e innovation resultados modalidad INNOVAPyME",

http://www.conacyt.mx/Convocatorias/Paginas/Convocatoria Programas-Estimulo-a-laInovacion_2010.aspx. Retrieved December 2, 2011.

Coe, D.T., E. Helpman and A.W. Hoffmaister (2008) "International R\&D Spillovers and Institutions", NBER Working Paper No. 14069, National Bureau of Economic Research, Cambridge, MA.

Cohen, W.M. and D.A. Levinthal (1990) "Absorptive Capacity: A New Perspective on Learning and Innovation”, Administrative Science Quarterly, Vol.35, pp. 128-152.

De Negri, J.A., M. Borges Lemos, and F. de Negri (2006) The Impact of University Enterprise Incentive Program on the Performance and Technological Efforts of Brazilian Industrial Firms. InterAmerican Development Bank, Office of Evaluation and Oversight Working Paper No.

Faal, E. (2005) GDP Growth, Potential Output, and Output Gaps in Mexico. IMF Working Paper WP/05/93.

Gereffi, G. (1999) "International trade and industrial upgrading in the apparel commodity chain" Journal of International Economics, Vol.48, No.1, pp.37-70. 
Javorcik, B. (2008). Can survey evidence shed light on spillovers from foreign direct investment? The World Bank Research Observer.

Jordaans, J. (2009) Foreign direct investment, agglomeration and externalities: Empirical evidence from Mexican manufacturing industries. Ashgate, Surrey.

Kemeny, T. (2011) "Does foreign direct investment drive technological upgrading?" World Development, Vol. 38, No. 11, pp.1543-1554.

Legatum Institute (2011) Entrepreneurship and Opportunity Sub-Index. Retrieved January 4, 2012 from: http://www.prosperity.com/entrepreneurship.aspx

Macario, C. (1998): Chile: From policies that subsidize exports to policies that enhance competitiveness, Integration and trade, vol. 2, Nos. 4-5, Washington, D.C., Inter-American Development Bank (IDB).

Maffioli, A. (2006). —Evaluating the Impact of Technology Development Funds in Emerging Economies: Evidence from Latin-America\|. Inter-American Development Bank. Washington, D.C.

Marshall, A (1890) Principles of Economics. Macmillan, London.

Ministério da Ciência, Tecnologia e Inovação (2011) Demonstrativo da Arrecadação, Orçamento e Execução dos Fundos Setoriais - Janeiro a Novembro de 2011. Retrieved January 3, 2012: http://www.mct.gov.br/index.php/content/view/27181.html

National Economic Advisory Council (2010) The New Economic Model for Malaysia. Retrieved January 4, 2012 from: www.pmo.gov.my

OECD (2011a), Education at a Glance 2011: OECD Indicators, OECD Publishing. http://dx.doi.org/10.1787/eag-2011-en

OECD (2009a) Online PISA database 2009; http://www.pisa.oecd.org/

OECD (2009b) OECD Reviews of Innovation Policy: Mexico, Paris.

OECD (2009c) OECD Reviews of Regional Innovation: 15 Mexican States, Paris.

OECD (2011b) OECD Economic Surveys - Mexico, OECD, Paris. May 2011

OECD (2011c) Main science and technology indicators, volume 2011/1, OECD, Paris.

Pietrobelli, C., and R. Rabellotti (2004) Upgrading in clusters and value chains in Latin America: The role of policies. Inter-American Development Bank, Washington D.C.

Ruiz Duran, C. (2008) MÉXICO: Geografia economica de la innovacion. Comercio exterior, vol. 58(11), Novembre.

Schmitz, H. (1999) "Increasing Returns and Collective Efficiency" Cambridge Journal of Economics, Vol. 23, No. 4, pp.465-483.

Storey, D.J. (2008) Entrepreneurship and SME policy in Mexico. Unpublished manuscript. 
World Bank (2010) Impact assessment of SME programs in LAC. World Bank, Washington, DC.

World Bank (2011a) Knowledge Assessment Methodology

World Bank (2011b) Doing Business. Retrieved January 4, 2012, from:

http://www.doingbusiness.org/rankings

World Economic Forum (2011) The global competitiveness report 2011-2012. World Economic Forum, Geneva. 


\section{CHAPTER 5 ACCESS TO FINANCE}

\section{Introduction}

When asked to identify the main barrier to business development, the most likely answer an entrepreneur will give is poor access to external finance, especially debt finance. True or not - credit is often as important as training or advice and mentoring to fuel business development - it is doubtless that enterprises, especially of small and medium sized, are faced with more challenges than large corporations in receiving debt and equity finance. This is all the more true in emerging economies such as Mexico, where large swathes of informality prevents many micro and small firms from interacting freely with government institutions and benefitting from public programmes. Some empirical research has, indeed, identified small firms finance on average 13 percentage points less of investment with external finance than large firms (Beck et al., 2008).

The reason behind existing financial constraints to growth for small and medium enterprises (SMEs) is that the provision of debt and equity finance is strongly affected by market failures, primarily information asymmetries, moral hazard, and adverse selection, which result in credit rationing as a rational screening strategy used by lenders to select reliable borrowers (Stiglitz and Weiss, 1981). Information asymmetries characterise the relationship between lenders and borrowers - indeed between any provider and beneficiary of any type of external finance. This is especially stressed in small firms whose financial information is opaque to the lending institution due to a greater degree of informality in management practices but also to more limited compliance requirements with rules and regulations. The lack of sufficient collaterals to guarantee the bank loan often makes access to credit even harder for SMEs. In theory, banks could put a higher premium on loans floated to firms for which they do not have sufficient information to assess the credit risk. But this would pull out safer borrowers and pull in riskier ones, resulting in adverse selection. In practice, therefore, banks give credit only to firms with sufficient collaterals and credit history, which are more likely to be large and consolidated businesses. It follows that credit rationing particularly affects new and small firms.

Constraints are not only on the supply side of business financing markets. Many small enterprises may lack a proper business plan and have incomplete financial statements, which make a proper assessment of their loan request all but impossible for a senior lending institution. Complaints by banks about the poor financial literacy of SMEs are very common. In addition, growth-oriented SMEs may not be ready for external investment, in general because small business owners are reluctant to forsake equities and therefore lose full control of the ownership and management of the enterprise.

Demand and supply constraints in business financing markets lead to a financial behaviour where entrepreneurs mainly resort to personal savings and other informal channels to launch their business (e.g. financial help from family and friends, or moneylenders in developing contexts), use whenever possible and prevalently bank loans to consolidate it, and only draw on equity finance if it achieves a sustained path of growth. The table below is a snapshot representation of key financing options available to SMEs at different stages of business development. 
Indirectly, it also highlights areas of policy intervention. For instance, policy makers can address limited access to debt finance by start-ups by providing subsidised loans or public guarantees for banks activating SME lines of credit. Private proof-of-concept funding is hardly ever available, which makes room for a public policy niche at this stage of entrepreneurial development. Increasingly, national and local governments also need to appraise the value of supporting equity capital provision to fuel high-growth entrepreneurship. A few small businesses able to grow considerably over a short time are, indeed, the main source of job creation in most economies (OECD, 2010a). That is, most local job creation is concentrated in a small share of extremely well-performing businesses, as against the largest bulk of small firms whose employment remain all but stable over time.

Table 5.1. Business financing options by stage of business development

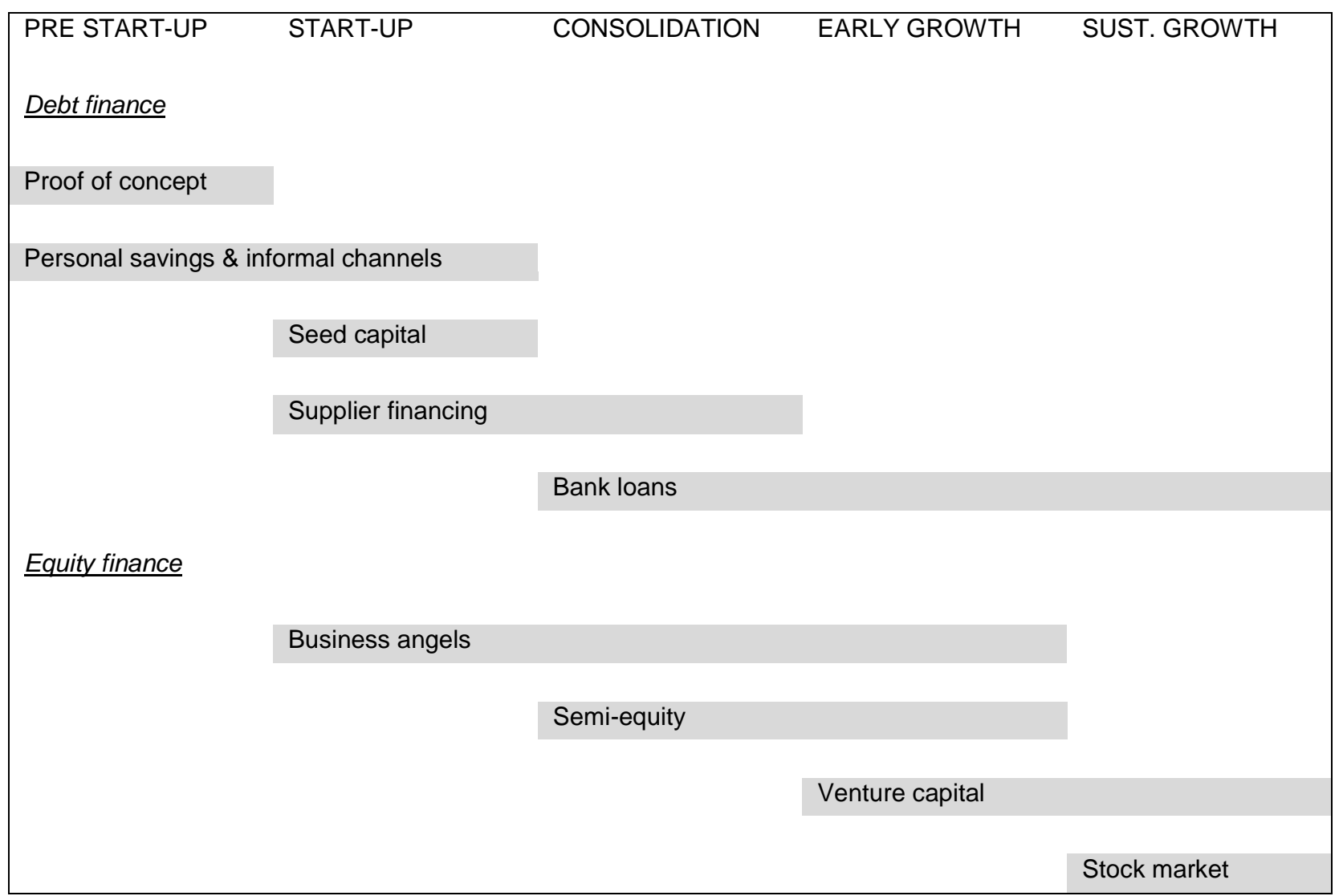

Source: Own elaboration

\section{Assessment of framework conditions}

The 1994 financial crisis, sparked by the sudden devaluation of the Mexican pesos, is the key turning point to understand the recent evolution and current situation of the credit market in Mexico. The crisis was followed by a severe credit crunch that brought credit provision to the private sector down from nearly $35 \%$ of national GDP in 1994 to slightly above 10\% a decade later in 2003. Among the different components of private credit, business credit was the one more dented as against consumer credit and mortgage credit. At the end of 2003 the volume of credit to business activities represented less than 5\% of the national GDP (Garrido, 2011). The financial crisis also meant that national banks were no longer able to finance Mexican sovereign debt, thus plunging the country into a public fiscal crisis too. It followed the decision of the federal government to open up the national banking sector to foreign competition and allow national banks to be fully foreign-owned. However, as will be seen later, this change by itself was not 
enough to introduce sufficient competition in the banking sector, the main outcome being that few large national banks simply became foreign-owned. ${ }^{10}$ The number of senior lending institutions able to engage significantly in business credit and facilitate long-term investment did not, therefore, increase as a consequence of the mid-1990s financial crisis.

A second background consideration is that micro, small, and medium enterprises (MSME) generate $78.5 \%$ of jobs in the country, but contribute only to $52.5 \%$ of national GDP. ${ }^{11}$ The low productivity of SMEs is perceived by the Federal Ministry of Economy (Secretaría de Economía) as a main barrier to aggregate economic growth, and it is felt that improved access to finance can enhance the development of MSME and their contribution to economic growth. Hence is the key role that entrepreneurship and SME financing policies play in the current strategy of the Ministry of Economy and, in particular, of its undersecretary for SMEs.

\section{Appropriate institutions are available at the national and local levels}

The volume of business credit provided by commercial banks to private companies has increased since 2002 and, more decisively, as of 2006 (Fig. 5.1.). As a percentage of national GDP, total business credit has risen since 2004 by 2 percentage points, to stabilise around $7 \%$ following the 2008 global economic crisis (Garrido, 2011).

\section{Figure 5.1. Evolution of business credit by commercial banks, 2000-2010}

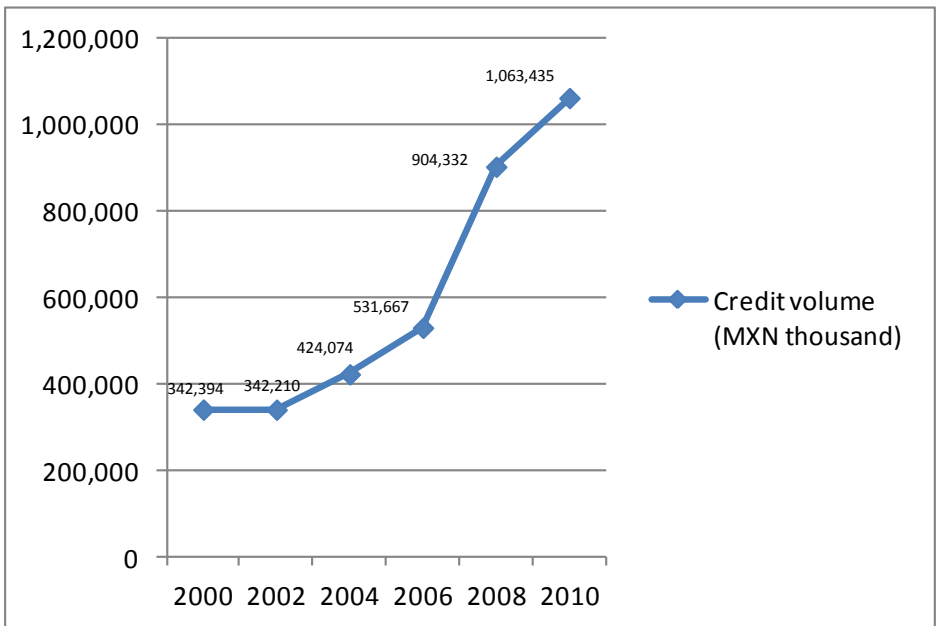

Source: Ministry of Economy of Mexico

Whilst it would be naïve to establish a close link between the presence of some institutions and aggregate economic performance, it is true that the federal government has set up appropriate bodies and earmarked sizeable resources for the promotion of SMEs, including for improved access to external finance. At the national level the most relevant bodies are the undersecretary for SMEs within the federal ministry of economy (i.e. Subsecretaría PYME - SPYME), which was established in 2004, and the

10. The four largest banks in Mexico are today foreign-owned: Bancomer (BBVA); Bancomex (Citigroup), HSBC, Santander-Serfin.

11. It should be noted that the definition of SMEs is different in Mexico from most other OECD countries. The Mexican government refers to micro firms as firms with less than 10 employees, small firms as firms with less than 30 employees in trade and 50 employees in manufacturing and services, and medium firms as firms below the threshold of 100 employees in any sector. 
national development bank NAFINSA (i.e. Nacional Financiera), which has gone through significant recent changes. At the local level, the main institutions committed to SME promotions are the state ministries of economic development (Secretarías de Desarrollo Económico - SEDECOs).

\section{SPYME}

The undersecretary's office for SME (SPYME) was established in the Ministry of Economy in 2004. One of the first actions was to merge the previous three funds devoted to SME support through advice, financing and value-chain integration, into one large fund, the SME Fund (i.e. Fondo PYME). Within the framework of the México Emprende initiative, the SME Fund targets five different groups of firms through five integrated actions. The five target groups are: i) entrepreneurs, which the government interprets as nascent and incipient entrepreneurs; ii) micro enterprises; iii) SMEs; iv) gazelles, which are high-growth firms growing at an annual turnover rate of above $25 \%$ and with between 50 and 250 employees; v) "tractor" companies, which are generally large companies that lead a supply chain and are able to contribute to the development of their suppliers. The five integrated actions are: i) financing; ii) training; iii) commercialisation; iv) management; v) innovation.

Since its establishment the SME Fund has steadily received increasing resources, which emphasises the renovated importance that the federal government of Mexico gives to the role of SMEs in the economy (Fig. 5.2.). This has enabled the SPYME to lay out an impressive array of programmes aimed at the five target groups of the business development strategy of Mexico (Table 5.2.)

Figure 5.2. Annual Budget of the SME Fund 2004-2011

(USD millions)

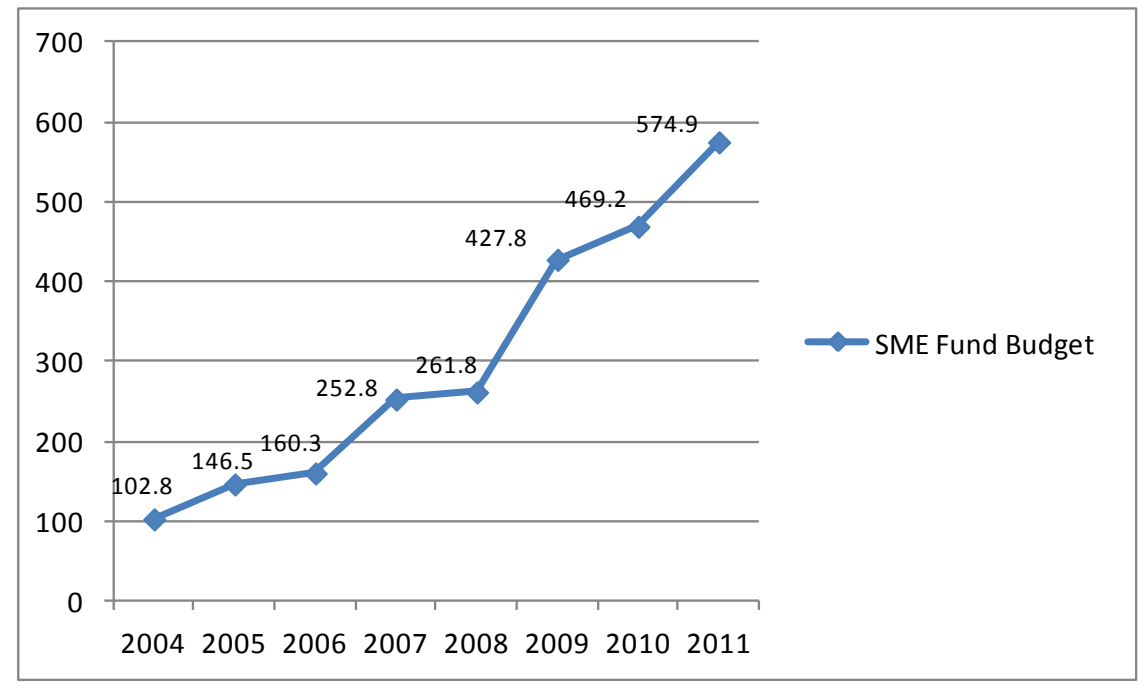

Source: Ministry of Economy of Mexico 
Table 5.2. SPYME Programmes in the framework of Mexico Emprende

\begin{tabular}{|l|l|}
\hline Target groups & \multicolumn{1}{c|}{ Programmes } \\
\hline Entrepreneurs & $\begin{array}{l}\text { Youth entrepreneurs } \\
\text { Incubators (traditional, medium-tech, high-tech) } \\
\text { Seed capital }\left(^{*}\right)\end{array}$ \\
\hline Micro businesses & Ml- series of sector programmes (Mi Tortilla, Mi Tienda,...) $\left(^{*}\right)$ \\
\hline SMEs & $\begin{array}{l}\text { National guarantee system }\left(^{*}\right) \\
\text { Financial extension programme (consultancy programme) }\left(^{*}\right) \\
\text { Non-banking financial intermediaries }\left({ }^{*}\right) \\
\text { SME Productive Project }\left({ }^{*}\right) \\
\text { Centros Mexico Emprende }(C M E) \\
\text { SME Export Centres }(\text { Centros Pyme Exporta) }\end{array}$ \\
\hline Tractor companies & $\begin{array}{l}\text { Innovation Fund }(\text { Innovapyme) } \\
\text { Business Accelerators } \\
\text { Technology parks }\end{array}$ \\
\hline & $\begin{array}{l}\text { Industrial parks } \\
\text { Sector projects } \\
\text { "Made in Mexico" Initiative }\end{array}$ \\
\hline
\end{tabular}

Source: Own elaboration based on information by the ministry of Economy of Mexico

The SME Fund goes beyond the support of access to finance, and the programmes that back up more specifically the provision of external finance to new and small firms are marked in the table above with an asterisk. The three main business financing schemes are the national guarantee programmes, which provides through NAFINSA guarantees to banks that activate SME lines of credit, the SME productive project, which supports through subsidised loans the acquisition of new equipment by medium-sized firms, and the seed capital tool (i.e. capital semilla), which provides seed capital to new firms graduating from the national incubation programme. Altogether, in 2010, the budget of these three programmes made up half of the total SME Fund, which brings out the relevance of business financing programmes in the national SME development strategy. The national guarantee programme by itself represented nearly $35 \%$ of Fondo PYME's total budget. ${ }^{12}$

The allocation of funds also suggests that lack of external finance is estimated to be a problem especially for small and medium firms, to which most of the financing programmes and related resources are addressed. This is a reasonable stance, as lack of credit is one of the most common barriers to business consolidation, but the attention of the SME Fund could be better balanced in the future by augmenting resources for seed capital, which is an equally critical stage of business development.

12. In 2010, the last year for which detailed figures by programme are available, the national guarantee programme counted with a budget of MXN 2300 billion (USD 161.5 million), the SME productive project with MXN 850 million (USD 59.7 million) and capital semilla with MXN 200 million (USD 14 million). This added up to USD 235.2 million, which is $50 \%$ of the total government budget allocated to the SME Fund. 
SPYME also appears to work well with other relevant institutions, namely NAFINSA and the SEDECOs at the state level. The guarantee programme is run in close collaboration between SPYME and NAFINSA, the latter being the operational arm of the scheme, and the involvement of state authorities in federal programmes is strong both in small-scale programmes such as capital semilla and the MI-initiatives and in most strategic choices such as the attraction of global players leading supply chains in specific localities.

The integrated approach of the undersecretary's office is also praiseworthy although, when it comes to business financing policies, the offer for the five different groups does not seem to be as differentiated as one would imagine. Most programmes provide subsidised loans or facilitate them through public guarantees. Conversely, equity capital, proof-of-concept funding, and mixed forms of loans/grants appear currently overlooked in the SPYME's strategy to enhance the access of SMEs to external finance.

\section{NAFINSA}

NAFINSA (i.e. Nacional Financiera S.A.) is the development bank of Mexico and operational arm in the framework of the México Emprende initiative. During the last decade it has gone through a very positive evolution, passing from catering for just 15000 firms in 2000 to nearly 750000 as early as 2006 . Losses stemming from outstanding loans have also been considerably curtailed, and its role in the wake of the 2008 global economic crisis has further been reinforced (Garrido, 2011).

Today, NAFINSA is a second-tier bank that provides commercial banks and other financial institutions with public funding to deliver federal and state programmes. It offers two main products, subsidised loans and guarantees, the latter being its predominant form of SME support. As with other federal institutions, NAFINSA works through an auction process in which the delivery of the policy is granted to those intermediary organisations that make the best offer in terms of credit conditions for the SME clients.

Thanks to its five national offices and branches in each state, NAFINSA is also able to design programmes tailored to specific needs. For example, in the visited state of Queretaro, NAFINSA had developed special credit programmes for tier-2 and tier-3 suppliers of the strong local automotive sector and was equally in the process of bolstering the incipient aeronautics sector. In Mexico City a specific scheme was conceived for taxi drivers, while in the state of Leon were the footwear and leather industries to be targeted.

If anything, one problem that NAFINSA shares with SPYME is the lack of real investment capital in their schemes, the maximum repayment term being four years and the average loan size being relatively small in the national programme of guarantees (i.e. USD 66000 in 2010). Most of the loans supported by NAFINSA seem therefore rather thought for working capital requirements or, at most, small-scale investments.

\section{SEDECOs}

SEDECOs (i.e. Secretarías de Desarrollo Económico) are the equivalent of state ministries of economic development and are the government bodies most closely involved in the promotion of entrepreneurship and SME development at the local level. In many programmes of the federal government, including those regarding business financing, SEDECOs are asked to match federal resources on a 1:1 basis. This permits a close involvement of state governments in policy implementation and policy tailoring to state needs, although it could arguably favour richer states that have more matching funds to allocate.

The SEDECOs are engaged both in microcredit for the self-employed and micro businesses and in subsidised medium-sized loans for SMEs. The IMOFI (Instituto Morelense para el Financiemiento del 
Sector Productivo) in the state of Morelos and SOFEQ (Programa de Soluciones Financieras) in the state of Queretaro are two examples of state institutions and programmes, partly funded by federal resources, actively committed in both areas and able to provide better credit conditions, especially with regard to interest rates, than private micro-finance institutions and commercial banks.

IMOFI and SOFEQ can act as intermediaries of federal programmes or can in turn rely on local intermediaries to deliver their own programmes, but it is when they directly implement their own schemes that they are in a position to offer the best credit conditions to local firms. In the case of SME credit, for instance, they were able to provide loans in the range of MXN 1 million at an interest up to 6\% lower than the one applied by commercial banks. Interestingly, they used a discounted interest rate towards borrowers able to repay on time. On the other hand, for the federally funded "SME Productive Project" programme in which SEDECOs were intermediaries of SPYME, credit conditions were no longer so favourable compared to those proposed by commercial banks, especially because public credit requirements are more demanding than those requested by private lending institutions.

This is revealing of the costs implied in a policy delivery approach that heavily rests on intermediary organisations. Whilst such as an approach has the merit of relying mainly on the private sector, thus avoiding the possible crowding-out of private business development organisations, it generally implies higher transaction costs than if the policy were implemented with fewer intermediations. This seems to be true at least with business financing policies.

\section{The system of intermediaries is well tuned}

SME policies are delivered in Mexico through a wide network of intermediary organisations working at the local level. By and large, the federal government designs the SME programmes and launches an auction in which intermediaries, which are mainly non-profit organisations but sometimes also state organisations such as IMOFI and SOFEQ above, submit a project for the delivery of the programme. The proposals that feature the best conditions for the government as much as for the client SMEs are then picked and funded.

A similar system, which applies the whole range of SME policies, is deemed to have a number of merits. It reduces crowding-out effects towards private business development service (BDS) providers if the programme is managed by private intermediaries, which is the most frequent case. It is gauged to guarantee a deeper geographical outreach at lower costs than if the government had to deliver programmes in peripheral regions of the country. And it aims to be an improvement from the past when public programmes directly managed by the government resulted in massive losses in the project portfolio.

With regard to credit policies the system appears to have worked well and is regarded as unanimously reliable by local intermediaries, which regularly fill the federal call for tenders for the implementation. An example is given by the national guarantee fund, which has never failed to cover the losses endured by the banking sector on the SME credit guaranteed by the programme. Whilst this might appear obvious, some guarantee programmes in the Latin American region have precisely failed because of the lack of adequate budget to cover defaulting guaranteed loans or the extremely slow and cumbersome procedures for lending institutions to receive payments (Ferraro and Goldstein, 2011). In this respect, the Mexican guarantee fund has been flawless.

At the same time, the aforementioned example of the "SME Productive Project" programme shows that an intermediary-based policy has its own costs, primarily related to greater transaction costs, which can lead to the paradox where the conditions of public programmes are less appealing than those available in the private market. There needs to be an effort in reducing as much as possible the number of 
intermediaries involved in the delivery of a single programme to reduce its overheads and make it still appealing to client SMEs.

\section{Local credit markets are increasingly diversified}

In the nearly twenty years since the financial crisis the credit market of Mexico has increased its level of diversification, partly thanks to opening up the banking sector to foreign competition but also as a result of the 2001 federal law for "savings and popular credit", whose aim was to regulate and institutionalise a diverse array of financial organisations such as credit unions and savings banks catering for the lower segment of credit markets. Two new forms of organisation were introduced, the Financial Society with a Specific Objective (Sociedade Financiera de Objeto Limitado - SOFOLES) and the Financial Society with a Multiple Objective (Sociedade Financiera de Objeto Múltiple -SOFOMES), with a view to serving the credit needs of micro and small business. In addition to operating as independent non-banking financial institutions, SOFOLES and SOFOMES have received rising funding from SPYME and NAFINSA to deliver programmes at the local level, which has enabled them to develop also at a period of general crisis. The reverse side is that, in spite of their original objective to encourage SME development, the range of loan size in which these institutions operate suggests that they are rather more active in the consumer credit market and that, as a result, business credit is still concentrated in a few traditional large banks.

\section{Business credit is still highly concentrated and precluded to SMEs}

Whilst the credit market looks increasingly diversified with regard to actors, it is still highly concentrated in terms of assets. At present, there are seven large banks in Mexico, six of which are foreignowned, that accounts for $84 \%$ of the total assets in the banking sector. Business credit is largely monopolised by these institutions which favour consolidated clients on SMEs, the latter representing less than $15 \%$ of their total business lending activity (Ferraro and Goldstein, 2010). SMEs appear to be marginalised in the senior credit markets and, indeed, the use of bank loans by small firms has even dropped by 10\% over the period 2002-2009 (Garrido, 2011). According to the 2009 economic census, nearly three/quarter of all firms in Mexico does not receive any credit, the two most common cited reasons being "no need" and "high interest rates". This highlights a problem of credit conditions on the supply side of the credit marker, but also of poor financial literacy and large swathes of informality associated with low productivity, on the demand side.

Public programmes, especially the National Guarantee Fund, help in widening the access of SMEs to external finance but in spite of their mounting budget allocations their impact can but be limited given the size of the country and the number of small enterprises to which credit is precluded. In the section on policy and programme assessment we will discuss possible improvements in the credit guarantee system that could, inter alia, boost its outreach towards more firms.

However, what seems to be most urgent is a more structural reform that strengthens competition in the banking sector and fine-tunes the latter to the needs of local SMEs. One option where both national and local governments could work together would concern the introduction of co-operative banks in the banking system. Co-operative banks are different from credit unions and savings societies, already available in Mexico, because they are real banks subject to the regulation of both the cooperative system and the banking sector. They provide services and sell products not only to members but also to external clients (usually at higher fees). Some of them can even raise capital in financial markets, thus turning themselves into semi-cooperative institutions. Nevertheless, specific rules prevent them from expanding beyond a delimited area, which makes cooperative banks local banks by definition.

As compared to large national banks, co-operative banks are in a better position to know local needs and trends and engage in "relationship lending" where loans are granted not only based on scores, ratios 
and collateral, but also on the personal knowledge of the business, its growth prospects and repayment capacity. As against credit unions, they have stronger capitalisation and a more consolidated structure that allow them to issue bigger and longer-term credit. Thus, they might fill the gap of SME lending that is currently left vacant by national banks, on the one hand, and credit unions and non-banking financial institutions, on the other. Further details of this policy option will be dispelled in the "policy recommendations" section of this chapter.

\section{There is a paucity of SME investment capital}

Not only are SMEs a minor share of large banks' business lending, but the average size of an SME loan hardly exceeds the threshold of USD 40 000. It can be assumed that this credit mainly meets working capital requirements rather than investment purposes. There is a general paucity of investment capital for SMEs in Mexico, and this also concerns public programmes run by the federal and the state governments. Most public subsidised programmes, despite giving up to MXN 2 million (i.e. approximately USD 150000 ), have indeed a maximum repayment term of 4 years, which is not germane to long-term investment.

Equity and semi-equity finance, which have proven key to stoke high growth entrepreneurship, are also basically latent in Mexico, bar some incipient activity by NAFINSA and the Monterrey Technology Institute (Instituto Tecnólogico y de Estudios Superiores de Monterrey - ITESM). The study visit has brought out how local wealthy individuals display a strong preference for investment in large corporations, often across the northern border, whereas US companies invest in Mexico mainly to undertake industrial restructuring projects worth above USD 20 million. There is also a more general complaint about the lack of viable projects. However, the presence of 21 technology incubators across the country and of 31 brandnew science parks such as the one in Queretaro should guarantee the presence of interesting investment opportunities also locally. The major problem lies therefore on the supply side of investment capital. National and state governments should, on the one hand, strive to increase the duration of their subsidised loan programmes and, on the other, back up the budding equity markets of Mexico through a range of actions that could include tax breaks for local equity investments, the set-up of public venture capital funds, the support to business angel clubs, and the creation of second-tier stock markets where mediumsized companies can tap growth capital.

\section{Assessment of policies and programmes}

This section analyses the business financing policies currently in place in Mexico at the national and local level. It garners the different schemes that have been presented during the study visit in four large policy categories, which are individually assessed: seed capital; credit guarantees; microcredit; and investment capital.

\section{“Capital Semilla": a well-conceived programme that should be scaled up}

Capital Semilla is the main seed capital initiative of Mexico and looks like a well-integrated programme. Conceived and co-funded by the SPYME within the federal Ministry of Economy, the evaluation and selection of the business applications is carried out by the SEDECOs at the state level. This represents a recent shift from a centralised approach of the programme that originates from a specific request of the states and that should in principle guarantee a more detailed appraisal of the business proposals and leaner management of the whole process. As with other programmes supported by the federal SME Fund, Capital Semilla requires the financial co-participation of the involved municipalities and states, which are asked to cover the first losses associated with programme-related defaulting loans. 
Capital Semilla is also closely integrated with the national business incubator programme in that only firms that graduate from one of the 500 incubators of Mexico are entitled to receive support in the frame of this programme. The policy rationale is to furnish seed capital only to solid start-ups such as those that have completed an incubation process are more likely to be. The fraction of incubated start-ups that obtains public seed capital is in the reality quite small (all but 5.6\% in 2010, see table below), but incubators are said to facilitate access to external finance also through a sort of "quality label" associated with tenant firms. The degree to which this occurs in the rigid credit market of Mexico could not have been explored.

Table 5.3. Key characteristics of Capital Semilla

\begin{tabular}{|l|c|r|r|}
\hline Type of incubator & $\begin{array}{c}\text { Credit provided } \\
\text { (MXN pesos) }\end{array}$ & Max. provision of support & $\begin{array}{c}\text { Repayment period } \\
\text { (grace period) }\end{array}$ \\
\hline Traditional & $50000-300000$ & $85 \%$ of the project & 42 months $(6$ months $)$ \\
\hline Intermediate Technology & $<500000$ & $85 \%$ of the project & 42 months $(6$ months $)$ \\
\hline High Technology & $<1500000$ & $85 \%$ of the project & 48 months (9 months) \\
\hline
\end{tabular}

Source: Ministry of Economy of Mexico

Table 5.4. Size (SME Fund contribution) and outreach of Capital Semilla

\begin{tabular}{|l|r|r|r|r|}
\hline Year & \multicolumn{1}{|c|}{$\begin{array}{c}\text { SME Fund } \\
\text { contribution } \\
\text { (Million MXN pesos) }\end{array}$} & $\begin{array}{c}\text { N. of firms graduated } \\
\text { from the national } \\
\text { incubator programme }\end{array}$ & $\begin{array}{l}\text { N. of firms requesting } \\
\text { public seed capital }\end{array}$ & $\begin{array}{c}\text { N. of firms obtaining } \\
\text { public seed capital }\end{array}$ \\
\hline 2007 & 120.00 & 5476 & 1138 & 530 \\
\hline 2008 & 46.63 & 6518 & 1581 & 201 \\
\hline 2009 & 90.99 & 6092 & 884 & 355 \\
\hline 2010 & 200.00 & 8467 & 1012 & 473 \\
\hline
\end{tabular}

Source: Ministry of Economy of Mexico

Precisely because Capital Semilla is a well-integrated programme that works through a close-knit collaboration between the national and local levels, it would deserve to be scaled up. With a federal budget of just MXN 200 million (i.e. less than USD 15 million) the impact of the programme is very circumscribed, as shown by the few start-ups that benefit from it. The 1:1 peso rule that provides for an equal contribution from the federal and state government could be a barrier to the further enlargement of the policy, inasmuch as state governments do not have as much resources to commit to local economic development. A recent evaluation of the SME Fund by the Monterrey Technology Institute advocates the quality of the seed capital programme and indirectly underpins our view of an upscale of the scheme. The ITESM evaluation concludes that Capital Semilla is amongst the top four federal programmes with respect to the impact, measured as improved productivity, on the participants.

In addition to an upsizing, the programme also appears short in differentiation. The experience from other countries shows that seed capital programmes supply either a combination of grants and loans (at times, at zero interest rates) or equity capital for growth-oriented start-ups. Latin American countries such as Brazil and Chile have espoused this second approach. Conversely, the Mexican programme confines itself to an offer of subsidised credit and lacks any element of growth capital. In the future, it could continue providing subsidised credit to new firms graduating from traditional and intermediate technology incubators, while funding firms from high-tech incubators through equity capital. ${ }^{13}$ This would alleviate

13. In fact, one could argue from the policy viewpoint of additionality and possible displacements the value of supporting incubators in traditional low added-value sectors where entry barriers are low and competition keen. But this argument would lead us beyond the scope of this chapter. 
the credit burden on new technology-based firms, more affected than others by innovation-related uncertainty, and take part in piloting public equity programmes at the local level thanks to its implementation through SEDECOs.

Some operational tweaks could also further improve the programme. The annual interest rate applied by Capital Semilla is $12 \%$, with a reduction to $9 \%$ in case of on-time repayment. This is a common practice in Mexican SME policy that aims to reward reliable borrowers. However, Capital Semilla is implemented at the state level by the SEDECOs, which also run their own schemes with better credit conditions at times. For example, IMOFI in Morelos runs a business credit programme which covers the full range of loan size as Capital Semilla (i.e. from MXN 70000 to MXN 1 million) but offers an interest rate of $7.5 \%$ on on-time repayments. Credito PYME by SOFEQ in Queretaro lowers this rate even to 6\% for loans of MXN 700000 averagely. In addition to the budget constraints of the programme, this could explain the relatively low number of incubated firms that apply for the seed capital programme (12\% in 2010) and points towards an alignment of interest rates so that similar public programmes offer similar conditions, avoiding to compete against each other.

Finally, in case of defaulting loans the programme's interest rate soars at $24 \%$, twice the regular rate. Whilst it is important to set a serious disincentive for late repayments, a double interest rate is certainly too much a handicap that can bring to his knees even a start-up that goes through mere temporary issues of cash-flow.

\section{The credit guarantee programme is well-performing but needs delocalisation to increase its outreach}

With an allocation of MXN 2.3 billion for the year 2010 the National Guarantee Fund (NGF) makes up for approximately $40 \%$ of the overall SME Fund and is the cornerstone of Mexico's SME finance policy. The NGF is the outcome of the cooperation between SPYME and NAFINSA, with the former putting the finance and the latter managing the programme. It operates through an auction process in which banks and other financial intermediary organisations submit an application to deliver the scheme. Those that propose the best credit conditions for SMEs and estimate the lowest losses on their SME lending activity are selected to deliver the scheme at the local level. Being a fund, this programme does not cover the single loan, but rather the full portfolio up to a limit based on the "expected losses" agreed between the bank and the management of the programme. Any additional loss beyond this ceiling is charged on the bank, which is therefore tasked with the appraisal of the loan. 
Figure 5.3. The evolution of the National Guarantee Programme of Mexico

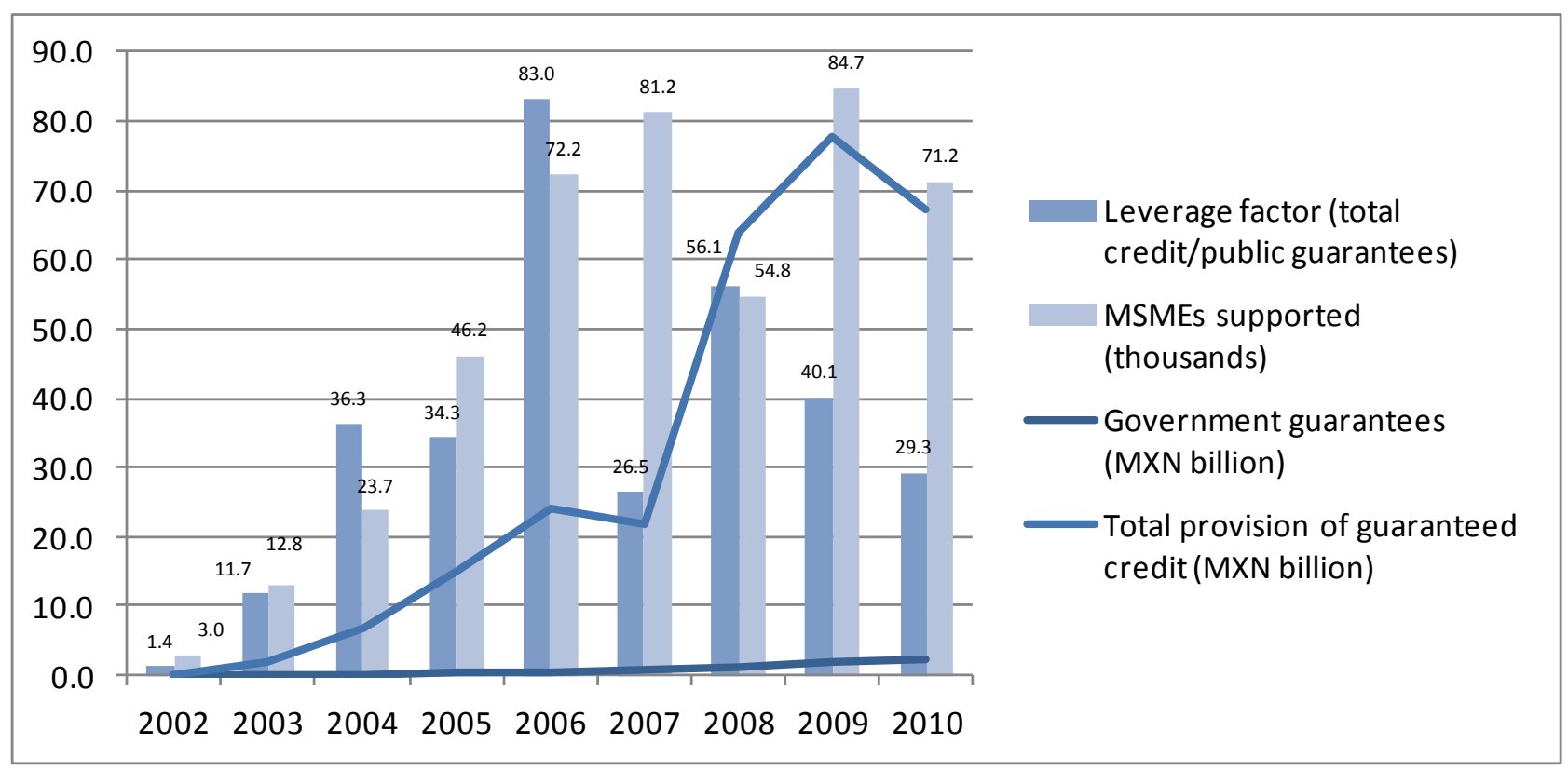

Source: Own elaboration based on data from the Ministry of Economy of Mexico

The graph above shows that the budget of the NGF (bottom line) has been increasing steadily since 2002 (the only exception being 2006, which is not perceptible in the figure), to attain in 2010 the amount of MXN 2.3 billion. The leverage factor, i.e. the multiplier effect of the single peso given as guarantee, has also achieved its peak in 2006, on the one hand because of the downsizing of the NGF and, on the other, due to the buoyant trend of credit before the outbreak of the global economic crisis. The evolution in the last four years is particularly revealing. After the drop in credit provision in 2007 the budget allocation for the NGF becomes bigger and bigger, which has a positive impact on the volume of SME lending that reaches the peak of MXN 77.6 billion in 2009. The leverage ratio attains its best, except for 2006, in 2008 (56.1), only to fall in the following years around values in line with those of the past, possibly because of the backwash of economic turmoil. The NGF has, therefore, played a key role in the keeping the credit market afloat and growing also at a time of economic turmoil.

Thirty-seven intermediaries are charged with the delivery of the programme, which proves the success of the public auctions launched by the SPYME and NAFINSA. This should not be taken for granted, as elsewhere in Latin America credit guarantee funds have notably failed due to burdensome regulations and delays in the provision of public guarantees that have shied banks away from joining the programme (Ferraro and Goldstein, 2011). This has not been the experience of Mexico, where auctions have been regularly filled and where intermediaries appear happy with the management of the scheme at the federal level.

The NGF has resulted in improved credit condition for SMEs, which is the most important outcome for a credit guarantee programme. Bank credit requirements have been softened - e.g. banks accept today simple bank statement instead of audited statement - and the interest rate for the broad range between MXN 250000 and 4 million is competitive in the market, being at 10\% in 2010, $2 \%$ lower than the one applied by most public programme in the same range of loan size. Yet, the interest rate for small-size loans (up to MXN 250 000) does not appear equally appealing. 
Table 5.5. Annual interest rates applied to credit through Mexico's NGF by loan size

\begin{tabular}{|l|r|r|r|r|}
\hline $\begin{array}{c}\text { Loan Size } \\
\text { (MXN pesos) }\end{array}$ & \multicolumn{2}{|c|}{2007} & 2008 & 2009 \\
\hline Less than 250000 & $33.6 \%$ & $21.8 \%$ & $18.2 \%$ & 2010 \\
\hline $250000-4000000$ & $14.7 \%$ & $8.4 \%$ & $12 \%$ & $21.6 \%$ \\
\hline $4000000-10000000$ & $14.2 \%$ & $6 \%$ & $9.9 \%$ & $10 \%$ \\
\hline More than 10000000 & $15 \%$ & $4.8 \%$ & $9.8 \%$ & $6 \%$ \\
\hline
\end{tabular}

Source: Ministry of Economy of Mexico

The downsides of the NGF mainly relates to its small outreach and to its very nature of Fund, two issues more intertwined than it seems at a first glance. There are more than 4 million MSMEs in Mexico, but the credit guarantee programme only attains each year between 70000 and 80000 in positive years, provided that these are always different firms and not repeated borrowers to which banks apply the scheme more than once. This is a tiny fraction that is difficult to scale up within the current framework of a fund. This is why it is important that the national and local governments together also experiments with mutual guarantee societies.

Mutual guarantee societies (MGS) share the same mission of a guarantee fund - i.e. ease access to credit - but they have also quite different operational rules. Firstly, they intercede with the bank only for members, who pay a membership fee that becomes part of the capital used to guarantee the bank loans member enterprises receive. Secondly, the evaluation of the loan is generally done by the management board of the MGS, which should know the repayment capacity of its member. This lowers the information asymmetries and transaction costs for the bank conceding the loan. Thirdly, the public sector can intervene through counter-guarantees beyond the capital of the mutual society. Fourthly, due to their mutual nature, MGS have a strong local streak, which makes them suited for enlarging the outreach of Mexico's guarantee system.

The international experience has so far been that guarantee funds have prevailed in Latin America, whereas guarantee societies have been more common in Europe. More recently, however, countries such as Brazil and Argentine are moving towards a mixed system that also foresees the presence of MGS. For instance, the Brazilian SME Agency (SEBRAE) is currently supporting local mutual guarantee societies through technical assistance and financing.

\section{Microcredit: federal and state programmes reconciling economic and social objectives}

There are nearly 4 million of micro businesses in Mexico, representing $95.2 \%$ of firms, $45.6 \%$ of employment and $15 \%$ of GDP contribution. These figures highlight the problem of low productivity that always characterises the small business sector.

The series of micro-business programmes (i.e. MI Tienda, MI Tortilla, MI Taller, etc.) at the federal level aims to tackle this issue by giving advice and training on basic principles of business management, together with subsidised credit to purchase new equipment that improves productivity, safety at work and the environmental impact of the microenterprise through reduced energy consumption. Mi Tortilla, which is the programme that the study visit has more specifically met, also supports producers through a quality logo that helps them compete with large companies and through a grant in change for old polluting equipment so that this is not sold in the second-hand market. Together with an economic objective of improved productivity, the MI series has also a social aim in seeking to formalise through participation in the programme the large swaths of informality that connotes the microenterprise sector in Mexico. 
State governments are also very active in the field of microcredit. In Morelos, for example, specific programmes are in place for taxi drivers and microenterprises related to tourism, a growing sector in this state. In Queretaro a programme called credito a la palavra (i.e. trust loan) has been set up to cater for the self-employed through microloans up to MXN 10000 and repayment within six months. Interest rates are competitive compared to those offered by private microfinance institutions and rates of default in the range of 5-6\%, which is very low for microcredit programmes. This is the result of close monitoring on the use of the loan and repayment terms, with visits to the enterprises and repayment deadlines that can be even on a weekly basis in some cases. A small difference between the two visited states of Morelos and Queretaro is that in the former group lending is customary, whereas this practice has not been mentioned in the latter.

Group lending has a certain number of advantages besides individual lending. Firstly, transaction costs are reduced because public authorities and banks only deal with the management board of one entity, rather than with a multitude of borrowers. Secondly, information asymmetries are equally lowered because group lending entails that group members know each other, in the same guise as in the mutual guarantee societies. Thirdly, collateral may not be necessary insofar as it is replaced by compulsory savings, group liability, and peer pressure. Some potential drawbacks have also been signalled, namely that group selfselection can result in the exclusion of the most vulnerable people from access to microcredit and that peer pressure can become unduly pervasive (Green, 2005).

Microcredit programmes have certainly an important role to unfold in an economy such as Mexico's where large areas of informality and poverty are common. In this respect, surprisingly business formalisation was not quoted as one of the objectives of microcredit programmes at the state level, even when programme managers were specifically asked. It is, therefore, recommended that state microcredit programmes be aligned with the federal series of MI programmes in trying to use microcredit as a lever to formalise microenterprises. Similarly, state programmes should combine microcredit provision with training in basic business management principles more than they have done so far. The international experience on this policy shows, in fact, that microcredit is more successful when it is combined with training provision.

\section{Investment capital programmes need to be made longer-term and diversified in its equity component}

Investment capital, which involves both debt and equity finance, is crucial to the long-term development of a business enterprise and to the expansion of those high-growth firms that generate most jobs at the local level. However, as said in the section on framework conditions, investment capital is latent in Mexico, thus creating an area for policy intervention.

Mexico's programmes tackle investment capital mainly from the angle of debt finance, while the provision of public equity capital is at a very incipient stage. At the federal level, with a budget in 2010 of approximately MXN 850 million, the SME Productive Project (SMEPP) is the flagship initiative in the field of investment capital, giving out loans of up to MXN 2 billion (i.e. around 150000 USD), at an interest rate of $12 \%$ which is discounted in case of early repayment, and with a repayment deadline of 4 years. As with the seed capital programme, SMEPP also provides for an equal contribution from the federal and state governments, with the latter being charged with the evaluation of the proposals. Proposals that focus on sectors of strategic importance to the state and that help SMEs to integrate global value chains are given priority in the selection process.

Similar initiatives are also available at the state level. In Morelos IMOFI delivers the "business credit programme", which has features akin to those of the federal SMEPP and helps SMEs obtain medium-sized credit that would be hard to receive by commercial banks. In Queretaro SOFEQ runs Credito Pyme, which disburses credit on the average of MXN 700000 for firms engaged in the strong manufacturing base of this state (e.g. automotive and aerospace industries). This programme has a ratio of approved requests out of 
the total of 8:1, which signals the interest of local SMEs in this type of credit and at the same time the budget constraints common to these initiatives.

In addition to representing another example of integrated approach between the federal and state levels (in the case of SMEPP) these initiatives have the main merit of targeting local strategic sectors. Rather than scattering resources in too many streams, they focus on those industries where the state has a comparative advantage and which can accordingly impact the most on local development. On the other hand, the main concern refers to the duration of four years of the loan, which appears too short for an investment to bring in the expected benefits and that it is not in line with the international experience of long-term loans, whose repayment term can be up to 10 years.

In the policy domain of investment capital there also needs to be more attention towards the development of an equity market, which is at a very incipient stage in Mexico. The reasons underlying this status have been exposed in the section on framework conditions. Here it is important to mention that the two most active actors in this field are the Monterrey Technology Institute (ITESM) and NAFINSA. The former runs a business angel network in every state where it is present with the objective of promoting investment in firms set out by the university's alumni. The latter, through the financial support of the Ministry of Economy, manages Programa Emprendedores (i.e. the "Entrepreneur Programme"), which focuses on early-stage investments, and a "Fund of Funds", which targets later stages of business development through investment in private funds and companies. The scope of both programmes is though limited, Programa Emprendedores having backed only 25 firms between 2004 and 2009 and the Fund of Funds a total of 115 since its creation in 2006 (Garrido, 2011).

The OECD study visit has met reserves by Mexican authorities about the future prospects of an equity market in Mexico. However, the stage of development of the equity market is so incipient and yet equity capital so important for high-growth entrepreneurship that more needs to be done in this field. For example, the two programmes of NAFINSA could be expanded and the same organisation could search partnerships with US venture capital (VC) funds to promote investment in Mexican firms selected by the private fund. Alternative, public venture capital funds could be experimented. Equity funds need commercial discipline and professional management, reason why public $\mathrm{VC}$ schemes are generally not the most preferred option. In the context of Mexico, though, public VC funds could raise awareness about this form of business finance and attract private investment capital, provided that they are managed with the support of professionals experienced in this specific branch of finance. Finally, from a local development viewpoint, it is fundamental that such an initiative be aimed only at business productivity improvements without second goals of geographical redistribution in mind. For a public VC scheme to be commercially viable it needs to be freedom to invest anywhere good opportunities arise, even if this occurs only in a few places.

\section{Policy recommendations}

Based on the previous analysis, the following three key recommendations are formulated for policy development in Mexico. They all have a strong local dimension in which state governments have a key role to play, in some instances with some degree of coordination by the federal government.

\section{Support the emergence of co-operative banks}

National and state governments should work together on this endeavour. The former would be tasked with setting the legal framework, which would frame co-operative banks under the jurisdiction of the central bank. The latter would facilitate the emergence of co-operative banks at the local level by raising awareness about their role, prompting business associations and wealthy individuals to join forces to set them up, and possibly participating in their share capital. 
Recent analysis by the OECD LEED Programme (OECD, forthcoming) shows that countries with a more decentralised banking system are in a better position to reach out to the bulk of small firms. Thanks to in-depth knowledge of a smaller base of customers, local banks are able to rest their lending on a more detailed knowledge of the business and on a continued relationship with the entrepreneur, as against the impersonal transaction lending techniques applied by larger institutions.

Whilst co-operative banks are uncommon in the Latin American context, they are a strong reality in Europe, suffice it to mention the networks of banca di credito cooperativo in Italy, banque populaire and caisse d'épargne in France, Rabobank in the Netherlands, and Raiffeisen Zentralbank in Austria. Altogether, they serve today 140 million clients and hold $20 \%$ of the EU savings market. Co-operative banks traditionally cater for loans to local SMEs, a broad section of the credit market that is presently underserved by large national banks in Mexico.

\section{Introduce mutual guarantee societies}

The National Guarantee Fund (NGF) is the main policy of Mexico towards easing access to credit and has so far proven successful in increasing the volume of lending by large banks towards SMEs. However, the main drawback consists in its limited impact, only attaining between 70000 and 80000 firms nationwide depending on the year.

Mutual guarantee societies (MGS) can help strengthen the outreach of the credit guarantee system by making it more decentralised. As with co-operative banks, there is broad scope for collaboration and integration between the federal and state governments in the promotion of MGS. The national government will need to set the legal framework in which the guarantee societies will operate and possibly ensure counter-guarantees. State government can also provide public counter-guarantees, in addition to encouraging the establishment of the MGS at the local level.

An important advantage of mutual guarantee societies besides a centralised guarantee fund is the reduction in information asymmetries and transaction costs for banks. MGS consist of members that are generally part of the same business association or economic sector and that are therefore aware of the growth prospects of their member. In order not to have the size of their mutual fund reduced by defaulting loans, they will have an interest in providing coverage only for reliable borrowers. In turn, this lowers information asymmetries for the lender. The latter also see transaction costs dropped because MGS take charge of the first screening of the SME loans.

Risk sharing is the most important parameter for MGS to be effective. There are three actors that need to strike a right balance, i.e. the borrower, the lender and the guarantor, with the possible additional participation of the government acting as the counter-guarantor. The distribution of risk should be such that the guarantor covers enough of the insolvency risk to convince banks to participate in the scheme, the banks have still an interest in properly assessing and monitoring the loan, and strategic default is not an easy option for the borrower. International experience suggests that the coverage rate guaranteed by the MGS should be between $60 \%$ and $80 \%$ (Levitski, 1997).

Other two important operational parameters to consider are fees and risk management techniques. Membership fees are commonly applied to firms that join MGS. They should be high enough to cover administrative costs, but low enough to incentivise participation. The experience shows that it is not realistic to expect MGSs to live out of only fees, but they should at least cover administrative costs. Risk management techniques are, on the other hand, key to decrease exposure to defaults and diversify risk. The most common practice is the use of counter-guarantees by the public sector, which has the function of increasing the incentive for banks to participate in the scheme but which can also augment "moral hazard" behaviour on their part (OECD, 2010b). 
A final caveat concerns the respect of the original mission of MGS, which is to make access to external finance possible for those firms that lack credit history or collateral. This also means that a wellconceived credit guarantee programmes should be designed so that borrowers who prove reliable and borrowers with sufficient collateral are progressively phased out of the scheme as, in principle, they should be able to obtain credit through mainstream channels in an efficient credit market. Indeed, too low a rate of default might flag that these schemes are being used to warrant enterprises which would not need to be guaranteed in principle. A sustainable scheme should have a default rate lower than $3 \%$, although higher default rates can be projected in the early years of operation for programmes in emerging economies (Levitski, 1997).

\section{Develop local equity markets}

Investment capital is missing in the context of Mexico, and this concerns both debt and equity finance. In the domain of debt finance, national and state authorities should apply longer-term repayment period in their medium-size loan programmes (e.g. the SME Productive Project at the federal level). However, where most needs be done is in the domain of equity capital, which is utterly latent in the context of Mexico. Whilst not every region can be like the Silicon Valley in California, it is true that there are pretty much anywhere in a country business opportunities where to invest, which needs equity investment to unfold their growth potential but whose growth is hindered by too high a debt/equity ratio.

National and local governments can both set up public VC fund to stir up equity markets, a strategy that is valuable especially when equity investment is at a very embryonic stage like in Mexico. But what justifies government intervention in equity markets are mainly information barriers between investors and entrepreneurs. The former can be hesitant to make public their investment intentions, whereas the latter are often reluctant to relinquish equities and lose full control of ownership and management decisions. Local governments can lower these barriers by encouraging the establishment of business angel networks and by strengthening the investment readiness of local entrepreneurs.

Business angels are wealthy people, often former entrepreneurs, who are ready to invest "informal" equity into new or growing firms but also to give management advice. They are also a vehicle for entrepreneurs to potential clients, service providers, and senior lending or equity institutions. From a local economic development point of view, business angels feature some advantages besides VC schemes. Namely, they wield a lower level of control and allow more time for the investment to come to maturity and they operate locally where they can more easily follow the investment.

The public support of business angel networks can take place in different manners. Firstly, it is important to create a critical mass of business angels potentially interested in investment, for instance, by gathering information about local investment opportunities and by initially offering the opportunity to be only a "knowledge angel", who only passes his/her expertise without necessarily making a capital investment. Secondly, because there are operational costs associated with keeping up a network of investors, local governments may consider subsidising administration costs to give an incentive for business angels to keep operations running. Thirdly, policy makers can provide investment training. Wealthy people may lack an adequate understanding of the investment process and be unable to bargain acceptable conditions with entrepreneurs. Investor education can become a key factor in turning wealthy individual into business angels.

On the demand side, investors often complain that business proposals are not solid enough to receive equity finance, something that has been heard also in the two visited states of Morelos and Queretaro. State and local policy makers could work on improving the investment readiness of entrepreneurs. Key features of investment readiness schemes include interactive workshops based on role-play exercises and delivered by experienced industry experts (e.g. lawyers, accountants, business angels, etc.), bespoke consulting 
services, and investment-readiness diagnostic tools that enable firms to understand their strengths and weaknesses, whether they operate in a growing sector, whether their products or services are innovative, and whether they are actually willing to relinquish equities. It seems that a similar initiative could be well framed within Mexico's business accelerator programme that targets growth-oriented firms (i.e. gazelles). 


\section{References}

Beck T., A. Demirgüç-Kunt, and V. Maksimovic (2008), "Financing Patterns around the World: Are Small Firms Different?", Journal of Financial Economics, 89 (2008), pp. 467-487.

Ferraro C. and E. Goldstein (2011), Políticas de Acceso al Financiamiento para las Pequeñas y Medianas Empresas en América Latina, Documento de Proyecto, CEPAL, Santiago de Chile.

Garrido C. (2011), Nuevas Políticas e Instrumentos para el Financiamiento de las PYMES en México: Oportunidades y Desafíos, Documento de Proyecto, CEPAL, Santiago de Chile.

Green A. (2005), Combining Strengths: Synergies between Cluster Development and Microfinance, SME Technical Working Paper n. 14, UNIDO, Vienna.

Levitski J. (1997), “Credit Guarantee Schemes for SMEs: An International Review”, Small Enterprise Development, No. 2.

OECD (2010a), High-growth Enterprises: What Governments Can Do to Make a Difference, OECD Publishing, Paris.

OECD (2010b), Facilitating Access to Finance: Discussion Paper on Credit Guarantee Schemes, www.oecd.org.

OECD (forthcoming), Local Policies for Entrepreneurship and Small Business Development, OECD Publishing, Paris.

Stiglitz J. and A. Weiss (1981), "Credit Rationing in Markets with Imperfect Information", The American Economic Review, Vol. 71, No. 3, pp. 393-410. 


\section{CHAPTER 6 \\ BUSINESS ENVIRONMENT}

\section{Introduction}

Business environment refers to the surrounding conditions, either national or local, that affect business performance. Two broad categories of variable are taken here to comprise it: product market regulations (PMR) and the rule of law. The former includes barriers to entrepreneurship (administrative burdens, competition issues, etc.), hindrances to trade and investment, and the degree to which the economy is government-controlled. The latter refers to contract enforcement, economic informality, and crime. Not all these elements are relevant at the local level; the degree of government control over the economy is, for example, centrally managed. So are the tax and social contribution regimes, although local governments may be allowed to raise additional taxes on companies active within their territorial jurisdiction.

Figure 6.1. The local business environment

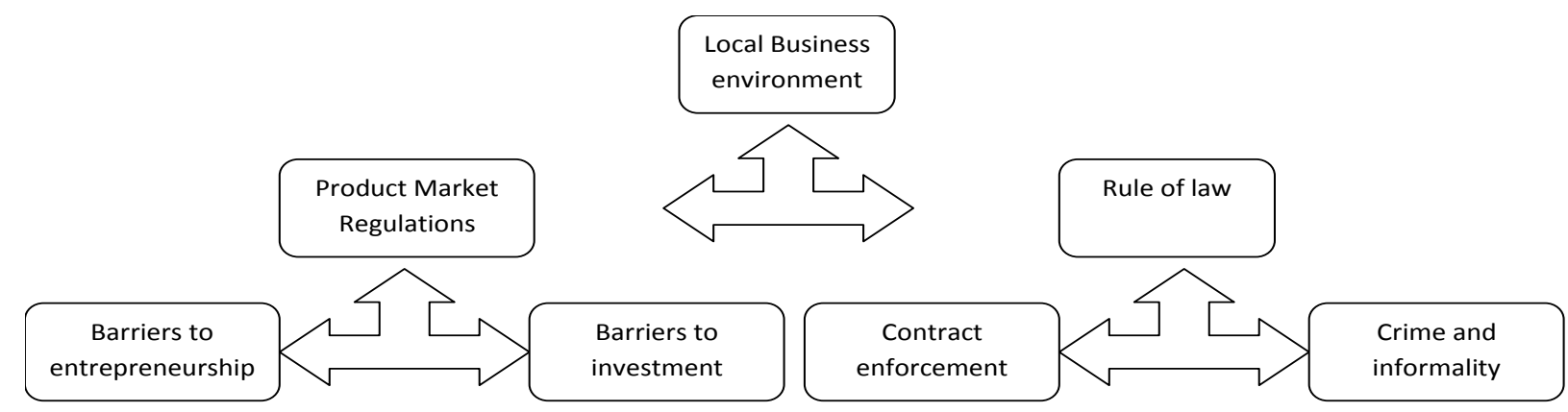

Source: Own elaboration

Particularly relevant for this chapter are "barriers to entrepreneurship" (i.e. regulatory and administrative opacity, administrative burdens on start-ups, and shortfalls in competition) and the impact of informality on regular firms.

Barriers to entrepreneurship refer to the cost of starting up a business in terms of time and financial resources, as well as to the impact of government regulations on business development. The lower the registration cost and the faster the registration process, the easier for an entrepreneur to set out an activity. Similarly, the easier is property registration and the stronger are property rights, the greater is the incentive and protection granted to entrepreneurs (De Soto, 2000). Competition policy is the domain of rules and regulations that sets a limit to market power by incumbents and facilitates entry by newcomers, facilitating in this way the entrepreneurial process of creative destruction. 
Informality undermines the development of new and small firms that respect business regulations and that suffer the competitive threat of enterprises complying only in part with the same rules. Especially in emerging economies where informality is widespread, entrepreneurs often quote informal enterprises as one of the main competitive threats to their business. ${ }^{14}$ Informality is not only a symptom of low productivity, but also a cause of it. Informal firms may be forced to camouflage part of their activity, thus restraining their growth. They invest less than formal enterprises in innovation and workforce training, both of which are drivers of business development. And they are less likely to draw on government support through public programmes or public procurement (OECD, 2011a).

This chapter proceeds with an assessment of the business environment of Mexico and of the two states of Queretaro and Morelos, keeping the focus on business regulations and informality. An analysis of the policies and programmes aimed at improving the business environment follows, including an overview of business regulations in Mexico, of strengths and weaknesses of the SME Fund - the main source of federal funding for entrepreneurship and SME policies - and of Centros Mexico Emprende (CMEs). Policy recommendations complete the chapter.

\section{Assessment of framework conditions}

\section{Product markets are getting more open, but more needs to be done}

With a number of key markets commanded by monopolies and oligopolies, including energy and telecommunications, Mexico is not an easy place to do business. This view is corroborated by the World Bank Doing Business surveys, which show that in spite of recent strides in making business regulations simpler, Mexico is comparatively loosing positions in this specific ranking. Thus, Mexico is making slower progress than other countries, including in the Latin American region. Three themes of the World Bank's Doing Business surveys appear relevant to this report, as they have emerged during the study visit of the OECD international review panel: $i$ ) starting-up a business; ii) construction permits; iii) property registration.

As regards the start-up process, Mexico currently ranks $75^{\text {th }}$ worldwide (2012) whereas it was $66^{\text {th }}$ in 2011. This is the result of no improvements over the last year, whereas other countries have outpaced Mexico in the same timeframe. A better picture of progress in Mexico is, however, given by looking at a longer spell. In the period of 2004-2012 the number of procedures to start up a business has dropped by one/third, from 9 to 6 , the number of days has plummeted from 58 to 9 , and the cost as a percentage of income per capita has passed from $17.6 \%$ to $11.2 \%$ (World Bank, 2012). In all of these indicators Mexico does better than the average of the Latin America \& Caribbean (LAC) region, although it is never the regional leader, a role that at the aggregate level is due to Chile.

Property registration is, on the other hand, an area where there have not been substantial improvements recently. Number of procedures (7), number of days (74) and cost as a percentage of property value (from $5.4 \%$ to $5.3 \%$ ) have remained stable over the period 2005-2012. Mexico ranks today fairly poorly in this indicator, $140^{\text {th }}$ out of the 183 surveyed countries, with Chile being again the leader in the LAC region (World Bank, 2012). As will be seen later in the chapter, however, there are some interesting developments both at national and state levels.

14. An overview of the feeling of entrepreneurs towards informal competitors is available in the country enterprise survey of the World Bank, www.enterprisesurveys.org. 
The OECD Product Market Regulation (PMR) indicators confirm that business regulation is burdensome in Mexico, and this is mainly due to high barriers to entry, investment and foreign ownership, especially in industries such as telecommunications, transport and electricity.

Figure 6.2. Product Market Regulation (PMR) in a sample of OECD countries, 2008

Scale of indicator is $0-6$ from least to most restrictive of competition

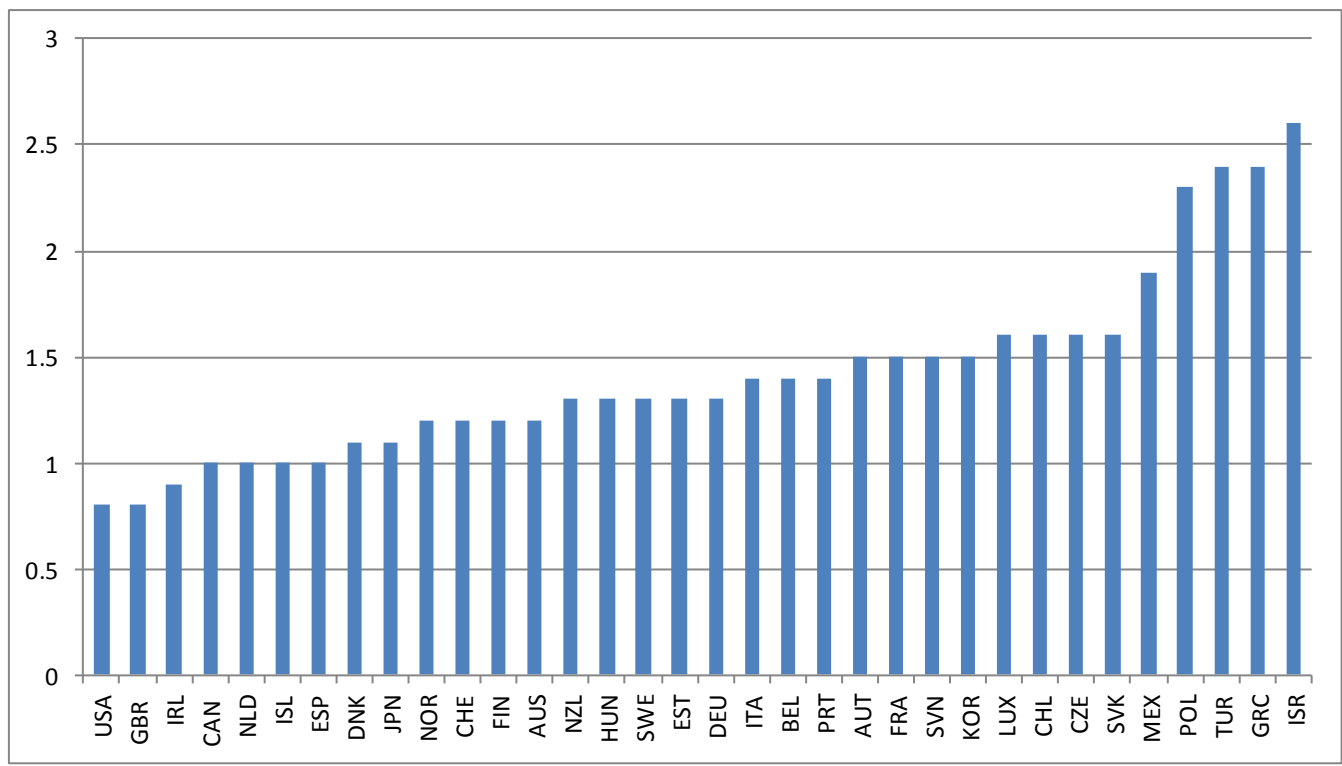

Source: OECD PMR Database

All sectors taken together, entry costs as a percentage of GDP per capita are twice as high as the OECD average, which is an incentive for entrepreneurs to stay in the informal economy. Small firms spend more days than medium and large companies to obtain operating licenses and construction permits, whereas the tax system is felt as a major constraint mainly by medium-size companies (World Bank, 2010). The latter could also be the result of larger tax evasion by small enterprises.

\section{State-level analysis}

At the state level, the business environment of the two states of Morelos and Queretaro in Central Mexico has been assessed through interviews with local policy makers aimed at filling out a set of selfassessment indicators. The latter cover three areas: $i$ ) ease of doing business; ii) SME institutional framework; iii) business support infrastructure. In the first domain Morelos outperforms Queretaro, especially with regard to number of days for business registration and ease of request of administrative information. It takes less than 3 days to register a business in Morelos thanks to the implementation of the SARE (i.e. Sistema Rápido de Apertura de Empresas), the federal rapid system for business start-up, whereas in Queretaro it can take up to 20 days. Moreover, Queretaro lacks an integrated electronic system where different government authorities can access information about SMEs without asking business owners each time. This is opposite to Morelos, where administrative information about a firm can be sourced online by public authorities at any time. In other "doing-business" indicators such as the presence of a one-stop shop, business registration's cost and number of procedures, and time to obtain licenses and permits, the two states performs more homogenously and fairly well. There are, for example, one-stop shops for business start-ups in both states, the time to obtain permits and licenses equally ranges between two weeks and two months in Morelos and Queretaro, and the business registration process is quite streamlined on account of an average of only two visits at the one-stop shop to become an operative firm. 
With regard to the SME institutional framework, both visited states fare similarly well. They both have a clear strategy, informed by local stakeholders, with the corresponding state economic development secretaries (SEDECO in Morelos and SEDESU in Queretaro) that lead the strategy-making process. There is not, however, an agency devoted to SME policy implementation in either state, which is the result of policy being delivered by a network of private intermediary organisations. Similarly, there is a lack of real evaluation of SME programmes other than the monitoring of outputs (e.g. number of firms attained, resources spent, etc.). Furthermore, compared to SME policy, there appears to be less of coordination between the federal and state levels in the attraction of foreign direct investment (FDI). Here, the national government in Mexico City only deals with custom duties and formalities, while states are the main responsible for FDI attraction and supply-chain development. This sometimes results in beggar-thyneighbour competition amongst close-by states, as witnessed by Queretaro and Guanajuato recently competing through subsidies for a large investment by a multinational carmaker that decided to settle in Guanajuato. The problem with beggar-thy-neighbour strategies is that they entail a benefit for the winning party only in the short-term, while in the long term all parties lose. It is therefore recommended that better coordination be put in place between the federal and state governments to avoid price-based competition amongst states in FDI attraction.

Finally, the business support infrastructure is relatively weak in both states in the sense that: $i$ ) a database of the range of BDS available to firms is either not kept (Queretaro) or kept but not shared with local firms (Morelos); ii) there is not a standard evaluation of intermediary organisations delivering SME programmes (Queretaro) or evaluation is only done through surveys of beneficiaries (Morelos).

On the whole, our conclusion is that there are differences in business environment and business support infrastructure amongst states within Mexico and that, as far as the two visited states are concerned, Morelos does slightly better than Queretaro in this field. This may be in part related to the industry structure of the two states, as Queretaro is largely an industrial state, dominated by big manufacturing companies, while Morelos, thanks to its proximity to Mexico City, is an economy driven by services where entry barriers are lower and start-up rates higher.

\section{Informality is still widespread}

Business density (i.e. the number of business per population in thousands), a common indicator of entrepreneurialism, is only 45.7 in Mexico, whereas it hovers around 80 in the United States and is approximately 87 in Italy, one of the EU's most entrepreneurial countries. This flags two problems: low entrepreneurialism, on the one hand, but also high informality on the other, for a figure roughly half that of the United States disguises a number of firms that operate without being recorded in any registry.

The size of the informal economy is by definition difficult to measure because a firm that exerts in partial or total incompliance with the law has an interest in hiding itself from any authority, including statistical ones. Nevertheless, an estimate by the UN International Labour Organisation (ILO) reports that $43.8 \%$ of Mexico's population is without pension and/or health coverage, a figure that ranks the country behind other main Latin American economies (Argentine, Brazil, Chile and Colombia). As mentioned, informality is not only a symptom but also a cause of low economic development (second chart). According to World Bank estimates, a $10 \%$ increase in the tax and social security evasion rates would result in a reduction by $7 \%$ in labour productivity and $10 \%$ in total factor productivity (World Bank, 2007). 
Figure 6.3. Informality in the Latin American region

Informality = share of population without pension and/or health coverage

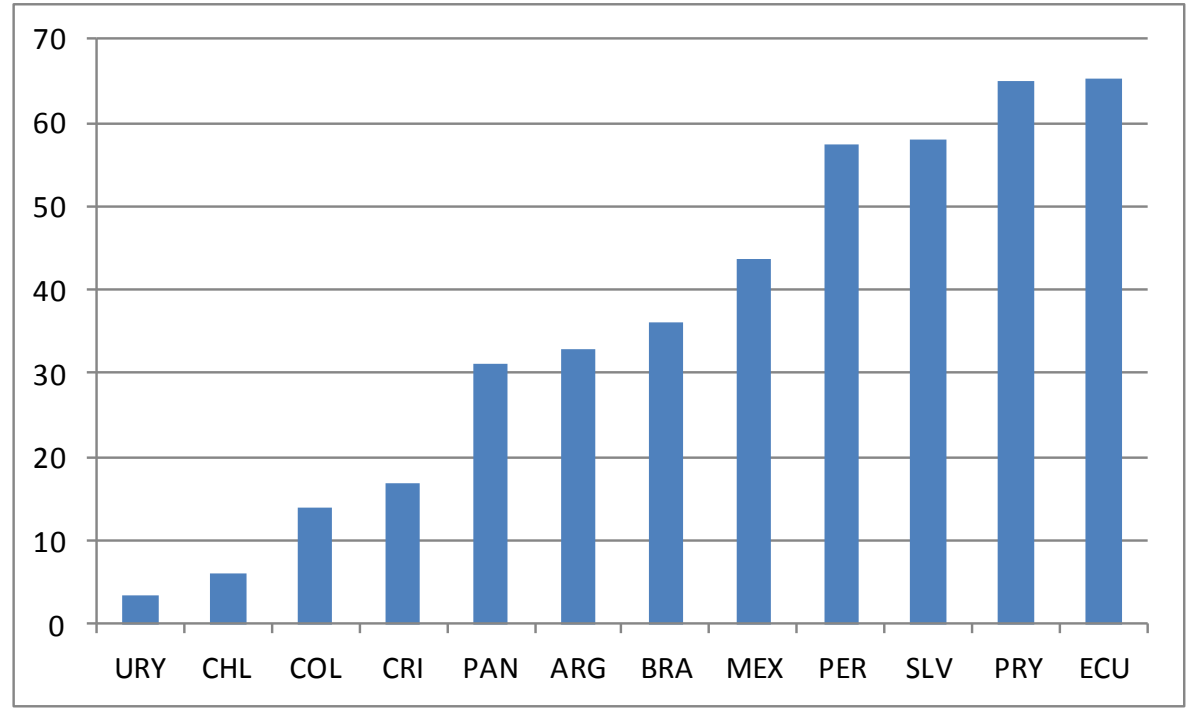

Source: OECD, 2011a

Figure 6.4. Informality and economic development

Informality measured as per Schneider et al. (2010)

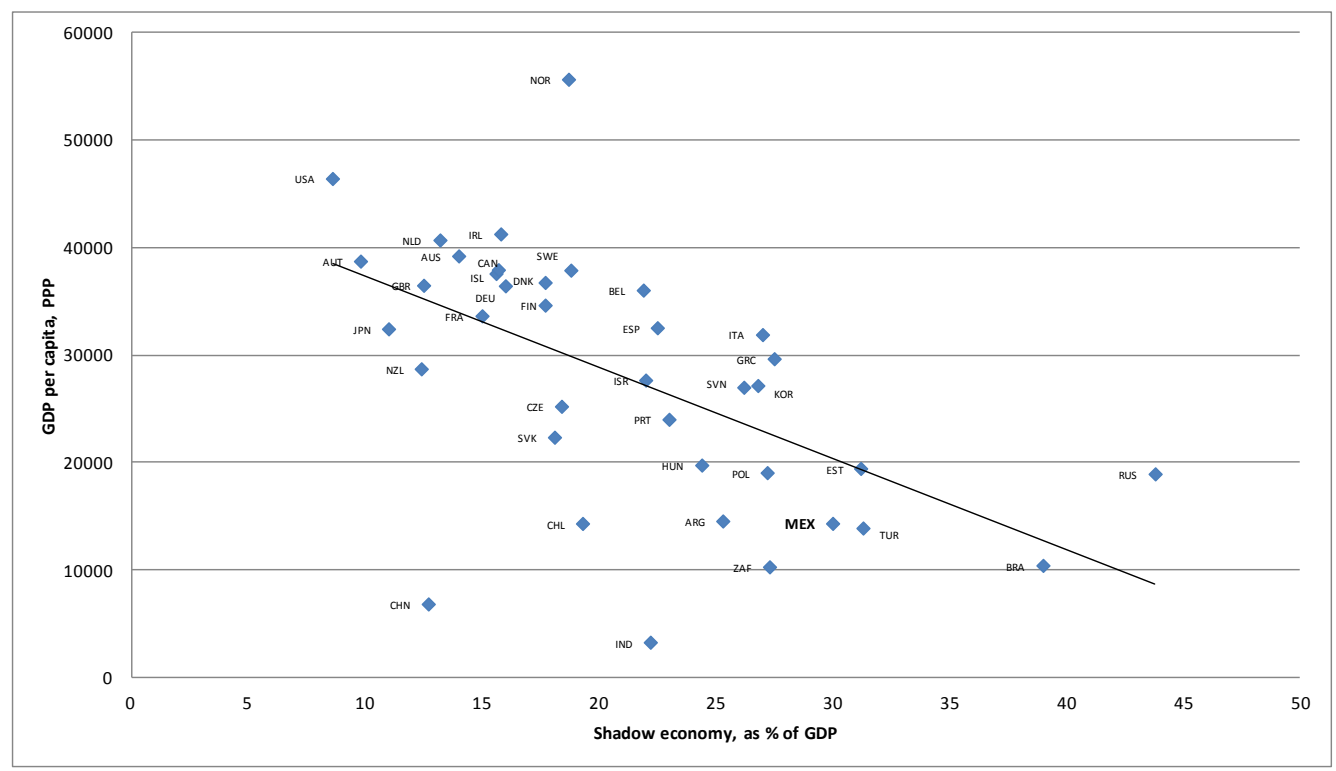

Source: OECD, 2011a

At the firm level, $20 \%$ of new small firms start operations in Mexico without business registration and remain informal for a period of approximately 2 years. Nearly $40 \%$ of medium-sized firms perceive firms in the shadow economy as a major constraint to development (World Bank, 2010). Two caveats are, however, necessary. First, the divide between formal and informal firms is less neat than commonly thought, as registered companies may draw on informal ones as suppliers to drop production costs. Second, 
while informal businesses still represent a competitive threat, they nevertheless display a $30 \%$ gap in perworker productivity compared to formal firms, even after controlling for firm size, sector, and region (World Bank, 2007).

It has not been possible to establish whether there is any difference in the size of the informal economy in the two states of Morelos and Queretaro. What can be said is that business density is higher in Morelos (57.8) than in Queretaro (42.2), but this is to a large extent related to Morelos being a services economy where entry barriers are low, whereas Queretaro is a manufacturing economy with a strong presence of heavy industries (e.g. automotive and aeronautics).

\section{Assessment of policies and programmes}

\section{Business regulations are being streamlined at swift pace at every level}

The previous section has shown that regulatory barriers to entrepreneurship and SME development are high in Mexico, but that strides have been made during the last ten years. This has been the outcome of tight co-operation between different levels of government, for business regulations fall within the remit of federal, state and local governments, making co-ordination and collaboration more than ever crucial for success. In Mexico this has mainly taken the form of co-ordination between the Federal Commission for Regulation Improvement (COFOMER) and the equivalent state commissions (CEMER) that have been set up in fifteen of the thirty-one states of the country.

At the federal level, the government has carried out regulatory impact assessment (RIA) on new legislation since 2000, but it has more recently rationalised its activity focusing only on new rules and regulations with major impact on business activity. In the specific area of competition policy, moreover, the Federal Commission for Competition (CFC) collaborates with the OECD in the application of guidelines intended to make key markets such as consumer credit, pharmaceuticals and telecommunications more open to competition.

With regard to start-ups, the central government has launched an online one-stop shop portal (www.tuempresa.gob.mx) where entrepreneurs can find all relevant information about the start-up process. It has also implemented with the collaboration of municipal governments the Rapid System for Business Registration (SARE - Sistema Rápido de Apertura de Empresas) which, according to some estimates, has resulted in between 4\%-8\% of additional business registrations and 12-19 additional jobs per month and per municipality (Kaplan et al, 2007). SARE has lowered the costs of formalisation (e.g. by making the presence of a notary unnecessary), providing an incentive for entrepreneurs to operate in the regular economy. Based on the OECD LEED study visit this seems to be especially true for new businesses with a corporate legal status, whereas sole-proprietor firms appear to have been less touched by this reform.

State-level analysis

The commitment of states to regulatory improvement has been heterogeneous, with some states setting up a dedicated state commission (CEMER) equivalent to the federal COFOMER, whereas others have delegated the same functions to a unit integrated in the state department for economic development (i.e. SEDECO). The first option may present some advantages compared to the second in light of bigger autonomy, including through a dedicated budget, with which independent commissions are generally granted (García Villareal, 2010). Fifteen states have so far decided to establish their own CEMER, including Morelos, whereas Queretaro has kept the responsibility for the simplification of business regulations within its ministry of economic development, named SEDESU (Secretary for Sustainable Development). 
The CEMER of Morelos has been very proactive, introducing SARE in 8 municipalities of the state. This has allowed businesses that do not present social or environmental risks to set out operations in less than 72 hours. Since then there has been an increase in the number of start-ups in Morelos, although a cause-effect relationship cannot be established due to the impact of the economic cycle on business creation.

The public registry of business property, once one of the most obsolete in the country, has been made electronic and accessible online, enabling public authorities and private citizens to check information through the Internet instantly. Today, Morelos's public registry is the second most modern of the whole country, whereas it was ranked $28^{\text {th }}$ until a few years ago. Interestingly, this advancement has been the outcome of collaboration between CEMER and the local polytechnic university at no cost for state authorities, as the system has been digitalised by students as part of their work towards completion of the degree. The CEMER of Morelos estimates that the digitalisation of the registry has made it possible savings for local firms in the range of MXN 14 million.

Reforms have also interested construction permits, with a new rule that enables some types of microenterprise to expand their business up to 200 square metres, from the previous limit of 50 square metres. This change in state legislation has mainly favoured micro businesses owned by disadvantaged social groups.

Regulatory impact assessment (RIA) is carried out by CEMER-Morelos for every new law promulgated by the state government, which has permitted streamlining many services such as business licenses and permits. However, with a staff of only 17 people, this body should probably concentrate only on the acts and rules with the greatest potential impact on enterprises, in the same guise of COFOMER at the federal level.

Finally, Morelos's authorities are trying to make progress also in the area of labour conciliation, where trials opposing business owners and workers can take up to one-and-a-half year to be judged. Morelos has been one of the first states to introduce oral hearings for criminal trials, which replace Mexico's traditional trials based on written communication, and is planning to do the same in the near future for trade-related and labour trials.

\section{The SME Fund: pros and cons of the main source of entrepreneurship and SME policy support}

With a total budget of USD 550 million, the SME Fund is by far the main source of federal funding for SME and entrepreneurship policies. It targets five different categories of company through an integrated portfolio of support including finance, training, commercialisation, etc. The five target groups are: i) nascent entrepreneurs, i.e. people who want to start a business but have not yet done so; ii) microenterprises, many of which are at least partly informal; iii) Small and medium enterprises (SMEs), mainly attained through the network of Centros Mexico Emprende (CME); iv) gazelles (i.e. technologybased firms able to grow swiftly over a short period of time), primarily targeted through internationalisation strategies geared towards the integration of global supply chains; v) tractors, which are leader companies able to trickle growth benefits down a local supply chain.

\section{An articulated and targeted tool}

Through its five target groups, the SME Fund holds a comprehensive and tailored approach to entrepreneurship and SME policy, each of the five groups being addressed through a specific programme.

- Nascent entrepreneurs are targeted through the National Programme of Entrepreneurship, which provides for a combination of incubation services and seed capital. Seed capital (i.e. capital 
semilla), through subsidised loans, is granted only to firms which have graduated from the incubation programme. ${ }^{15}$

- Microenterprises are addressed through the series of MI programmes (MI Tortilla, MI Tienda, MI Panadería, etc.), which encourage the technological upgrading of these firms through the purchase of new equipment and the replacement of old ineffective ones. An implicit objective is here to induce the formalisation of Mexico's large informal sector.

- $\quad$ SMEs are mainly taken care through the Mexico Emprende Centres (CME), a wide network of 71 centres and 140 stands available in over 100 cities. These centres are located at the offices of intermediary organisations such as business associations and chambers of commerce. They are one-stop shops for local SMEs to receive specialised and integrated services, either directly by the intermediary hosting the centre or by contracted external consultants. An implicit mission is to strengthen the local rooting of employer associations and chambers of commerce. ${ }^{16}$

- Gazelles, i.e. fast growing firms, are primarily served by business accelerator programmes. Through this scheme they receive technical assistance for business internationalisation. Training and advice involve certification, linkages with universities, supplier opportunities, and outward FDI.

- "Tractors", which are leader firms either national or international, are finally assisted in setting out their activity in Mexico, e.g. in a technology park, and in the development of local supply chains. They are not necessarily large firms, but rather companies able to contract out work to local suppliers.

\section{Flexible governance arrangements}

The SME Fund does not deliver its programmes directly, but exclusively through local intermediary organisations. Intermediaries apply for any of the programmes managed by the Ministry of Economy and are allocated funding to deliver services to firms. Most intermediaries are private not-for-profit organisations (e.g. chambers of commerce, business associations, etc.), but state organisations can also act as intermediaries.

The disbursing process follows a three-step approach: i) a local organisation presents a project proposal to the state; ii) the states examine the proposals through a dedicated commission and present the most valuable ones to the Federal Ministry of Economy; iii) the Federal Ministry selects the projects and disburses the funds through the states to local intermediaries.

It is therefore a competitive process that involves the federal government, state authorities and local organisations, which can range from chambers of commerce to universities, from business associations to NGOs. As the first screening of projects is done by state governments, the use of the SME Fund is aligned with the strategic needs of the single states. Local policy makers therefore can tweak the structure and objectives of the Fund to the needs of their states.

A possible drawback is that too many levels of intermediation - e.g. when a local intermediary does not deliver the policy directly but through consultants - will raise the overheads of the projects, thereby

15. There are 500 incubators in the whole of Mexico, which are divided by the Ministry of Economy in traditional (217), medium technology-based (262), and high-tech (21). Many incubators, especially the traditional ones, serve not only the manufacturing industry but also services.

16. A very large majority of centres (63) are hosted in the premises of CONCANACO (Confederation of Chambers of Commerce), COPARMEX (Mexican Employers' Association), and CANACINTRA (National Chamber of Manufacturing Industry). 
reducing the resources spent in support of client firms. Similarly, the 1:1 rule - i.e. for each peso of the federal government, one "matching" peso by the state government - could impair the poorest states and favour the most developed ones.

\section{Leadership and accountability by the Ministry of Economy}

The SME Fund emerges at both the national and local level as a tool conceived and implemented by the Federal Ministry of Economy, which leads the process both in the stages of design and implementation. The Ministry of Economy is the body behind the elaboration of the five target groups as well as of the concrete programmes supporting such groups. And the same Ministry is also the final decision-maker about the projects submitted by local intermediaries through state governments, although the latter make a first screening. ${ }^{17}$

The presence of a leadership by the Ministry of Economy enables the Fund to express clear strategic orientations. For instance, the allocation of funds casts light on how small and medium firms are the main target groups, mainly thanks to the credit guarantee programme that attracts $40 \%$ of the total budget. However, thanks to a governance system drawing on state governments and local intermediaries, national leadership is exercised without prescribing the states for what the SME Fund's resources should be used.

Leadership is also key to the accountability of public resources. As the disbursement of resources occurs at federal level, the Ministry of Economy is in a position to account for the use of taxpayer's money in each single project approved. Of course, the drawback is that a centralised system can make the process lengthy. Indeed, a very common complaint by intermediaries has been the late payment - i.e. usually last quarter of the year - of the approved funding.

\section{Heavy administration}

Whilst the effort in transparency and accountability is remarkable, it is making the use of the SME Fund increasingly tangled for local intermediaries. This point has been reiterated during the study visit and concerns different stages in the use of the SME Fund: i) bottlenecks in the online application process due to a standard application form, regardless of the legal nature of the applicant; ii) standard rules regardless of the sector and size of the firm (e.g. the obligation for each supported firm to create four jobs); iii) late disbursement of agreed funding (generally, last quarter) and obligation to use the received resources within the same year of obtainment; iv) tight and repeated reporting requirements. This is partly the price to make sure that public resources are used correctly, but a better balance between accountability of public resources and lean administration needs be stricken.

\section{Lack of real evaluation}

Considering the sizeable amount of the SME Fund, it is surprising that there is little evaluation of the Fund and its results beyond mere outputs such as resources spent, number of SMEs attended, etc. Some local intermediaries have carried out surveys of beneficiaries for specific projects, but independently of the Federal Ministry of the Economy. The only real outcome reported concerns job creation and job preservation, based on the number of people employed by the recipient firms before and after the public aid. But the job creation requirement seems to be often bypassed in the reality through bogus hiring. More generally, the Fund would probably benefit from a focus not only on job creation/preservation, but also on the quality of jobs being created (e.g. skills profile, salary levels, etc.).

17. The decision-making role of the states varies depending on the specific programme. It is, for instance, more important in the cases of capital semilla and the SME Productive project where the selection of candidates is done directly at the state level. 
A more rigorous evaluation of the Fund would enable national policy makers to take better stock of what works and what doesn't so as eventually to readdress policy priorities. Currently, despite the presence of five target groups, micro firms in services are being prioritised in light of their number and the urge to formalise further the Mexican economy, together with SMEs through the credit guarantee programme. But as Mexico advances its economy, the federal government might ponder whether to earmark more resources on innovation programmes backing the creation of added-value and the integration of supply-chains, such as those currently addressing gazelles and 'tractors'.

\section{Policy dependency}

The wide recourse to intermediaries makes the governance of the SME Fund flexible and tailored to local development needs. However, it can also raise the cost of some policies and cause dependency on public policy support. The first case was especially evident in the case of financing policies, where the cheapest schemes for client firms in terms of interest rate and credit conditions were those directly managed by SEDECOs without drawing on any further external organisation.

The second case was most evident for repeated beneficiaries and for some specific institutions such as business incubators. As the SME Fund's rules are getting more complicated over time, entry barriers to the use of the Fund are on the rise. This holds back competition to the advantage of consolidated intermediaries who already master the Fund's mechanisms and who can apply higher administrative charges on their programmes. In the long term, this may cause dependency on public support for some intermediaries who draw more than others on the Fund.

\section{Centros Mexico Emprende (CME): A tool for strengthening policy outreach and policy tailoring}

Centros Mexico Emprende (CMEs) were introduced by the federal government as one-stop shops in 2008 to sponsor and deliver locally the schemes fuelled by the Fondo PYME. They arise as an important coordination mechanism between the federal government, which designs the policies, and the local intermediary organisations, which deliver them. CMEs are the initiative that more than any other relies on intermediary organisations, chiefly local branches of national chambers of commerce and employers' organisations such as CANACINTRA, CONCANACO, and COPARMEX. The three together manages 63 of the overall 70 centres and 102 of the total 124 modules associated to CMEs. The main difference between centres and modules is that the former are bigger and furnish a broader range of services, whilst the latter are smaller units that reach out more remote localities. Funding comes in three/quarter from the federal government and amounts to MXN 100 million, while the remaining quarter is put by the intermediary organisations co-participating in the scheme. Based on the monitoring of the Ministry of Economy, in the last one-and-a-half year (2010-mid 2011) CMEs have supported 43000 SMEs and 25000 nascent entrepreneurs.

The rationale for this extensive programme is manifold. Firstly, CMEs are an instrument for the federal government to attain SMEs and nascent entrepreneurs also in relatively peripheral areas and tailor public programmes to their specific needs. They are a tool of policy outreach and policy tailoring. Secondly, and in only apparent contrast with the previous point, CMEs are also an instrument to achieve a minimum degree of standardisation and certification in the supply of business development services (BDS), as proven by the standard training in business consulting that the staff of the centres receives. Thirdly, CMEs are conceived not only to avoid crowding-out effects towards private BDS providers, but also to enhance their role by tasking them with the delivery of policies.

The CME initiative has definitely points of strength, but also a few shortcomings. The main merits refer to what has been presented as the rationale of the programme. Policy outreach and policy tailoring, as well as the support of intermediary organisations charged with policy delivery, can be deemed positive 
features of the scheme. Moreover, CMEs appear relevant to the formalisation of the shadow economy, for they can be used to advertise public programmes that increase the incentive for entrepreneurs to formalise their activity.

However, there are also elements that need reconsideration. First of all, large incumbent employer associations and chambers of commerce are strongly favoured in the implementation of the scheme, and it is not clear the extent to which CMEs subsidise part of their operational costs. The fact that in Queretaro CME funding was partly used to refurbish the local premises of one of the big three intermediary organisations seem to confirm this concern, together with the view of policy makers in Mexico City looking at CMEs expressly as a tool to enhance business associations and chambers of commerce locally. There should be more competition in the allotment of funding, and the latter should be tied up more closely to client firms. Secondly, coordination amongst the different CMEs is only ensured through a common web portal where information on SME policy programmes is made available. However, there is not any consolidated exchange of information about practices in the different centres and modules. Thirdly, there is not a real evaluation of the initiative beyond the mere monitoring of the number of firms which have been referred to public programmes or some erratic surveys of firms that have benefited from a CME. But the problem of lack of evaluation transcends the CMEs and relate to most of Mexico's SME and entrepreneurship policies both at the national and local level.

\section{Policy recommendations}

Based on the previous analysis, the following recommendations can be formulated to strengthen the business environment in Mexico.

\section{Streamline and evaluate the SME Fund}

The use of the SME Fund is becoming increasingly tangled by accounts of most intermediaries. This responds to the government need of accountability in the use of public resources, but there is nevertheless room for streamlining some details that govern the Fund. The application form could be adapted to the legal status of the applicant; the job creation requirement, which does not make much economic sense and is often bypassed through loopholes in the reality (e.g. bogus recruitments), could either be abolished or at least bespoke to the size and sector of the recipient firm (e.g. knowledge-intensive businesses in manufacturing generate less jobs than in services); the payment of project money could be made faster by involving more closely the state delegations of the Federal Ministry of Economy, currently cut off from the selection and disbursement process; and reporting requirements could be made less demanding, for instance grouping them quarterly or biannually.

Given the size of the SME Fund, it is surprising that there is not a real evaluation of its results. Are the Fund and its programmes being effective in attaining their goals, not only in terms of outputs (e.g. hours of training delivered), but also of outcomes (i.e. people obtaining a new or better job)? Is the Fund being efficient in the use of its resources, compared to possible policy alternatives? Is the Fund being "additional", generating outcomes that would not be possible without public support? These crucial questions cannot be answered without a proper evaluation that goes beyond the views of users on the programme and its impact. At the very least, especially for programmes endowed with sizeable resources such as the credit guarantee programmes and the Mexico Emprende Centres, the evaluation should include comparison with a control group of matched firms, that is, firms similar to those receiving support (e.g. firms that made it to the final stage of the selection process but were not chosen for assistance). Differences-in-differences techniques, which compare the conditions of the beneficiaries before and after support with a matched control group over the same time period, are particularly suited for policy evaluation and are yet relatively inexpensive exercises. 
We provide the example of the credit guarantee programme, whose evaluation appears overriding given the resources it absorbs. Its impact should be assessed against its key objectives, i.e. levering business loans from commercial banks, improving access to finance amongst SMEs, and strengthening the performance of SMEs using guarantees. These parameters could be assessed in three groups, i.e. firms that receive the guarantee (i.e. treatment group), similar firms that are excluded only on the basis of limited public resources but that would otherwise be worth of support (i.e. control group), and firms that are not deemed creditworthy and are, therefore, sidelined by programme management (i.e. typical group). A panel survey comparing these three groups over two time periods (pre- and post-intervention) would be appropriate to evaluate the impact of credit guarantees on SME's improved access to finance and business performance (Storey, 2008).

Evaluations applied in a similar fashion to other key programmes financed by the SME Fund would enable federal and state governments to understand the strengths and weaknesses of their policies, leading to adjustments and even a possible strategic re-orientation of Mexico's SME and entrepreneurship strategy.

\section{Continue working on the simplification of business regulations}

The chapter has brought out that national and state governments have made progress in making business regulations simpler, reducing for example the time and cost of business entry through SARE, the rapid system for business start-up. At the same time, World Bank's and OECD's surveys and indicators confirm that doing business is still difficult in Mexico, also comparatively with countries in the same region. It takes, for instance, still considerable time and resources to obtain permits and licenses, and trade and labour trials remain a lengthy and painful process for entrepreneurs. Further reforms are necessary in these areas through close collaboration between federal and state governments in the same guise as SARE, which is a success story.

Given its status of good practice, SARE should be introduced in as many localities as possible. It makes the process of business start-up much faster than in the past, but it has been introduced as yet only in the main municipalities of each state. A greater geographical outreach would lower the cost of business registration also in more peripheral areas, contributing to the formalisation of the Mexican economy.

Similarly, state commissions for regulation improvement (CEMER) have hitherto been established in fifteen of the thirty-one states of Mexico. For example, Morelos is endowed with one, while Queretaro is not. Setting a similar commission, a decision which falls within the remit of state governments, would grant greater autonomy and political independence to policy makers working on the theme. In brief, it would stress the importance given by state authorities to the simplification of business regulations.

\section{Fight economic informality through a wider range of tools}

Large swaths of informality blight the economic prospects of Mexico. The simplification of business rules (see above) goes towards economic formalisation, especially for firms with a corporate legal status, as does the reduction of social charges for employers (e.g. childcare and housing benefits) and their merge with equivalent tax-financed services for the general population (OECD, 2011a).

In addition to strengthening business density (more new firms), Centros Mexico Emprende have also a potential role in encouraging business formalisation (more regular firms) locally. In acting as a signpost for government programmes, CME could allure informal enterprises in the regular economy through participation in public programmes and the related incentives. However, the current management of most of these centres by the three largest employer associations and chambers of commerce hampers this task, insofar as the managing organisations will have an interest in catering for their associate members, rather than to target small firms on the brinks of the formal economy. In fact, the latter are even likely to be seen 
as competitors of their membership. Involving more and different intermediaries in the implementation of the CMEs can help overcome this stumbling block.

Finally, more needs to be done in the area of labour inspection, a matter that has not emerged forcefully during the OECD LEED study visit. Inspections should not target micro firms, whose formalisation is better prompted through programmes such as Mi Tortilla and Mi Tienda that provide selfemployed and micro firms with financial incentives for small-scale modernisation, but rather those enterprises that act as first- or second-tier suppliers in supply chains led by so-called tractor companies. Tractors and suppliers, directly or indirectly, often benefit from public support (e.g. through the business accelerator programmes), so it makes sense to expect them to be in full compliance with rules and regulations, certainly more than it does to pretend the same from micro-enterprises struggling to make ends meet. 


\section{References}

De Soto, H. (2000), The Mystery of Capital: Why Capitalism Triumphs in the West and Fails Everywhere Else, Basic Books, New York.

García Villarreal, J. P. (2010), "Successful Practices and Policies to Promote Regulatory Reform and Entrepreneurship at the Sub-national Level", OECD Working Papers on Public Governance, No. 18, OECD Publishing, Paris.

Kaplan, D., E. Piedra and E. Seira (2007), "Entry Regulation and Business Start-Ups: Evidence from Mexico", World Bank Policy Research Working Paper Series, No. 4322, The World Bank, Washington, DC.

OECD (2011a), OECD Economic Surveys: Mexico 2011, OECD Publishing, Paris.

OECD (2011b), Competition Assessment Toolkit, www.oecd.org/dataoecd/52/6/46193173.pdf

Schneider, F., A. Buehn and C. Montenegro (2010), "New Estimates for the Shadow Economies all over the World", International Economic Journal, Vol. 24, No. 4, Routledge Press, Abingdon, Oxon, pp. 443-461.

Storey, D. (2008), Entrepreneurship and SME Policy in Mexico, unpublished manuscript.

World Bank (2007), Informality: Exit and Exclusion. Latin American and Caribbean Region, The World Bank, Washington, DC.

World Bank (2010), Enterprise Survey: Mexico 2010, www.enterprisesurveys.org.

World Bank (2012), Doing Business. Economy Profile: Mexico, The World Bank, Washington, DC. 


\section{CONCLUSIONS}

This report has investigated the local dimension of entrepreneurship and SME policies in Mexico, focusing on policy coordination amongst different levels of government - mainly between the federal (national) and state (regional) levels - and policy tailoring, i.e. the extent to which federal and state policies are adapted to local development needs.

To this purpose, an international review panel made up of three experts and one staff member of the OECD secretariat has visited the two states of Morelos and Queretaro to interview state authorities and relevant stakeholders and understand the design and implementation of Mexico's entrepreneurship and SME policies at the local level. The selection of the two states has been made jointly by the OECD secretariat and Mexico's Ministry of Economy, namely its Undersecretary Office for SMEs, in light of the very different economic structure of the two states providing more scope for learning on policy adaptation to local needs.

Four thematic areas crucial to entrepreneurship and SME development have been more closely investigated by the review panel: human capital and skills; knowledge flows and innovation; access to finance; and business environment. Policy coordination and policy tailoring, being the main issues of the report, have been tackled both by a specific chapter of the report and horizontally by the other chapters with a narrower focus on their specific theme. The latter have, however, extended the analysis to include an assessment of the strengths and weaknesses of framework conditions and policies for human capital, innovation, access to finance, and business environment at state level.

The key findings of this analysis are summarised below:

\section{Key findings}

\section{Policy coordination and policy tailoring}

The main strategic document of economic policy and the main source of federal funding for entrepreneurship and SME policies in Mexico - respectively the National Development Plan and the SME Fund - have afforded for sufficient decentralisation, allowing for policy tailoring to local needs. In the case of programmes such as capital semilla or the SME productive project, for example, project applications have been pre-selected by state governments, which has permitted screening out projects not in line with state priorities or unlikely to survive without public support in the given local economic context. The largest national investments have always been preceded by a close dialogue between federal and state authorities. The co-funding mechanism, which provides for co-participation by the states in financing projects within their territorial jurisdiction, has further enhanced the principle of policy adaptation to local needs. And so have Centros Mexico Emprende (CME), an extended network of one-stop shops throughout the country where firms can obtain information about public policies and join government support programmes, and which has enabled the federal government to extend its outreach to peripheral firms. If anything, a more active role could be envisaged for the Ministry of Economy's state delegations, which are currently unable to diffuse relevant information about federal policies to local stakeholders and, therefore, to perform well their original mission of liaising between the national and local level. 
Policy formulation has so far been comprehensive, but not as participative as policy implementation. Comprehensiveness is warranted by the five target groups of Mexico's entrepreneurship and SME policy (i.e. nascent entrepreneurs, micro-enterprises, small and medium enterprises, gazelles, and tractors), which ensures that every category of business, from microenterprises in traditional low-tech activities to large companies leading local supply chains, is addressed by specific programmes (e.g. the Mi-schemes for microenterprises, CMEs and national guarantee fund for SMEs, business accelerators for gazelles, etc.). At the same time policy formulation could be more participative, involving key SME and entrepreneurship stakeholders not only in the stage of policy implementation but also of policy design. It should also be more proactive than has been so far, especially if it is to address long-term problems that entrepreneurs may not necessarily perceive engaged as they are with everyday business concerns. Significant upgrading in innovation, for example, calls for more than purely market-led solutions due to the uncertainty that surrounds the innovation process and the public-good nature of knowledge.

Policy delivery rests on a broad range of intermediary organisations, largely not-for-profit institutions like chambers of commerce, business associations and training agencies, but occasionally also public local authorities. A similar system has the main benefits of strengthening the market for private business development service (BDS) providers and allowing for specialisation and flexibility in the implementation of policies. Fragmentation and duplication of services, as well as excessive administrative costs associated with multiple layers of governance, are the risks to be aware of when a government runs a similar policy delivery system. Likewise, it is important that a proper management of the intermediary system be put in place, leading to some degree of quality certification, specialisation and complementarities of intermediaries. The network of Centros Mexico Emprende (CME) goes in this direction through the standard training in business consulting offered to the staff members of the centres.

The SME Fund is the key operational tool and main source of funding for SME and entrepreneurship policies in Mexico. It is conceived in such a way as to allow the co-funding and co-decision of projects by national and state governments, and this enables federal policies to be bespoke to the development wants of states. Its administration needs, however, streamlining whilst remaining accountable for the use of public resources. In particular, the project lifecycle could be made longer, moving from one year to two or three years; reporting requirements could be grouped and made less frequent, for example biannual rather than quarterly; they could also be more adapted to the legal nature of the recipient organisation and to the size and sector of the client firms; and the disbursement of project money could be more timely, as this would allow intermediary organisations to make a better planning of the project-related activities.

A stronger evaluation of the SME Fund beyond the mere collection of figures on inputs (e.g. resources spent) and outputs (e.g. firms attained) is also necessary. It would help federal and state government understand what works and what doesn't in their programmes, adjust them accordingly, avoid overlaps and duplication, and possible readdress the strategic orientations of national and local entrepreneurship and SME policies.

\section{Human capital and skills}

Within the OECD area Mexico is an underperforming country when it comes to education and skills performance. However, the reality is not homogenous and there are states where school attendance and workforce skills appear stronger than elsewhere. Morelos and Queretaro, the two visited states, both fall in the group of national leaders. Morelos, largely a services economy, harnesses its proximity to Mexico City, which makes it an attractive place for the headquarters of national and multinational corporations. This mainly boosts generic and semi-generic skills, such as those related to ICT. Queretaro, whose economy hinges on traditional industries, boasts manufacturing skills more specific to the sectors driving the local economy, such as automotive, aeronautics, and white goods. 
In Mexico vocational education and training (VET) has been developed mainly at the high-school level through the National College for Professional and Technical Education (CONALEP). Directly funded by the federal Ministry of Education, its courses are informed by the local industry and tailored to its needs. In Queretaro, for example, CONALEP has today four campuses delivering three-year programmes in which the last year is spent by the student in a local business enterprise. Since its inception in the mid1990s, the programme has proven successful in helping students enter the labour market in technical positions. Where, on the other hand, VET is weaker is at the university level, for only $2 \%$ of students in tertiary education undertake this path against an average of $15 \%$ in the OECD area. In the long run this can represent a barrier to industrial development, as tertiary VET is the main source of the skilled labour force that is crucial to improved collaboration of SMEs with knowledge-intensive companies and research organisations. This view is corroborated by local surveys that show how the lack of a skilled workforce is a major concern especially amongst medium-sized enterprises, which are often at the core of sector development in a locality.

There is a wide spectrum of universities in Mexico, both at the national and local level. At the national level there are the prestigious public National Autonomous University of Mexico (UNAM) and private Monterrey Technology Institute (ITESM), both at the cutting-edge of research in the whole Latin American region. UNAM and ITESM run campuses across the country, but they do not engage significantly with local SMEs, showing a strong preference for research and teaching and for collaborations with large national companies. Local firms, when they need knowledge-based assistance, primarily resort to state universities and technical universities, which are institutions offering shorterdegree programmes. Technical universities and polytechnics should, nevertheless, be more committed than have been so far to continued professional development, which is the means by which workers maintain career-related skills. This will call for a close co-ordination between policy makers in the two areas of education and economic development, as professional education falls within the remit of education policy but mainly benefits the business sector. Similarly, there is scope for exploring the potential of the cooperative education model for Mexico. This model is now found in over 60 countries worldwide, but not yet in Mexico.

Entrepreneurship training appears relatively strong in the two states of Morelos and Queretaro, and most universities have an entrepreneurship education strategy delivered through academic courses, corporate training or business incubators in the case of universities which have one. This regards both national and state universities, both of which integrate entrepreneurship notions such as business negotiation and time management in most of their major degree programmes. The Monterrey Technology Institute additionally offers an optional final six-subject business development course for their students regardless of the discipline in which they have graduated. Most of this training is interactive in nature, although only approximately half of the courses are formalised through approved training material and training of trainers. This means that in some cases entrepreneurship education is left to ad-hoc initiatives. Approximately $30 \%$ of university students undertake a course more specifically related to entrepreneurship and/or business management, which is a good score by international standards. Together with the so-called "demographic bonus" - i.e. an active population (in an age suited to work) that is bigger than the dependent population (in age of compulsory school or retirement) - this figure raises hopes for a more entrepreneurial economy in the future. Out of the university system, entrepreneurship training is more erratic and organised only if there is a demand from a specific group of people.

Co-ordination in this specific policy domain is finally made complex because human capital and skills development fall within the remit of the federal ministry and the state departments of education, whereas entrepreneurship and SME development is within the competences of the Ministry of Economy and the SEDECOs at the state level. Policy co-ordination has, therefore, not always been optimal. It has worked well in vocational education and training through CONALEP, whose courses appear bespoke to local needs, whereas it has proven more problematic at the university level. A notable exception is the 
University of Aeronautics in Queretaro, where a close co-operation between CONALEP and the National Council for Science and Technology (CONACYT) is making the training of mid- and high-level technicians for the budding local aeronautics sector possible. The Technological University Emiliano Zapata (UTEZ) in Morelos and its Cisco Networking Academy also represent a good example of policy responsiveness to industry needs, as it has enabled local small firms to widen their customer horizon and obtain the expensive certification necessary to work for big players in the industry (e.g. Cisco itself and IBM).

\section{Knowledge flows and Innovation}

The contribution of Morelos and Queretaro to national added value is disproportionate compared to their contribution to national employment. This points to a higher than average industrial productivity, which is based on low wage in Morelos and higher wage in Queretaro. This is also the result of the industry structure of the two states. Employment in Morelos is largely concentrated in services, and lowincome branches such as tourism are particularly relevant for the overall economy. Queretaro, on the other hand, is a manufacturing economy able to command higher-than-average salaries.

The Mexican innovation system lags behind that of other large Latin American economies in most aspects (e.g. number of researchers, R\&D investment as a percentage of GDP, etc.). However, there are regional differences within the country, and both Morelos and Queretaro outperform the national average with regard to education and share of researchers in the National Investigation System (SNI), which is higher than their share of Mexico's total population.

In spite of the comparative delay of Mexico's innovation system only 9\% of the SME Fund is devoted more specifically to innovation, most of which is concentred on gazelle firms. The main source of public spending is the Innovation Fund, which prioritises technology development in manufacturing and does not make an explicit attempt to address regional differences. Nonetheless, the two visited states have been able to use innovation funding for their own goals, adapting federal policies to local needs and making different strategic choices. Morelos has invested especially in technology infrastructure, including first-rate technology parks such as the Monterrey Technology Institute's. Queretaro has wagered on the attraction of multinational companies and local supply chain development, trying to develop related-variety industries, i.e. complementary industries that build on transferable skills and competences (e.g. the aeronautics sector from the automotive one).

Altogether, while funding is limited, innovation policies appear comprehensive by addressing both the simple improvement needs of micro and small firms interested in equipment upgrading (e.g. the series of Mi-programmes) and those more complex of growth-oriented companies looking for new outlets in international markets. They also build on extant industries and natural resources, as witnessed by the case of Queretaro with the aeronautics cluster and Morelos with the pharmaceutical sector. This is good news, as related-variety industrial development is more likely to be sustainable than any investment in completely new sectors where the locality does not have a specific comparative advantage.

On the negative side, the contribution of universities to regional innovation is not yet fully fledged. The first technology transfer offices have only recently been created, and there are not yet enough incentives for university staff to engage with the business sector. Horizontal linkages in the form of collaboration amongst small firms are also not properly unfolded, and there are some risks of policy dependency for firms that have been repeatedly eligible for funding. 


\section{Access to finance}

National and local governments have emphasised the role of external finance as a major driver of enterprise development. As much as 50\% of the SME fund is devoted to three programmes whose objective is the promotion of credit for small firms, namely the national guarantee fund, the SME productive project, and the seed capital programme.

The guarantee fund takes the lion's share, with an allocation that amounts to $35 \%$ of the SME Fund's total budget. It is a good programme which has enhanced the access of SMEs to bank loans, helping recipient firms to weather the storm of the 2008 global economic crisis. However, considering the size of the Mexican economy, this programme has quite a small impact and its ability to lever additional credit from commercial banks has declined in the last three years despite its growing public budget. The introduction of mutual guarantee societies entitled to draw on the resources of the national fund could help strengthen the outreach of this key programme.

There is good complementarity in the design and implementation of credit policies amongst the main involved organisations, namely the Ministry of Economy and the development bank (NAFINSA) at the national level, and the economic development secretaries (SEDECOs) at the state level. For instance, the guarantee programme is run in close collaboration between the Ministry and NAFINSA, the latter being the operational arm of the scheme, and the involvement of state authorities in the implementation of federal programmes is strong both in capital semilla and in the SME productive project. This allows programmes to be tailored to local needs, as shown by the credit programmes envisaged by NAFINSA for suppliers in Queretaro's aeronautics sector and for taxi drivers in Mexico City.

The system of intermediaries in well-tuned business financing policies, and there is a good rate of programme take-up by banks, client firms, and other intermediaries. Banks, for example, have expressed interest in the national guarantee fund, which has not always been the case for similar schemes in Latin America due to tangled regulations and delays in the payment of the public guarantees for the agreed losses of banks on SME lending. At the same time, Mexico's credit policies highlight the main risk associated with a policy delivery system hinged on intermediaries, which is its potentially higher administrative cost. The most interesting programmes for client firms in terms of credit conditions (i.e. interest rates and repayment terms) were, in fact, those directly delivered by local authorities (i.e. SEDECOs), namely the microcredit programmes of IMOFI and SOFEQ respectively in Morelos and Queretaro.

Thanks to the recent introduction of new institutions such as SOFOLES and SOFOMES, local credit markets are more diversified than they used to be ten years ago in Mexico. However, owing to their small capitalisation, these institutions have primarily entered the consumer credit market, so business credit remains concentrated in few large foreign-owned banks. This poses a problem because, while the total volume of business credit has increased in the last ten years, big commercial banks have exhibited a strong preference for corporate lending, with SMEs representing less than $15 \%$ of their total business lending. Indeed, the resort of small firms to bank loans has dropped by $10 \%$ in the last decade.

Finally, there is a lack of investment capital that is not addressed by current policies, which are overly focused on short-term subsidised loans. Programmes that give 10-year credit or longer are inexistent, and the longest spell of public loans that has been observed by the study team is only four years. Similarly, local equity markets, formal and informal, are at a very incipient stage. For example, it can be deemed an anomaly that the seed capital programme (i.e. capital semilla) is only based on short-term subsidised credit and has not spawn yet an equity branch providing or facilitating access to risk capital for growth-oriented firms. 


\section{Business environment}

Mexico has made strides in the simplification of business regulations, reducing the number of days and the cost of starting-up a business. However, progress has been slower than in most other countries, resulting in Mexico losing its position in the worldwide ranking about the ease of doing business. The business environment is not the same everywhere in the country and, as far as the two visited states are concerned, Morelos does slightly better than Queretaro thanks to a faster start-up process and the presence of an integrated electronic system where authorities can source information about a firm any time they need without having to ask entrepreneurs each time. Possibly, this is also the result of Morelos having invested in the establishment of an independent state commission for regulatory improvement (CEMER), which works closely with the parent commission at the federal level (COFOMER), whereas Queretaro has preferred to keep the task within the existing government structure, thereby giving a lower profile to this activity.

Given their horizontal nature crossing different policy fields and their presence throughout the country, Centros Mexico Emprende (CMEs) are the most relevant tools specifically affecting the quality of the local business environment. So far, they have been an important instrument to increase the geographical outreach of federal policies, enabling firms everywhere in the country to access information about existing policies and programmes. In doing so, they have also become a vehicle for the formalisation of the shadow economy, a stumbling block to the development of Mexico, as participation in public programmes is a common way to allure informal businesses in the regular economy. Being managed by intermediary organisations, CMEs also facilitate the local rooting of these organisations. If a drawback is to be singled out, this is the shortage of competition in the selection of the intermediaries running the centres. The very large majority of the centres are managed by the three main employer associations and chambers of commerce, whereas the implication of a more heterogeneous group of intermediaries should in principle result in better terms and conditions for the client firms of the centres.

\section{Policy recommendations}

The previous analysis has led to the formulation of a set of recommendations, which are discussed at length within the report. The main recommendations are summarised in the box below. 


\section{Box 3. Main policy recommendations}

\section{Policy co-ordination and policy tailoring}

- Set up clear timeframes for policy programmes to avoid policy dependency of recipients and make programmes available to as many participants as possible who meet eligibility requirements. This is especially important considering that public funding is restrained, and the largest majority of small firms are faced with market failures in credit markets and beyond.

- Strengthen the co-ordination and build the capacities of intermediaries to stave off fragmentation, duplication and overlaps of programmes. Ensure quality and specialisation of intermediary organisations.

- Make a stronger assessment and evaluation of existing programmes beyond collection of inputs and activities, to build evidence on outcomes and impacts of policies. Use the new improved evaluation system to feed the policy cycle, set out new strategic priorities, amend existing programmes, and phase out those that are not proving effective.

- Reinforce the capacity of the federal delegate offices of the Ministry of Economy to include them more actively in policy dialogue, turning them into a real liaison office between the Federal Ministry and the state economic development secretaries and an independent source of knowledge about the effectiveness of federal policies at state level.

- $\quad$ Establish a standing committee on SME and entrepreneurship policy within AMSDE to build contact networks, share good practices, and provide co-ordination among states. A similar reform can also address problems of price-based inter-state competition for the attraction of foreign investment.

- Incorporate the views of local actors and stakeholders in policy formulation to make not only policy implementation but also policy design more bottom-up and informed of local development needs.

- $\quad$ Move towards more proactive policies able to identify unperceived needs at local level and to avoid possible technology lock-ins that can hold back the economic development of the locality. In this respect, apply foresight techniques to single out technologies and market niches that have growth potential in the region.

\section{Entrepreneurship and SME policies at state level}

- $\quad$ Stimulate greater collective efficiency in local business clusters by directing more efforts at fostering interfirm collaboration across related industries in the same locality. Most of the emphasis has so far gone on linkages between anchor firms, or Tractors, and small suppliers, whereas there is scope for learning and increased collective efficiency (e.g. through economies of scale) also in co-operation among small firms.

- $\quad$ More emphasis need to be placed on vocational training and continued professional development, both key to strengthen the "absorptive capacity" of small firms and their co-operation with research organisations or technology-based companies.

- Introduce mutual guarantee societies to extend the geographical outreach of the national guarantee fund and make it more decentralised. Lending institutions are also set to benefit from a similar scheme through lowered information asymmetries and transaction costs for the lending institutions. State authorities can work with local intermediaries (e.g. local chapters of national business associations and chambers of commerce) to help them set up the mutual guarantee societies and can provide public counter-guarantees in addition to those offered by the mutual societies.

- $\quad$ Develop local equity markets by setting up small pilot public venture capital schemes to raise awareness about investment capital locally and, most importantly, by encouraging the emergence of a private equity capital market through the support of local business angels, on the supply side, and investment readiness programmes, on the demand side.

- $\quad$ Continue working on the simplification of business regulations, for example, setting up a state commission for regulatory improvement in each of the thirty-one states of Mexico. This will warrant greater autonomy and political independence to policy makers devoted to this function. Given constraints on the size of staff, regulatory impact assessment should be focused only on those regulations that are more likely to have an impact on businesses, rather than on each and every new Law passed by state governments. 


\section{ANNEX A \\ LEARNING MODELS}

\section{Australia's Enterprise Connect}

Relating to the recommendation regarding the management, co-ordination and capacity building of intermediaries the experience of Enterprise Connect in Australia may be instructive for future development in Mexico.

\section{Description of the approach}

The Enterprise Connect network was established by the Federal national Government in Australia in 2008. Currently, 12 Enterprise Connect centres have been established across Australia supported by an A \$251 million investment. The first nodes of the network were Manufacturing Centres seeking to act as 'hubs of expertise' with new institutions set up in South Australia, Victoria, Tasmania, Sydney and Perth as well as the connection of an existing provider in Queensland to the network (Minister for Innovation, Industry, Science and Research 2008). The next set of nodes established for the network were Innovation Centres with particular specialisations focused upon resources technology in Mackay, remote enterprise in Alice Springs, innovative regions in Geelong, creative industries in Ultimo, defence in Dandenong, and clean energy in Newcastle.

\section{Rationale for the intervention}

Enterprise Connect aims to support SME competitiveness, growth and development to contribute to the national economic development strategy to support innovation for long-term productivity growth and the creation high wage and high skilled employment in Australia. The centres in the network aim to connect SMEs to business and management advisory services with a particular focus upon innovation, technology and research. Specific services provided by Business Advisors working out of the Centres include Business Reviews, benchmarking, identification of technological and organisational innovations, connections to prototyping and testing facilities, and signposting and assisting applications to government support programmes.

\section{Reasons for success}

Enterprise Connect is a national network currently operating 12 centres and employing 100 business advisers and facilitators. It aims to provide services for businesses across Australia, including metropolitan areas, country centres and remote regions. The network has generated substantial levels of activities since its inception, including assisting 7,500 SMEs - several of which have achieved awards (Department of Innovation, Industry, Science and Research and IP Australia 2011). Survey assessment for its responsible ministry the Department for Innovation, Industry, Science and Research (DIISR) demonstrates that $90 \%$ of Enterprise Connect client SMEs are implementing at least one recommendation arising from the Business Reviews provided. The full formal of assessment of Enterprise Connect will be undertaken between 2012- 
13 and 2013-14. Several elements appear to have contributed to its achievements to date. First, Enterprise Connect is a flagship federal government programme with strong lead from the national ministry DIISR. It provides a focus as the major vehicle for federal government support for SMEs and attempts to complement state government initiatives. Second, horizontal co-ordination at the local level has been delivered by collaboration between staff from the DIISR based in the regions and other regional partners, for example the AusIndustry Regional Managers Network, have supported complementary provision of services rather than overlap. Enterprise Connect staff have co-operated in effective joint working including cross-referring businesses and delivering shared events such as seminars and workshops (Department of Innovation, Industry, Science and Research 2011). Last, oversight of the network's development and evolution has been supported by an advisory board, involving experienced members from the private and public sectors, trade unions and research organisations.

\section{Obstacles and responses}

Enterprise Connect addresses directly the problems experienced by SMEs in finding the time and knowledge to develop and deliver innovation in their businesses. Enterprise Connect engages these challenges by connecting businesses to new ideas and technologies to boost productivity and increase international competitiveness. The changing context has raised further issues for SMEs to which Enterprise Connect has tried to respond through new and additional programmes. Increasing international competition and climate change have been addressed with new elements, including the Clean 21 Technology Innovation Network and Buy Australian at Home and Abroad' initiatives. Enterprise Connect has gone even further to develop new initiatives for the provision of tailored services, for example addressing the needs of SMEs in the tourism sector affected by the 2011 floods and other natural disasters.

\section{Relevance to Mexico}

Enterprise Connect's experience may provide some learning opportunities for Mexico because both countries are federal states trying to develop national programmes for SMEs and entrepreneurs over their extensive national territories. While at different stages of economic development, the institutional frameworks are similar in using an Under Ministry in Mexico and Departmental Division in Australia to lead and development the policy framework. Similar too is the use of an indirect network model of intermediate organisations to deliver policy. Enterprise Connect is delivered in partnership with a range of different kinds of intermediate delivery bodies, including business associations (e.g. Australian Industry Group), Chambers of Commerce (e.g. Queensland, Western Australia), sector organisations (e.g. Geelong Manufacturing Council), innovation institutions (e.g. Industry Capability Network, Queensland) and local government (e.g. Gold Coast City Council). The challenges faced by both countries in managing, coordinating and building capacity amongst its network of intermediaries are therefore similar. Both countries have grown delivery networks in relatively short periods of time and each now have comprehensive (and in Australia's case growing) programmes of support. They are both entering a phase where they need assessment and reflection upon system-wide issues of effectiveness and efficiency, the trade-offs between national coverage and specialisation, and the potential need for further competition amongst providers. As the evaluation of Enterprise Connect begins in 2012-13, it will be timely for the administration in Mexico to engage experience in Australia.

\section{Further information (web page or contact information)}

Ms Judith Zielke, Head of Division

Enterprise Connect Division - Industry House, 10 Binara Street - Canberra ACT 2601

Tel : (02) 62137330

Fax: (02) 62908693

Email: judith.zielke@innovation.gov.au 
www.enterpriseconnect.gov.au

\section{England's Regional Government Offices}

Addressing the need to strengthen the capacity of Federal Delegates of the Ministry of Economy working at the state government level, the example of the Government Offices for the Regions in England in the UK provides some useful opportunities to consider for reform in Mexico.

\section{Description of the approach}

The Government Offices for the Regions (GORs) were established under the Conservative Government in 1994. The GORs provided a renewed regional map of public administration which had been removed in the 1980s following the abolition of the Metropolitan Counties and the Regional Planning Councils. At the outset, the GORs included representation from 3 central government departments including Environment and Local Government, Employment, Trade and Industry (Musson et al. 2005). Over time this representation grew with the addition of other departments including Education, Food and Rural Affairs, Home Office and Transport. At the centre, a Regional Co-ordination Unit was established to coordinate the work of each of the 9 GORs, share experience and knowledge, and address cross-regional issues.

\section{Rationale for the intervention}

The UK is not a federal state and has a highly centralised system of government and governance especially in England. In addition, the departmental structure of public administration, organising its functions into specific national Ministries, was seen to encourage vertical silos that were weak in working across departmental boundaries and addressing cross-cutting policy challenges. The lack of integration and co-ordination that this government department structure generated at the national centre was accentuated at the regional level. For the national centre, this meant that public policy was designed without sufficient input from the regions and that its delivery in the regions was insufficiently connected to maximise its effectiveness. The aims of the GORs were then, first, to co-ordinate policy and investment by the central government departments at the regional level and, second, to act as the 'eyes and ears' of central government in monitoring and relaying information from the regions back to the central national departments (Performance and Innovation Unit 2000). The GORs also delivered other roles including representing central government in the region, communicating government policy to regional partners, providing policy advice and capacity to regional institutions.

\section{Reasons for success}

The expansion of central government representation from the initial 3 departments demonstrated the effectiveness of GORs for national ministries as well as their responsibility for administering over $80 \%$ of central government expenditure in their regions especially in housing and transport. Several elements underpinned the success of the GORs. First, GORs provided an institutional focus and lead for direct twoway dialogue and co-ordination between the national centre and the regions. Second, clearly specified service level contracts were agreed between the GORs and their central government departments. These contracts established output and expenditure targets by programme for each region.

\section{Obstacles and responses}

The GORs adapted to address particular issues in their evolution. First, between 1994 and 2000, the Regional Directors leading each GOR reported directly to individual Ministers in their 9 sponsor departments. However, this was considered to reproduce co-ordination and integration problems. Therefore in 2000, the Regional Co-ordination Unit (RCU) was established in the national government centre and 
each Regional Director reported directly to the Director General of the RCU who managed the liaison with Departments and Ministers in central government. Second, the GORs had to adapt to the differential extent to which national central government departments decentralised responsibilities to GORs, ranging from enthusiastic devolution in the departments responsible for Local Government and Transport to continued centralisation in Education, Work and Pensions, and Home Office. While the GORs and the RCU have since been abolished as part of the current UK Coalition Government's removal of the regional tier of administration in England in 2011, this reform was part of its decentralisation and localism agenda rather than the result of any systematic assessment of the effectiveness or otherwise of the GORs.

\section{Relevance to Mexico}

Given the role of the Federal Delegates of the individual national ministries is proving insufficiently connected to the central ministries and the state governments, there is a case for exploring bringing together all the Federal Delegates of each ministry into a single federal office at the state government level. This larger and stronger Federal Office might then be able to create a stronger administrative presence better able to perform its role and add value to the administration in coordinating national and state government policy, integrating approaches at state level and providing state level input into national ministries. Rather than separate state level offices for each federal ministry, the GOR experience demonstrates how a single office for all the Federal government ministries in each of the 31 states and DFMexico City can co-ordinate and ensure the effectiveness of national policy at state level and provide the 'eyes and ears' to feed back up state level issues to the national federal level.

\section{Further information}

Joanna Key

Deputy Director

Department for Communities and Local Government

ElandHouse

Bressenden Place

London

SW1E 5DU

$\mathrm{UK}$

Tel: +44 (0)3034440000

Email: joanna.key@communities.gsi.gov.uk

http://www.communities.gov.uk/corporate/

\section{The Test Panel of Entrepreneurs in Auvergne}

Regarding the need for stronger incorporation of the views of other actors in strategy and policy for SMEs and entrepreneurship, the experience of the Test Panel of Entrepreneurs in Auvergne, France, is instructive as a model for local level consultation with relevant stakeholders.

\section{Description of the approach}

A new consultation mechanism was established based on 'Panel Meetings of Entrepreneurs' (called Economic Democracy Panels). The aim of the panels was to gather the advice and views of entrepreneurs and SMEs on the main themes in the economic, social and territorial environment for business development. Members of the panels were either nominated or elected as representatives of the business community within the region of Auvergne. The role of the panel members was to aggregate and voice the views of their respective constituencies. The members comprise: volunteers; elected or nominated representatives from specific constituencies (e.g. organisations, unions, groups of entrepreneurs); active 
and retired entrepreneurs; experts in the topics undergoing consultation; and, interest groups from sectors, areas and different sized enterprises.

\section{Rationale for the intervention}

Well formulated policy and appropriate forms of regulation are critically important to the business development of SMEs and entrepreneurs. Central to designing and developing good policy is the involvement of the subjectcs of policy interventions - namely the SMEs and entrepreneurs. Their views, situations and interests are integral to formulating effective policy (OECD 2009). But SMEs and entrepreneurs face significant time and resource pressures that often limit their involvement and contributions. Means were needed to provide opportunities for SMEs and entrepreneurs to articulate their views in a regular and systematic way. The development of a regional level panel was seen as an effective institutional mechanism to involve SMEs and entrepreneurs. This example from Auvergne, France, sits within the broader context of work undertaken by the European Commission's Directorate General for Enterprise and Industry seeking stronger consultation and better involvement of SMEs and entrepreneurs in policymaking (DG Enterprise and Industry 2005).

\section{Reasons for success}

An estimated 400 entrepreneurs participate in the panel meetings in a region with a population of $1.3 \mathrm{~m}$ and business stock of 58,000 companies (100 with more than 200 employees) (Bourgogne 2002). The panel model has been highlighted as an example of 'best practice' in engaging SMEs and entrepreneurs by the European Commission. Key elements of its effectiveness comprise: first, its representativeness in affording a voice to the various local stakeholders with an interest in issues affecting SMEs and entrepreneurs; second, its capacity to react rapidly to panel decisions and required actions; and, last, its ability to support knowledge exchange and transfer by convening experts in the topics under consultation. Clearly defined principles underpin the panel and its working arrangements. The panel is therefore an active and dynamic institutional mechanism for the involvement, consultation and analysis of non-state actor views in policymaking rather than just a receptacle for collecting the myriad opinions of local stakeholders.

\section{Obstacles and responses}

Given the time and resource pressures faced by SMEs and entrepreneurs which often limit or preclude their participation in policy consultation, the panel deploys internet-based tools to facilitate the easy and rapid collection of views and works to short timescales to provide responses. Background information is provided to enable SMEs and entrepreneurs to understand the issues and provide informed views. The panel's way of working has proved effective. For example, in the first panel survey relating to consultation on national economic policy guidelines and priorities in 2004 generated a response rate of $37 \%$ from the 382 panel members within a consultation period of 18 days. The results of the consultations are evaluated and analysed by the panel's Scientific Committee which is independent from the panel members and the business community. The Scientific Committee validates the analysis and ensures the main themes are distilled from the material received as part of the consultation. This independence ensures some objectivity and credibility in articulating business concerns to policymakers. The analysis of results is disseminated quickly to the relevant wider audiences to inform policy deliberations and development. The views of the panel are considered important and are valued as a source of information and knowledge on the concerns and views of business. 


\section{Relevance to Mexico}

Given the relatively rapid emergence of the framework for SME and entrepreneurship policy in Mexico and its need for evaluation and reflection prior to its next phase of development, effective and relatively light touch consultation mechanisms would help gather the views of business. The panel model provides a way of engaging business, perhaps at the state or even municipal level. The process could be divided into an initial phase to gather the view of SMEs and entrepreneurs on the issues relating to policy and, second, once the policymakers have researched and analysed the policy issues and options to consult on the proposed changes. Given the different economic development contexts and institutional frameworks in different countries, such consultation models should be adapted to their particular regional and local contexts. A key question is whether they constitute temporary groups only convened during periods of policy change or standing groups that provide a sounding board for ongoing consultation for policy evolution.

\section{Further information}

Elisabeth Durantin

Director

Agence Régionale de Développement Économique d'Auvergne (Regional economic development acency of Auvergne)

7 Allée Pierre de Fermat

63178 Aubière Cedex

Phone: +33(0)4 73196019

Fax: +33(0)4 73196039

\section{The co-operative programmes of North-eastern University, USA}

This model concerns the recommendation to strengthen vocational education at the tertiary level of education so that local firms are well-suited to collaborate with research organisations and knowledgebased companies.

\section{The Model}

The Northeastern University Co-operative Programme provides a broad-based network of support that helps students prepare for and get the most from their placements. This includes an academic advisor for the student and for the university school, programme coordinators. It is a comprehensive programme with some 6000 students who alternate semesters of academic study with semesters of full-time employment in positions related to their academic or career interests. Academic areas which support cooperative education include business, health care, education, engineering and technology, the visual and performing arts, and public policy.

The model involves a network of coordinators within each college supporting students in preparing for and succeeding on their cooperative programme. Follow-up is provided which helps students to reflect on the experience and see how it integrates with classroom studies. The reflection process may include participation in seminars, faculty conferences, writing assignments, and presentations.

\section{Market failures}

The rationale for intervention is to create a more practical approach to post secondary education thereby matching technical skills with industry in a region. It is also related to the market failure of individuals to the possibility of becoming a business owner as a career option. Cooperative programmes have been identified as contributing to 'virtuous cycle entrepreneurialism' (see OECD 2011b, 106). They 
can play a role in spin-offs and technology transfer, by co-opting entrepreneurial academic staff to form a company. Northeastern University prioritises entrepreneurship so that those students interested in founding their own business are able to pursue co-operatives with start-up companies and connect with mentors who will show them what it takes to establish and grow a new enterprise.

\section{Success factors}

The success of the programme lies in the commitment of the university to a wide portfolio of cooperative programmes. Students have the option of pursuing up to three cooperative experiences in a five year programme, or up to two in the course of a four-year programme. This gives students the opportunity to explore a range of working environments helping them with their career choice

Students benefit from gaining valuable work experience and developing a broader view of the world in which they live and work. They also acquire soft skills relating to communication and ability to organise ideas and information as well as more economically and intellectual benefits such as exposure to career paths and opportunities. The university and the firm benefit from closer ties to local industry engaging in two way relationships relating to technology transfer and curriculum development.

\section{Obstacles}

The main obstacles in co-operative programmes identified in a number of studies relate to their status, the costs of finding and maintaining student placements, and the lack of programme evaluation thereby enabling a consistent set of standards to be identified. However, the process of accreditation for example in the USA and Canada, suggests that this problem is being addressed.

The programme requires commitment from the university in the way of resources for financing, managing the programmes and their quality. This includes best practices, policies, technology application, quality management and a clear view of how cooperative education fits into the overall university structure (Wessels and Jacobsz undated [1]). This is to avoid marginalisation within the academic programme, so that academic and vocational gains are seen as complementary and not as alternatives.

\section{Relevance to Mexico}

The lesson from these programmes is that the benefits to students, universities and local interests are complementary. The OECD has previous identified that reforms in higher education are needed to contribute to the development of an adult education and training sector that will provide upgrading of the labour force, across the spectrum of technological orientation and size of firm from SMEs to tractors, and fostering entrepreneurship. Extending its provision could create more job opportunities for Mexican students. Moreover, assessment of existing programmes in Mexico, lessons learned from other countries, and the support from the World Association for Cooperative Education would be valuable in identifying best practice. Part of that assessment would be whether students who undertake a cooperative type work experience are likely to undertake further training when in employment, thus potentially overcoming the problem in Mexico that the country has one of the lowest rates of participation of 25-to-64 year-olds in job-related training among OECD countries.

\section{Further information}

http://www.northeastern.edu/experiential-learning/coop/coopoutcomes/index.html

http://www.waceinc.org/history.html

http://www.co-opaccreditation.org/mission.htm

http://www.cafce.ca/

[1] http://www.waceinc.org/papers/madrid/Marius\%20Wessels.pdf 


\section{Knowledge Transfer Partnerships: The Centre for Knowledge Transfer in London South Bank University (LSBU)}

This model deals with improved relationships and co-operative research between industry and higher education institutions.

\section{The model}

Knowledge Transfer Partnerships (KTP) are government funded programmes designed to help businesses improve their competitiveness and productivity through the better use of knowledge, technology and skills available within UK Universities. The government pays nearly two-thirds of the $£ 65.5 \mathrm{k}$ annual budget for a KTP project. This means that companies pay an average of $£ 21 \mathrm{k}$ annually and get $£ 65.5 \mathrm{k}$ worth of services. Small, Medium and Large companies are all eligible for grant funds, as well as charities, not-for-profit organisations and the public sector such as educational institutions and health organisations. Providing the business has been trading for a minimum of 2 years and has more than 5 full time staff an application can be made.

The KTP programme is the UK's most successful technology transfer and training programme. It creates jobs and makes a return on investment. Teaching and research ideas are improved through realworld experience with participating business partners. Associates spend two years on the project, working for a postgraduate qualification (Masters or $\mathrm{PhD}$ ) while working in the company. It provides training for the KTP associates in the university and the company, providing significant career benefits. For example, many become senior managers in industry, for example as IT managers. The programme can best be described as a management apprenticeship scheme.

LSBU's clients are 70\% SMEs (less than 250 employees) and 30\% larger companies. SMEs get $67 \%$ funding and larger companies $50 \%$. On average it costs $£ 2000$ per month to pay for training. It is equally popular with men and women associates.

Every month LSBU runs a KTP drop-in clinic for companies to learn about the scheme and how to get involved. The university has joined forces with a local region Better Bankside, a Business Improvement District in London which exists to improve the quality of the Bankside area and enhance the competitiveness of its businesses.

\section{Market failure}

The programme seeks to overcome skills gaps in mainly small business and industrially-relevant training for students at postgraduate level. It also overcomes barriers of information asymmetries between companies and universities, leading to better relationships in many forms.

\section{Success factors}

The programme offers strong subsidies to firms, particularly SMEs. The programme offers a wide range of training for the associate and the firm. An advantage of the programme is that expertise can be called in from anywhere in the university, for example marketing and business skills. This means that both the company and the associate gets a wide set of skills during the training process. Very often a KTP project will lead to another one, or a request for student internships or placements, as well as consultancy and firms coming in to speak to students during classes. 


\section{Obstacles}

The main obstacles are fourfold. The first is finding the companies interested in the scheme. LSBU is proactive. It has a team of six people dedicated to marketing the programme. The programme is not marketed nationally. The second is recruiting the right associates. This is critical to the success of the scheme. LSBU receives a high level of overseas applications. The third is the economic climate. In recessionary times, the number of companies wishing to participate decreases. The final one is that the programme can be very bureaucratic.

\section{Relevance to Mexico}

The programme illustrates a particularly successful model of how universities can deploy their expertise to provide high level training to SMEs that benefit the associate, the firm and the university. Mexico's universities could be more involved in setting the national skills agenda and thinking creatively about how to capitalise on their resources.

\section{Further information}

http://www.centreforknowledgetransfer.co.uk/ http://www.ktponline.org.uk/

\section{Entrepreneurship education in schools: Walhalla High School South Carolina, USA}

This model tackles the recommendation to improve entrepreneurship education at the university level.

\section{The model}

In a number of countries such as the USA, UK and Nigeria, entrepreneurship education forms a growing element of school curricula from primary through to secondary education. Some are targeted to particular sections of society, others to industrial sectors, while others have the objective of improving entrepreneurship awareness.

A number of different models operate with respect to the management of programmes, but often include the private sector or non-profit organisations. In Nigeria, a private company has trained school children at the 'First Ever Information Technology Entrepreneur program for Children'. Training delivered covered the fundamentals of technical support and IT entrepreneurship.

In the US the Network for Teaching Entrepreneurship, a non-profit with \$15 million in revenue has introduced business ownership to nearly 400,000 low-income middle school and high school students in the U.S. and nine other countries. The NFTE was founded in 1987 by a Ford Motor executive-turned-South Bronx math teacher. Also in the US the Appalachian Regional Commission (ARC) a regional economic development agency that represents a partnership of federal, state, and local government, working with the Ewing Marion Kauffman Foundation has a young entrepreneurs programme.

In the UK the Business Initiative for Schools assists 12-18 year olds within the South-West region along with helping schools deliver enterprise training and curriculum. It is run by a Community Interest Company with all profits returned to the organisation so the local community can benefit from the company's support and services.

In the UK the success of television programmes such as Dragon's Den which brings would be entrepreneurs with angel investors together, and The Apprentice and its spin-off Junior Apprentice, in 
which 17-18 year olds are set entrepreneurial tasks in teams in competition, have created greater awareness of the possibilities for entrepreneurship.

\section{Walhalla High School}

Walhalla is the county seat of Oconee County, a rural county with a population of about 66,000 . Its high school entrepreneurship programme goes back to the 1998-1999 school year. After recognition by the U.S. Department of Education as a "New American High School," Walhalla used a $\$ 60,000$ grant from the Ewing Marion Kauffman Foundation to promote entrepreneurial thinking by students and faculty. The grant was intended to stimulate creativity, rather than emphasise business mechanics like accounting and marketing.

The school adding an entrepreneurship unit to a course taken by all 9th-graders and created the Entrepreneurship 1 and 2 courses taught by Templin within its Consumer and Family Science department. (The district's three elementary schools have also added entrepreneurship lessons as a component of their Social Studies curriculum.) In the 2002-2003 school year, 48 students took Entrepreneurship 1, and 27 took Entrepreneurship 2. In Entrepreneurship 1, students work individually or with partners.

On the academic side, students read and write reports on entrepreneurs whose products they already know: for example, Ray Kroc, founder of McDonald's. On the experiential side, they interview Oconee County business owners, learning how entrepreneurs turn ideas into successful enterprises.

During their first semester, students develop a plan for a hypothetical business and sell their idea to a panel of local judges with a working knowledge of the promise and perils of small start-ups. During their second semester, they run a school-based business, each of them retaining a share of any profits. Students launch a business that meets two criteria: it must be doable during school hours (or immediately before or after) and be based on a product or service that students and teachers will pay for repeatedly. Students can raise start-up capital however they choose. Often this involves fundraisers. Students are required re-invent the business every year. Programmes enable students from all sections of the student body to participate including honour students, learning-disabled students, and some whose first language is not English. It attracts disenfranchised kids and especially female students. It also helps keep students in school.

\section{Market failure}

The programme is designed to overcome lack of entrepreneurship awareness. Raising the awareness of individuals to the possibility of becoming a business owner as a career option applies to all socioeconomic groups. The earlier an individual is exposed to the private benefits of starting a business, the larger the potential supply of both entrepreneurs and people with entrepreneurial skills, such as handling challenges, creating opportunities and managing risks. Entrepreneurship education is not just about starting new firms but it is also about helping existing firms to be more innovative. By including entrepreneurship in the school curriculum, this may increase the supply of both. It has also been found to help students raise their academic standards in subjects such as English and maths.

\section{Success factors}

Success factors at Walhalla and elsewhere are the general appeal to young people to new and exciting activities combined with the opportunity of making money by working in a team. The $\$ 60,000$ grant from the Ewing Marion Kauffman Foundation was crucial in underpinning the programme. Leadership from within the school by curriculum co-ordinator was also a key factor in its success. 


\section{Main obstacles}

Main barriers are the acceptance by schools of the relevance of this activity in already crowded curricula, and the capacity to teach entrepreneurship skills. In Walhalla, the school was able to employ an expert and imaginative teacher. In other schools, the organisation of such teaching sometimes requires external expertise in coaching and in previous and or current experience of being an entrepreneur. The model also relies on strong cooperation between schools which have identified this as a priority, initiating organisations who manage the programme, local entrepreneurs and those which provide finance to the new ventures. This requires considerable commitment by the schools to make those connections.

\section{Relevance to Mexico}

The relevance to Mexico lies in its demography and social and economic structures. These include a very high percentage of young people in the population, considerable social inequalities particularly in rural areas, the need for specialist skills for example in IT, and low productivity in some states. Entrepreneurial education addresses all of those targets, particularly that of addressing social inequalities by increasing entrepreneurship in the more disadvantaged sections of society. More generally, students can be sensitised at an early age to the possibilities of 'high expectation entrepreneurship' (NESTA 2009), necessary for the incidence of gazelles to increase in Mexico.

\section{Further information}

http://www.bizforschools.biz/about_business_initiative_schools.html

http://nigeriacomputers.com/ict-children/first-it-entrepreneur-program-for-children-by-jidaw- andgrange/

http://www.nfte.com/what/mission

http://www.arc.gov/images/programs/entrep/Learning_By_Doing.pdf

http://www.bbc.co.uk/programmes/b006vq92

http://www.bbc.co.uk/programmes/b00scvl2

\section{Brazil's Sectorial Funds: Stimulating links between industry and academy}

This model regards the recommendation to incentivise productive links between industry and academy.

\section{Description of the Approach}

In 1999, Brazil created the Science and Technology Sectorial Funds to finance domestic research, development and innovation. The programs provide non-reimbursable subsidies for scientific and technological research, with the specific aim of stimulating partnerships between universities and enterprises as a means to build a stronger innovation system. The funds are administered by Brazil's Research and Projects Financing Agency (FINEP), and are allocated as part of The National Fund for Scientific and Technological Development (FNDCT), the Brazilian equivalent of Mexico's CONACyT. Funding is not delivered directly to private firms, but is instead contingent on participation with universities and research centers in cooperative projects.

The Sectorial Funds are made possible by a special tax on corporate earning from licensing on government-owned natural resources, with participating firms contributing matching contributions.. There are 16 funds in total, targeting such sectors as biotechnology, petroleum, information technology and energy. Two of the 16 funds cut across sectors. One of these 'horizontal' funds is an infrastructure fund aimed at supporting the improvement of academic research infrastructure. The second is the Green-Yellow 
Fund (Fundo Verde Amarelo), whose aim is to support meaningful interaction betweem universities and private firms.

Budgets for the Sectorial Funds have grown considerably since they became operational. The entire program had approximately BRL $\$ 300$ million at its disposal in 2002 (de Negri et al, 2006). In 2011, the Green-Yellow Fund alone was able to disburse over BRL\$330 million, while the size of the entire Sectorial Funds grew to BRL\$3.2 billion (Ministério da Ciência, Tecnologia e Inovação, 2011). This expansion has made it possible for new ways of encouraging business innovation to be adopted, such as the granting of a subsidy to any company carrying out Technological and Industrial Development Programs (PDTI). The Fund will also incentivize the formation of venture capital funds. The decree authorizes the use of resources from the fund for a direct participating stake in the company's capital, particularly in those firms that have been recently created..

\section{Rationale for the Intervention}

Measures to reform the higher education system often overlook the efficiency of the generation and dissemination of new knowledge. The reference model has continued to be the formation of offices of technology transfer and licensing, with little attention given to increasing the generation of useful knowledge as input for the technological advancement of companies through partnership. Arguably establishing collaborative partnerships between academics and companies is a required first step. Nonetheless it is a step that is far from automatic, requiring careful calibration of incentives, complex negotiations regarding intellectual property rights, and in many cases considerable shifts in institutional cultures in both business and the academy. There is a sensible role for government intervention in this regard.

\section{Reasons for Success}

In an evaluation of the program performed by de Negri et al (2006) involving a sample of 80,000 participant and non-participant firms, the Sectorial Funds have shown initial signs of success. The Funds have incentivized considerable spending on technological upgrading, and it has also created a wealth of new links between firms and the academy. At the same time, in 2006, there was little unambiguous evidence of improved economic performance among participant firms, though these effects are likely to take some time to appear.

One important strength of the Funds are their stable funding, tied to corporate taxes. The FNDCT considered this to be an explicit rationale for the creation of the Funds, without which support was at the mercy of annual budgets. Another benefit is that, by opting for a direct subsidy, rather than tax exemptions, they are likely to better suit the needs of small firms who might otherwise have insufficient funds to undertake collaborative projects. The major strength, however, is simply the emphasis on collaboration. By making linkages between firms and universities and research centers entirely central in the Sectorial Funds, the FNDCT has clearly identified the need to go beyond technology licensing offices. Instead, the Sectorial Funds are directive in their aim of fostering meaningful and deep collaboration between the private sector and higher education institutions.

\section{Obstacles and Responses}

While the Brazilian emphasis on university-industry cooperation makes strategic sense, there is less available information with regard to the manner by which academic agents are motivated to participate. As in Mexico, this could be a problem that results in less-than-optimal take-up of the program among knowledge-producers in the academy. There are scant details on this point in existing reviews of the Sectorial Funds, and no mention of responses to this potential problem. A second potential issue is the 
absence of observed productivity gains in the study by de Negril et al (2006). Ultimately, the aim of such cooperative ventures between industry and the academy ought to be substantive improvements in processes and the introduction of new goods and services. These innovations ought to enhance firm productivity. One plausible explanation for this finding is that it simply may take more time for technological investments to bear fruit.

\section{Relevance to Mexico}

Brazil instituted a series of higher education reforms aimed at incentivizing innovation in the academy and increasing knowledge flows that address two bottlenecks have been identified in Mexico. The first is an inadequate system of financing that gives preference to research projects defined by individual as opposed to the conduct of scientific research through collaboration and networking, a team-based model indispensable for the generation of cutting-edge knowledge.

A second bottleneck is the disparities in the level of scientific development among different states. From the perspective of the demands and the economic potential of a continental country like Brazil, scientific research needs a national policy for integrating the measures that would promote the structuring of research activities to meet the specific demands generated by the local economic development. Brazil has recently opened new university campuses and advanced technical schools to respond to local industrial needs. This model has potential to be adopted in Mexico.

Empirical evidence finds a positive association between industrial activity and academic publishing for Mexican researchers (Becerra-Rodríguez 2011; Dutrénit, De Fuentes and Torres 2010; Lowe and González-Brambila 2007; Rivera et al 2009). These studies have consistently found positive benefits when researchers engage in linkages with private firms. It may be that Mexican academics are incentivized to participate in these collaborations as they may serve as source for new research that could result in publications. Some innovation systems have a more pronounced division of labor, with universities focused primarily on basic research. But the evidence suggests that greater interaction between Mexican academic and industry would be mutually beneficial.

\section{Further information}

http://www.mct.gov.br/index.php/content/view/1419.html

\section{Chile's PROFO: Creating greater horizontal collaboration}

This model refers to the recommendation of strengthening collaboration among firms geographically co-located and in related sectors.

\section{Description of the Approach}

Seeking to stimulate greater collective efficiency among firms in the same industry, the government of Chile created Programs of Managerial Development (PROFO). PROFO is directed at increasing the productivity of small and medium firms (Alarcon and Stumpo, 2001), by encouraging the formation of horizontal networks. Through the formation of these networks, it is hope that SMEs can overcome scalebased barriers related to the ability to license technology, access markets and hire skilled managers.

Legally, a PROFO is a partnership in which small and medium-sized businesses participate for a maximum of three to four years. There must be at least 5 firms to form a PROFO. Operating costs are shared between the public and private sectors, with public support starting at $70 \%$ in the first year, falling to $60 \%$ in the second year and $50 \%$ for the third year. Correspondingly, participating businesses finance at least $30 \%$ of the costs the first year, $40 \%$ the second and $50 \%$ the third. The agreement usually is made for 
three years, but an extension for a fourth year may be obtained if positive results can be demonstrated and if the group of companies decides to extend its partnership by undertaking joint investments or forming further consortia.

The amount of the government subsidy can be as much as US\$100,000 per year per group, with a contribution limit of US\$12,000 per participating company. The activities and types of expenditure that these funds can finance are: the remuneration of the PROFO manager (appointed by the member companies) and other support staff, technology transfer seminars, exhibitions, shows and consultancy work, travel, training and purchases of specialist books and reviews.

Corporacion de Fomento de la Production (CORFO), the state agency responsible for the promotion of national productive activity, is responsible for approving PROFO projects and allocating funds. PROFOs have been initiated by diverse entities such as public-sector bodies and private-sector trade associations such as the Chilean Textile Institute. The program is very grassroots and adaptive. CORFO has no direct operation oversight of individual PROFOs.

\section{Rationale for the Intervention}

Researchers have extensively documented the benefits that can arise as smaller firms within an industrial sector band together to achieve the kinds of efficiencies due to scale that each alone cannot achieve (Pietrobelli and Rabellotti, 2004; Marshall, 1890). Not least among these external economies of scale or collective efficiencies (Schmitz, 1999) are the prospects for the enhanced diffusion of knowledge and for innovation. Yet the kind of collective action required for the formation of such links are challenging, and they require considerable trust - an societal attribute often thought to be wanting in many less-developed economies. Given such coordination problems, and in light of the potential private and social benefits, there is a clear rationale for governments to facilitate such interactions.

\section{Reasons for Success}

CORFO's model has generated cost savings over a centralized government program and has led to experimentation and locally calibrated innovative approaches, but also has important limitations. Despite the increased outreach and low administrative costs, locally hired managers tend to limit their work to more standardized functions, and are noted not to contribute to the strategic side of CORFO operations. Moreover, there does not appear to be consistency in the service intermediation model, and clients have complained that agents offer what they know rather than what local business requires to become more efficient, competitive or profitable.

Benavente and Crespi (2003) evaluated Chile's PROFO program by administering a survey to a random sample of participant firms, as well as to a control group of firms in the same productive sectors and of similar size. Using a variety of econometric methods to address selectivity bias in program participation - including before-and-after comparisons, difference-in-difference (DID) techniques and DID with common support (propensity score matching) - they found significant net improvements in total factor productivity growth (TFP) ranging from 11.7 to 22.9 percent. Qualitative analysis of the survey of PROFO beneficiaries attributed many of these gains to reorganization of the production process, implementation of joint marketing strategies, introduction of quality control techniques, and managerial training.

Maffioli (2006) evaluated the impact of technology development funds (TDFs) in five Latin American countries-Argentina, Brazil, Chile, Colombia, and Panama-supporting research and development (R\&D), innovation, and technology upgrading among enterprises, principally SMEs. Using nonexperimental data drawn from innovation and industrial surveys linked to firm balance sheets and patent 
databases, Maffioli used a variety of econometric techniques (propensity scores matching, DID estimators, and instrumental variable models) to estimate TDF impacts, with mixed results. On the positive side, TDFs improved the capacity of firms to interact with external sources of knowledge and financing, helped increase R\&D intensity in Argentina and Brazil, and did not crowd out private R\&D funding. However, the study did not find statistically significant improvements in innovative outputs such as patent registrations or new product sales. Patent applications showed significant improvements only in one country, Brazil, where firm-university cooperation may have played a role. On firm performance, Maffioli found positive net gains in sales and employment growth, but no statistically significant impacts on firm-level productivity.

\section{Obstacles and Responses}

The evaluation performed by Benavente and Crespi (2003) revealed a variety of benefits enjoyed by SME participant firms in PROFO. One are where the intervention proved has less successful is in the generation of process and product innovation (ibid). This might reflect an unmet challenge of the policy. If so, it is one that has not yet been adequately responded to by CORFO.

\section{Relevance to Mexico}

In field studies, Mexican SMEs appear to put insufficient value on interfirm collaboration with other small firms in their sector, preferring instead to seek out linkages with large MNCs and anchor firms in global supply chains. However, the two are not mutually exclusive, and in fact achieving collective efficiency may promote supply chain activity, as a result of raised productivity and other benefits. Chile's PROFO program may be the kind of incentive required to get small and medium-sized Mexican firms working together to maximize collective benefits.

\section{Further information}

http://www.investchile.com/

\section{Malaysia's New Economic Model}

This broader model deals with the recommendation to introduce basic reforms to encourage entrepreneurship.

\section{Description of the Approach}

In 1971, Malaysia was an exporter of raw materials. Since that time, it has transformed itself into a diversified middle-income economy. To achieve this, Malaysian leaders have taken an iterative approach, with programs like the New Economic Policy and the National Economic Policy. In 2010, Malaysian Prime Minister Najib Razak unveiled their successor: Malaysia's New Economic Model (NEM). The NEM is a broad ranging plan, with the ultimate aim of taking an economy, though much improved, that finds itself stuck in the middle-income trap, and transforming it into a global leader in knowledge production and economic competitiveness (National Economic Advisory Council, 2010). Chief among its stated goals is a transformation of a national culture that does not easily embrace risk-taking and entrepreneurship (Ortmans 2011). The main planks of the intervention are: re-energizing the private sector; developing a high-skill indigenous workforce; enhancing market competitiveness; strengthening the public sector; increasing transparency; building a infrastructure for the knowledge economy; enhancing sources of growth; and ensuring sustainability. Within these goals, the NEM seeks to streamline programs and initiatives to foster entrepreneurship. Education and skills development have been made a priority and the funding landscape is being restructured to enhance financial support, especially for SMEs, while reducing dependent mentality and the possibility for rent-seeking among large, government-supported 'champions'. A recently 
introduced Competition Act attempts to liberalize the economy and prevent monopolistic and anticompetitive actions by large corporations.

\section{Rationale for the Intervention}

Though Malaysia is currently reasonably highly in global entrepreneurship and innovation rankings, considerably more work is required to properly incentivize entrepreneurship and particularly innovation among small and medium-sized firms. ${ }^{18}$ The Malaysian government properly recognizes that entrepreneurship, and the learning and innovation that can accompany it, is about mindset: recognizing opportunity and organizing resources. Changing the mindset and cultural attitudes of people towards entrepreneurship is indeed a difficult and long-term process but it is possible.

\section{Reasons for Success}

It is too early to say whether the NEM will be successful in achieving its bold aims, not least due to political opposition as well as inter-ethnic conflict. However, if it can be carried out at a sufficient scale and dedication, the NEM offers considerable strengths. Perhaps most significant is its 'deep' nature, aiming not simply to create a few programs but to transform an entire economy, and with it a set of social norms that are perceived by many as an obstacle to continued economic success. The kind of 'big push' approach being proposed by the Malaysian government has the advantage of setting the right target, recognizing that the move from middle-income to high income country is at least as significant a transformation as industrialization itself, if not greater.

\section{Obstacles and Responses}

Great political obstacles and push-back from entrenched interests are perhaps the largest obstacles preventing the success of the NEM. It remains to be seen whether the bold provisions put forth in the plan can truly be operationalized.

\section{Relevance to Mexico}

Like Malaysia, Mexico has not optimally managed the difficult growth transition from industrialized, middle-income economy to one engaged in the knowledge economy at the highest level. As discussed in the introduction, to do so requires the intensive involvement of the SMEs sector, as small firms learn and innovate, while also growing in size to seize upon scale economies. Field studies in Queretaro and Morelos revealed policymakers who remarked on the need for widespread trust-building and other profound societal shifts in order for the country to meaningfully incentivize the kind of collaboration, risk-taking and interaction required to achieve economic goals. These shifts are particularly relevant in the SME context, but they pertain as well to economic agents of all kinds. With this in mind, the kind of broad social transformation being sought by Malaysia is an apt fit in the Mexican context.

\section{Further information}

http://www.neac.gov.my/publications.php?subcategory=nem\%20reports

\footnotetext{
18 The Legatum's Entrepreneurship and Opportunity sub-index for 2011 ranks Malaysia 36th out of 110 economies (Legatum Institute, 2011). The World Bank's 'Ease of Doing Business' ranking has Malaysia at 18th among 183 economies (World Bank, 2011b).
} 